\title{
Electrical energy storage in highly renewable European energy systems: capacity requirements, spatial distribution, and storage dispatch
}

\author{
F. Cebulla, ${ }^{\mathrm{a}, 1}$ T. Naegler ${ }^{\mathrm{a}}$, M. Pohl ${ }^{\mathrm{a}, 2}$ \\ ${ }^{a}$ German Aerospace Center (DLR), Institute of Engineering Thermodynamics, Department of Systems Analysis and Technology Assessment, Germany
}

\begin{abstract}
One of the major challenges of renewable energy systems is the inherently limited dispatchability of power generators that rely on variable renewable energy (VRE) sources. To overcome this insufficient system flexibility, electrical energy storage (EES) is a promising option. The first contribution of our work is to address the role of EES in highly renewable energy system in Europe. For this purpose, we apply the energy system model REMix which endogenously determines both capacity expansion and dispatch of all electricity generation as well as storage technologies. We derive an EES capacity of $206 \mathrm{GW}$ and $30 \mathrm{TWh}$ for a system with a renewable share of $95 \%$. An extensive sensitivity analysis shows that ESS requirements range from $126 \mathrm{GW}$ and $16 \mathrm{TWh}$ (endogenous grid expansion) to $272 \mathrm{GW}$ and $54 \mathrm{TWh}$ (low EES investment costs). As our second contribution, we show how the spatial distribution of EES capacity depends on the residual load, which — in turn - is influenced by regionally predominant VRE technologies and their temporal characteristics in terms of power generation. In this sense, frequent periods of high VRE excess require short-term EES, which naturally feature low power-related investment costs. In contrast, long-term EES with low energy-related costs are characteristic for regions where high amounts of surplus energy occur. This relationship furthermore underlines how EES capacity distribution is implicitly influenced technical potentials for VRE expansion.
\end{abstract}

Keywords: Electrical energy storage, storage requirements, renewable energy, energy systems modeling, linear optimization.

\section{Contents}

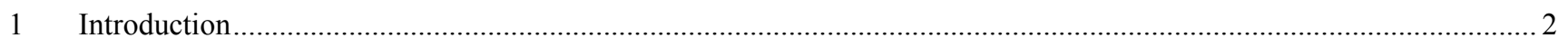

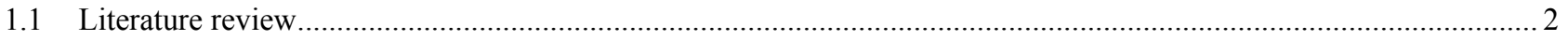

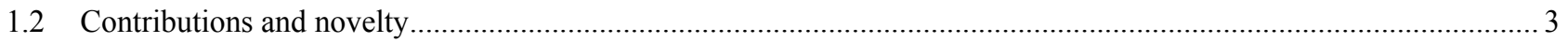

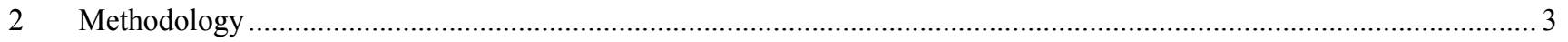

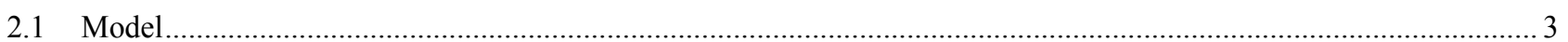

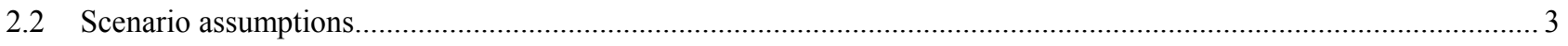

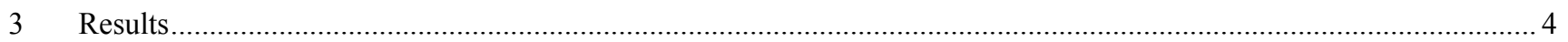

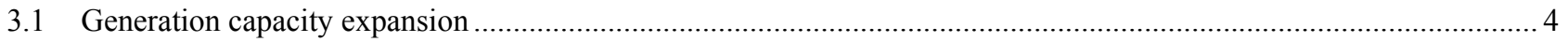

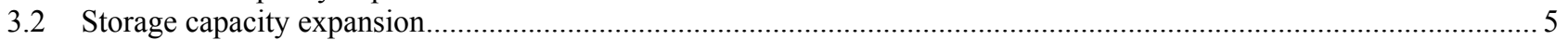

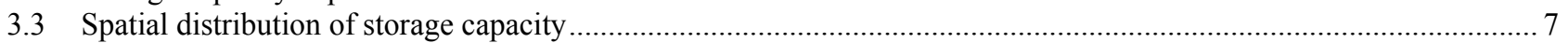

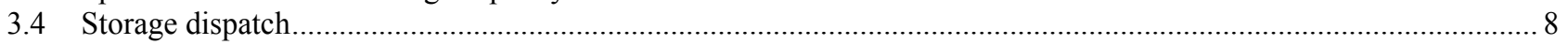

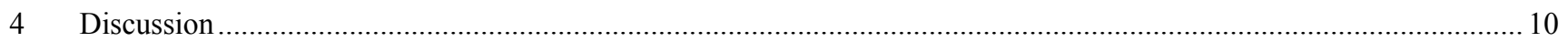

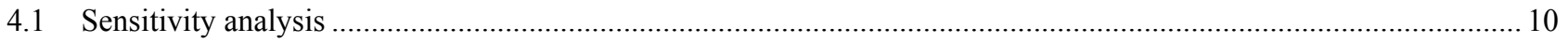

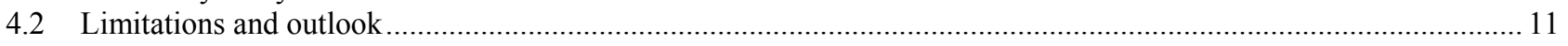

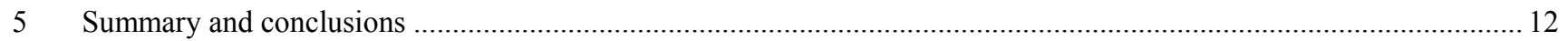

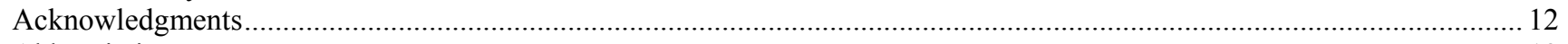

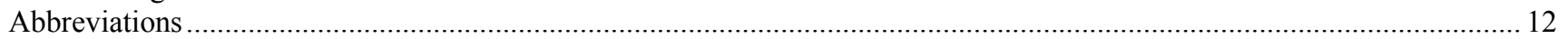

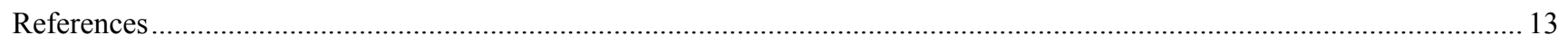

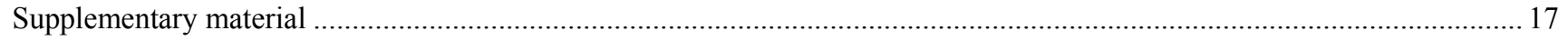

\footnotetext{
${ }^{1}$ Corresponding author.

E-Mail address: felix.cebulla@dlr.de (F. Cebulla).

${ }^{2}$ Present address: ZIEHL-ABEGG SE, Heinz-Ziehl-Straße, 74653 Künzelsau, Germany
} 


\section{Introduction}

The reduction of greenhouse gas emissions is one of the main challenges of our society towards more sustainable energy supply [1]. Electricity generation from renewable resources (RE) represents a promising option to tackle this problem. However, the mismatch of electricity generation and load caused by the limited dispatchability of intermittent electricity generation such as photovoltaic (PV) or wind power (hereinafter referred to as variable renewable energies (VRE)) requires an increase of flexibility of future energy systems. While various definitions of flexibility exist (see Ref. [2], [3]), the term is commonly understood as the ability of technical devices to contribute to the balancing of the net load [36] (which, in turn, is defined as the electricity load minus the generation from VRE). More specifically, flexibility might be provided e.g. by electrical energy storage (EES) or the electricity grid (see Ref. [10], [26], [38], [53], [66]). While the former option provides flexibility on a temporal level, i.e. allows shifting of energy from one point in time to another, grid expansion can be considered as a spatial flexibility, since it enables large-scale balancing of generation and demand between different regions which otherwise have to balance their internal mismatches themselves. Additional technical solutions for flexibility are demand side management, in particular in combination with new loads (electric heating, electric cooling, e-mobility, and power-to-gas) and supply-side flexibility (flexible powerplants, curtailments of VRE) [4], [5]. In this work, we focus on flexibility provided by EES which is characterized both in terms of necessary power and energy related capacity.

\subsection{Literature review}

Current research addresses the question of future EES requirements typically via model-based analyses, often emphasizing the quantification of EES capacity for different energy scenarios [7], [12], [25], [26], [38], [53], [66]. Reviews for the required EES capacity in Europe are, for example, provided by Kondziella and Bruckner [5], DrosteFranke et al. [6], or Cebulla et al. [44]. All three publications show broad ranges of required EES capacity ${ }^{3}$ in the current research, highlighting the necessity of a thorough examination of the underlying assumptions in the original studies.

In this sense, storage requirements have been studied with regard to different RE shares [7], [10], [15], [16], [32], [37], wind-to-PV generation ratios [36], [48], [66], weather years or climate effects [8], [9], cost assumptions [12], [53], and the representation of the electric grid [10], [33], [53]. Moreover, the resulting EES capacities in model-based assessments are influenced by the applied modeling approach (I), different temporal (II), technological (III), and spatial resolutions (IV). A profound review of methods, challenges, and trends for flexibility requirements (including EES) is provided by Haas et al. [11].

\footnotetext{
${ }^{3}$ For a fully renewable European energy system the storage power capacities range from $14 \mathrm{GW}$ [44] to $900 \mathrm{GW}$ [6].
}

(I) Storage requirements have been analyzed with the help of various modeling approaches; some of the most prominent ones are optimizations (e.g. in [12], [13], [25], [26], [33], [52], [55], [66], [67]) and simulations (e.g. in [14-18], [32], [36]).

(II) The influence of the temporal resolution has been studied in an optimization model for ramp flexibility and system costs in Deane et al. [19], for day-ahead utility scheduling through unit-commitment in Pandzzic et al. [20] and in O'Dwyer and Flynn [21], and for utility dispatch in energy scenarios with high shares of RE generation in Poncelet et al. [22] as well as in Nahmmacher et al. [23].

(III) Technological resolution can either refer to the abstraction level in the modeling approach to characterize the technologies or to the considered energy sectors in the model-based analysis.

With regard to the technological representation of storage, the literature shows numerous approaches, ranging from representations of a single generic storage [24], to storage classes (e.g. short-, mid-, long-term, without further details on the assumed technologies, see Ref. [38]), or detailed representations of actual storage technologies [25], [26], [34], [66].

Model-based quantifications of ESS requirements typically only analyze the power sector. If other sectors are included (e.g. with transportation, heating, or cooling), the approaches mostly rely on accounting frameworks on an annual basis (e.g. in [27], [28]) or optimizations which use a simplified temporal resolution in terms of representative time periods (e.g. in [29], [30]).

(IV) Storage requirements have been analyzed for several observations areas with different spatial resolutions within the models, i.e. the number of model-regions. The latter plays an important role, as it defines the distribution of capacities, generation, electricity load, and transmission grid topology within the observation area. Tab. 1 gives an overview with regard to spatial examination areas and resolution in different studies (number of model-regions in brackets). 
Tab. 1: Observation areas and spatial resolutions in different analyses which focus on flexibility demand calculations (number of model-regions in brackets)

\begin{tabular}{|c|c|c|c|}
\hline Author & Model type & Observation area & Spatial resolution \\
\hline$[31]$ & Optimization & Small exemplary region & Single node \\
\hline$[32]$ & Simulation & Texas & Single node ${ }^{a}$ \\
\hline$[33]$ & Optimization & California & Multi node (12) \\
\hline [34] & Optimization & Germany & Multi node (440) \\
\hline$[54]$ & Optimization & Germany & Single node \\
\hline$[35]$ & Optimization & $\begin{array}{l}\text { US: Western Electricity } \\
\text { Coordinating Council }\end{array}$ & Multi node (50) \\
\hline [36] & Simulation & Ireland, Germany, Italy ${ }^{\mathrm{b}}$ & Single node ${ }^{c}$ \\
\hline$[37]$ & Simulation & $\begin{array}{l}\text { EU } 27+\text { offshore } \\
\text { regions }\end{array}$ & Single node ${ }^{c}$ \\
\hline $\begin{array}{l}{[38],} \\
{[53]}\end{array}$ & Optimization & $\begin{array}{l}\text { Europe, Middle East, } \\
\text { North Africa }\end{array}$ & Multi node (21) \\
\hline [39] & Simulation & Worldwide & Single node ${ }^{c}$ \\
\hline
\end{tabular}

${ }^{\text {a }}$ Small import and export capacities $<1 \mathrm{GW}$ exist.

b The study includes 27 European countries, excluding Malta and Cyprus and including Norway and Switzerland, focuses, however, on the 3 countries listed in the table.

c Although the observation area includes several regions, each region is analyzed isolated as one model-region (no grid).

\subsection{Contributions and novelty}

As illustrated in the literature review, the question of the required EES capacity has been tackled by a substantial amount of studies for various energy scenarios and under different assumptions, applying a broad spectrum of methods. Despite these manifold analyses, the number of studies which derive the EES capacity for Europe with an adequate spatial resolution is limited. Furthermore, recent research rarely assesses the reasons for the optimum spatial distribution of storage expansion and its dispatch but takes the model results as granted.

This paper, therefore, aims to analyze the optimum spatial resolution and dispatch of different storage technologies in European energy systems with high shares of nondispatchable renewable power production and aims to shed light on the underlying causes of both the optimum spatial distribution of storage capacity and storage dispatch. For this purpose, we apply the linear, cost minimizing optimization model REMix (Renewable Energy Mix), which endogenously determines all generation and storage capacities as well as their dispatch. Furthermore, we analyze the consequences of different VRE scenarios as well as the sensitivity with respect to main input parameters and model assumptions in order to answer the aforementioned research questions.

\section{Methodology}

\section{$2.1 \quad$ Model}

The energy system model REMix was developed in the department of Systems Analysis and Technology Assessment at the German Aerospace Center [40], [55], [67], [87]. The model minimizes the system costs under perfect foresight, considering pre-defined techno-economic constraints for the expansion and dispatch of technologies, such as resource availability for RE or cost and efficiency assumptions for generation technologies. The system costs include the annuities of the overnight investment costs of capacity expansion as well as the operating costs of the utility dispatch. The latter consist of fuel, emission certificate as well as operations and maintenance costs (O\&M). The model's decision variables are capacity dispatch and expansion, optimized together during one model run. REMix is developed in the mathematical programming language GAMS [41] and solved with CPLEX [42]. An overview of the model functions is provided by Fig. 1, whereas a detailed model description including the mathematical framework can be found in Gils et al. [60].

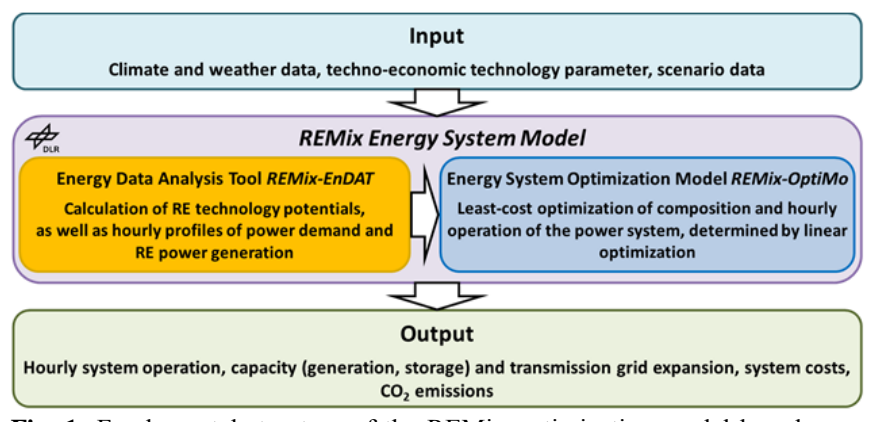

Fig. 1: Fundamental structure of the REMix optimization model based on [43].

\subsection{Scenario assumptions}

The main application of REMix is the dimensioning of a least cost supply system that can reliably cover the electric load at any time. For this analysis, we incorporate a partial greenfield approach, which optimizes the expansion and dispatch of all storage and most of the power generation capacities for the year 2050. Optimized power technologies comprise VRE technologies (PV, onshore and offshore wind, run-of-the-river hydroelectricity), dispatchable $\mathrm{RE}$ (biomass), reservoir hydroelectricity, and fossil-fired powerplants (lignite, hard coal, combined cycle gas turbine (CCGT), and gas turbine (GT) power plants). Additionally, the model encompasses geothermal, concentrating solar thermal (CSP), and nuclear power plants, whose capacities are exogenously pre-defined (based on Ref. [70]). Since the installed capacities of those technologies are relatively small (see Tab. A 3), their influence on the storage capacity distribution is expected to be small. Furthermore, this simplification reduces the solving time of the model. Curtailments of electricity generation from VRE technologies are not associated with any costs. In detail descriptions of the modeling approach and the underlying assumptions for each technology are provided in the supplementary material.

The partial greenfield methodology is based on the assumption that almost no capacities are installed at the beginning of the observation year and investments are necessary to reliably cover the electric load at any time. The approach is valid since most of the existing capacities at the present will not last until the observation year 2050. However, due to their long life time, some technologies will prevail until 2050, including some fossil-fired and reservoir hydro power-plants. For this purpose, we consider the 
decommissioning of generation capacity based on its technology-specific life time (see Tab. A 4).

The analysis focusses on the electricity sector and excludes interactions with the transportation and heat sector.

Current research agrees that the importance of storage will rise significantly with higher shares of VRE power (e.g. $>80 \%$ [44]). Therefore, we include a model constraint which enforces at least $80 \%$ of electricity generation to come from VRE (averaged over the whole observation area), hereinafter denoted by $80 \% \%_{\text {constr }}$. Although dispatchable RE (e.g. biomass or CSP with thermal storage) can also reduce $\mathrm{CO}_{2}$ emissions, their availability in Europe is limited and $80 \%_{\text {constr }}$ is, therefore, a valid assumption. For a detailed analysis of the influence of this model constraint see Sec. 10.5 of the supplementary material.

For the analyzed year 2050, the optimization period is divided into 8,760 hourly time-steps. The observation area comprises northern, western, and central Europe (see Fig. 2). While larger countries are generally represented by individual model-regions, smaller European countries are aggregated. In contrast, Germany is split into 20 sub-regions, resulting in 29 overall model-regions for this analysis (see Fig. A 1).

The model uses exogenously, hourly and model-regionspecific load profiles of the electricity demand. They are based on the load profiles from 2006 of the European Network of Transmission System Operators for Electricity (ENTSO-E) [45], [46]. All profiles are scaled through estimates of the development of the total electricity demand for the year 2050 for each country based on Ref. [69], [70], [94] (see Tab. A 14).

A simplified representation of the transmission grid (exogenously specified in the standard analysis) allows electricity import and export between the model-regions (see Sec. 2 in the supplementary material). Within each region, a perfect grid without any transmission constraints is assumed (copper plate). In the sensitivity analysis, we further allow for an endogenously calculated transmission grid expansion between the model-regions (see Sec. 4.1 and Sec. 10.3 of the supplementary material).

The model includes five storage technologies which are characterized by different charging and discharging efficiencies, investment costs for the power and energy capacity, and O\&M costs. Represented EES technologies are pumped hydro power (PHS), hydrogen storage $\left(\mathrm{H}_{2}\right)$, adiabatic compressed air (aCAES), stationary lithium-ion (Li-ion), and redox-flow batteries. For $\mathrm{H}_{2}$ storage it is assumed that electricity is converted to $\mathrm{H}_{2}$ via alkaline water electrolysis, stored in underground salt caverns and reconverted via a CCGT. An overview of all relevant technology parameters can be found in Tab. A 15.

Apart from storage expansion, REMix also optimizes the storage dispatch and furthermore allows an individual and independent dimensioning of the storage power $\left(\mathrm{GW}_{\mathrm{el}}\right)$ and energy capacity $\left(\mathrm{GWh}_{\mathrm{el}}\right)$, implying no pre-defined energy to power ratio $(\mathrm{E} 2 \mathrm{P})^{4}$, sometimes referred to as disjoint

\footnotetext{
${ }^{4}$ The E2P describes the time in hours a storage needs for a complete cycle with its nominal power and allows an identification whether a storage technology is mainly used for short, mid, or long-term applications.
}

capacity. A detailed description of the methodology for storage modeling is provided in Gils et al. [60], whereas the main techno-economic parameters are shown in Tab. 2. The assumptions regarding the existing storage power and energy capacities of PHS, aCAES, and $\mathrm{H}_{2}$ as well as their technical expansion potentials are discussed in Sec. 8 in the supplementary material. For Li-ion and redox-flow batteries it is assumed that there are no constraints regarding their technical potential (both maximal installable storage power and energy capacity).

Although the techno-economic input parameters are carefully chosen and based on a broad literature review as well as expert assessments, we are aware that their exact values are highly uncertain for the observation year 2050 . We therefore include a broad sensitivity analysis in the discussion section and the supplementary material to validate our key results. The scenario setup as described above serves as the reference scenario for those sensitivity tests.

Tab. 2: Main techno-economic parameters for the storage technologies.

\begin{tabular}{lrrrr}
\hline Technology & $\begin{array}{l}\text { Invest }_{\text {power }} \\
{\left[€ / \mathrm{kW}_{\mathrm{el}}\right]}\end{array}$ & $\begin{array}{l}\text { Invest }_{\text {energy }} \\
{\left[€ / \mathrm{kWh}_{\mathrm{el}}\right]}\end{array}$ & $\begin{array}{l}\eta_{\text {charge }} \\
{[-]}\end{array}$ & $\begin{array}{l}\eta_{\text {discharge }} \\
{[-]}\end{array}$ \\
\hline $\mathrm{H}_{2}$ & 1,200 & 1 & 0.75 & 0.62 \\
Li-ion & 50 & 150 & 0.97 & 0.97 \\
aCAES & 570 & 47 & 0.84 & 0.89 \\
Redox-flow & 630 & 100 & 0.92 & 0.92 \\
PHS & 450 & 10 & 0.91 & 0.91 \\
\hline
\end{tabular}

\section{Results}

\subsection{Generation capacity expansion}

Fig. 2 shows the endogenously derived total generation capacities for all renewable and fossil-fired technologies in 2050. Moreover, the VRE share with respect to the gross annual electricity generation for each model-region is depicted. Unless otherwise stated, the 20 German modelregions are aggregated in the following sections. Furthermore, the analysis concentrates on the technologies with the highest installed capacities and neglects technologies with smaller amounts of installed capacities, such as run-of-the-river hydroelectricity or biomass. 


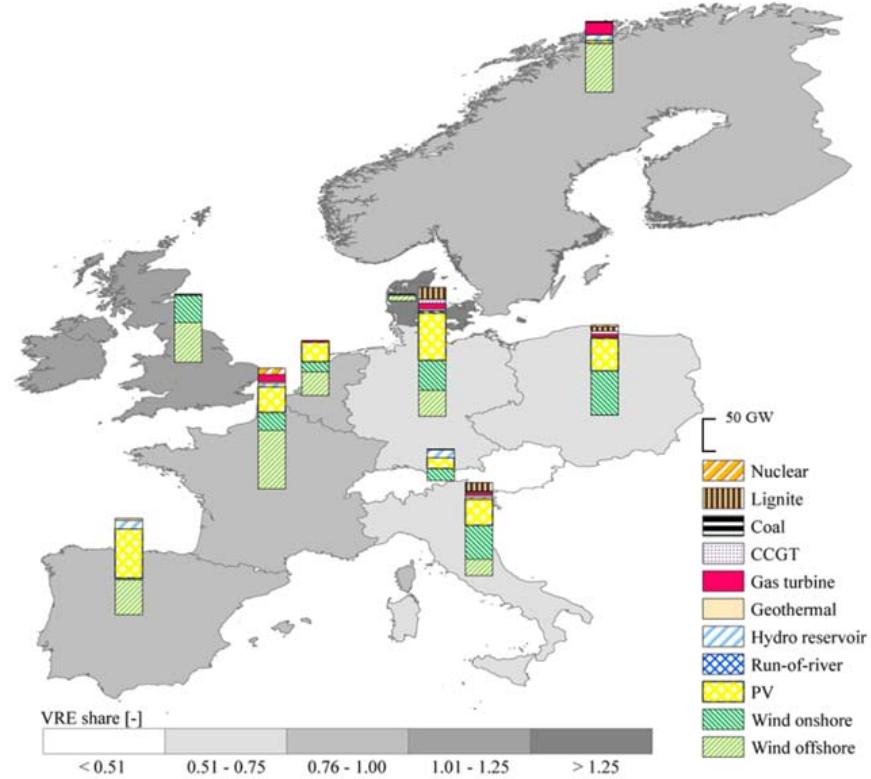

Fig. 2: Technology-specific installed generation capacities for Europe in 2050. VRE shares are depicted in relation to the annual gross electricity generation. VRE shares $>1$ indicate model-regions which export electricity (i.e. generation $>$ demand). All numerical values also can be found in Tab. A 18

The overall VRE capacity is $1,185 \mathrm{GW}$, mainly provided by offshore wind ( $465 \mathrm{GW}), \mathrm{PV}(392 \mathrm{GW})$, and onshore wind $(328 \mathrm{GW})$. Fossil-fired technologies (lignite, CCGT, GT) sum up to $119 \mathrm{GW}$, mainly provided by GT's (58 GW). In terms of annual electricity generation, offshore wind systems generate 1,482 TWh, whereas onshore wind and PV result in $624 \mathrm{TWh}$ and $419 \mathrm{TWh}$, which equals $47 \%, 20 \%$, and $13 \%$ of the overall gross electricity generation.

Naturally, the optimization favors technologies which are (regionally) cost-effective with regard to capacity expansion and dispatch. In consequence, investments for VRE happen predominantly in regions with high technical potentials and high full load hours. Regions with high solar irradiation for example — such as Iberia - show comparatively high installations of PV systems, whereas high wind speeds - as in the UK + IE or in Northern Europe-will foster the installation of wind power-plants. Furthermore, regionspecific technical potentials restrict the capacity expansion of VRE, as this is, for instance, the case for onshore wind (in $\mathrm{AT}+\mathrm{CH}, \mathrm{BeNeLux}, \mathrm{PL}+\mathrm{CZ}+\mathrm{SK}$, Italy, UK + IE) and for $\mathrm{PV}$ (in BeNeLux, PL $+\mathrm{CZ}+\mathrm{SK}$, Iberia, Italy) (see Fig. 3).

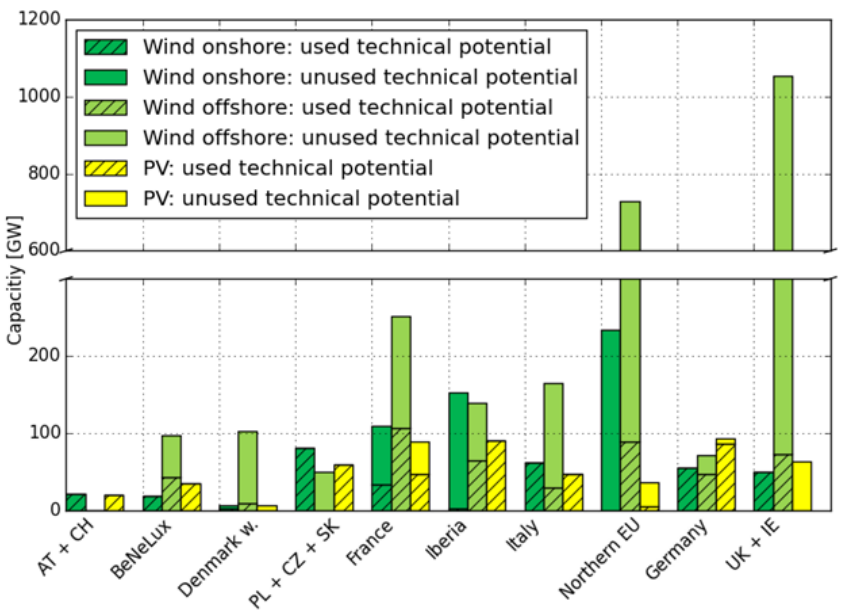

Fig. 3: Used and unused technical potential of VRE capacity for each model-region. The sum of used and unused technical potential defines the total technical potential.

The high share of electricity generation from PV, onshore and offshore wind reflects the VRE constraint $\left(80 \%_{\text {constr }}\right)$ set for the reference scenario (see Sec. 2.2). Without this constraint, the VRE share in Europe would be much smaller: Assuming the same $\mathrm{CO}_{2}$ certificate prices and fuel costs as well as identical investment and O\&M costs, calculations without $80 \%_{\text {constr }}$ result in a significant lower VRE share $(42 \%)$ on the European average (see Sec. 10.5 in the supplementary material). However, if a very high $\mathrm{CO}_{2}$ certificate price is chosen $\left(130 € / \mathrm{t} \mathrm{CO}_{2}\right.$ instead of $57 € / \mathrm{t} \mathrm{CO}_{2}$ as in the standard case), optimum capacity expansion leads to a VRE share that is almost identical to the one of the reference scenario $(75 \%)$.

\subsection{Storage capacity expansion}

Fig. 4 depicts the total installed EES power capacity for all storage options for the European model-regions, as obtained from our calculations. For PHS this includes today's existing capacities ( $39 \mathrm{GW}$ and $271 \mathrm{GWh}$, see Tab. A 16 and Tab. A 17) as we assume that these will not be retired until 2050 due to the long life time of the water reservoir. Additionally, a simulation run with no existing capacities of PHS was performed as part of the sensitivity analysis. The scenario confirms that a stock of PHS capacities does not influence the installed PHS, as both model runs result in an identical expansion of PHS capacities (see Sec. 10.6 in the supplementary material). Apart from redox-flow batteries, the model derives investments into every storage technology. The endogenously determined storage power capacities result in $166 \mathrm{GW}$. The largest share is provided by $\mathrm{H}_{2}$ storage with $86 \mathrm{GW}$, whereas capacities from Li-on batteries account for $58 \mathrm{GW}$. 


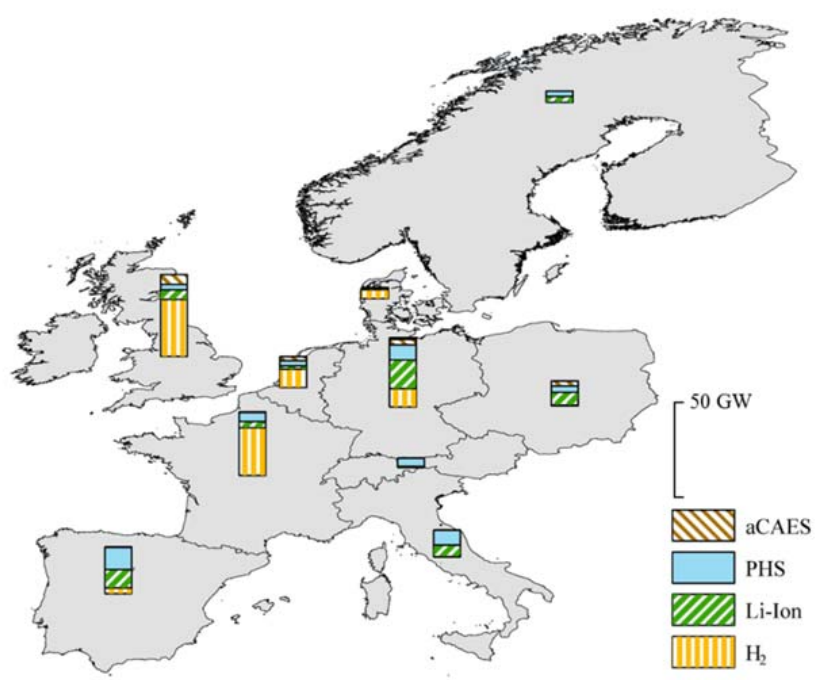

Fig. 4: Technology-specific storage power for Europe in 2050 (see Tab. A 19 for all numerical values).

The lack of redox-flow storage can be explained by the cost optimizing model logic. For mid-term applications, i.e. the balancing of surplus energy and deficits of time periods up to several days, redox-flow batteries compete with aCAES which have rather similar techno-economic characteristics (see Tab. 2). Despite the favorable efficiencies of redox-flow batteries, their higher energy capacity investment costs (at similar storage power costs) prevent the expansion as long as aCAES expansion limits are not reached.

This hypothesis has been validated with model-runs where the energy capacity investment costs for redox-flow batteries were set to the respective value for aCAES. The results confirm that mid-term storage applications of aCAES could be substituted by redox-flow batteries if battery costs improve to the level of aCAES (see Sec. 10.6 in the supplementary material). As a consequence of negligible installed capacities of redox flow batteries, this storage type is not taken into account in the remainder of this paper.

While the majority of storage power capacity is provided by $\mathrm{H}_{2}$ storage and Li-lion batteries, aCAES and PHS also play an important role in certain regions. In the model-region Iberia, for example, the installed capacities of PHS reach the technical potential of $137 \mathrm{GWh}$ (see Tab. 3) and $12 \mathrm{GW}$ of storage power. Italy is another region where the capacity expansion of PHS reaches its technical potential (77 GWh). Notable capacities of aCAES occur in UK + IE, resulting in $5 \mathrm{GW}$ and $72 \mathrm{GWh}$.
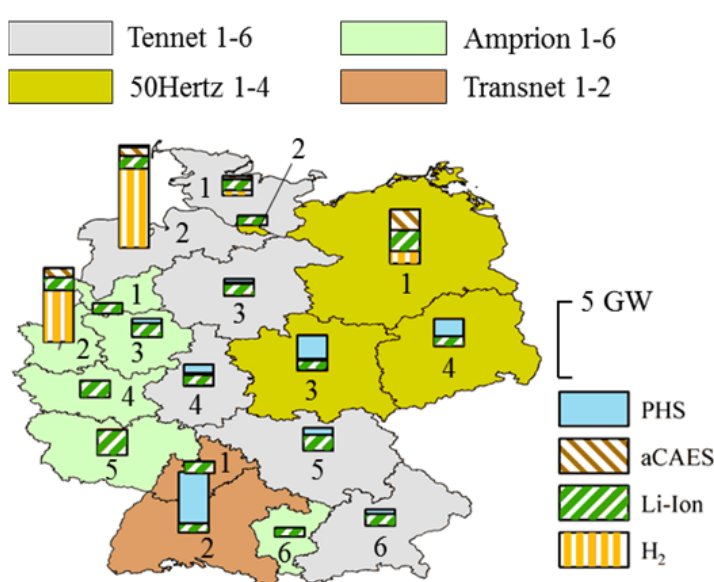

Fig. 5: Technology-specific storage power for Germany in 2050 (see Tab. A 20 for all numerical values)

For the German model-regions (see Fig. 5) the optimization results in $30 \mathrm{GW}$ of ESS power. The largest share is provided by Li-ion batteries and $\mathrm{H}_{2}$ storage with $16 \mathrm{GW}$ and $10 \mathrm{GW}$ respectively. The highest power capacities can be observed in Tennet2, Amprion2, and 50Hertz1 (6.80 GW, 5.03 GW, 3.70 GW), mainly providing flexibility for the integration of offshore wind generation (Tennet2, 50Hertz1) and additionally high amounts of PV and onshore wind capacities (50Hertz1). In this regard, the favorable transmission grid infrastructure between Tennet2 and $50 \mathrm{Hertz} 1$ foster the storage capacity expansion in these regions.

Particularly in regions with high shares of electricity from wind turbines - such as 50Hertz1 or Tennet2-higher amounts of aCAES expansion were observed, resulting in $1.38 \mathrm{GW}, 0.59 \mathrm{GW}$ respectively. All model-region and technology-specific ESS power capacity expansion is also shown in Tab. A 19 and Tab. A 20.

Tab. 3 lists the model results for storage energy capacities for each region.

Tab. 3: Installed storage energy capacity for all model-regions in 2050 .

\begin{tabular}{lrrrrr}
\hline \multicolumn{5}{c}{ Storage energy capacity $\left[\mathrm{GWh}_{\mathrm{el}}\right]$} \\
\hline & $\mathrm{H}_{2}$ & Li-ion & aCAES & PHS \\
\hline AT + CH & 36 & - & 1 & 40 \\
BeNeLux & 3,117 & 4 & 44 & 22 \\
Denmark w. & 2,264 & 1 & 4 & - \\
PL + CZ + SK & 86 & 30 & 48 & 25 \\
France & 6,927 & 6 & 5 & 37 \\
Iberia & 901 & 38 & 3 & 137 \\
Italy & 38 & 16 & 2 & 77 \\
Northern Europe & - & 13 & - & 27 \\
Germany & 3,671 & 32 & 58 & 54 \\
UK + IE & 12,578 & 10 & 72 & 22 \\
\hline Total & 29,616 & 151 & 236 & 441 \\
\hline
\end{tabular}

While the quantity, technology-specific composition and spatial distribution of the storage power is quite diverse over 
the observation area, storage energy capacity is, as expected, mainly provided by $\mathrm{H}_{2}$ long-term storage $(29,616 \mathrm{GWh})$. We observe the highest energy capacities in the regions $\mathrm{UK}+\mathrm{IE}$, France, Germany, and BeNeLux respectively (12,578 GWh, 6,927 GWh, 3,671 GWh, 3,117 GWh). With respect to energy capacity, aCAES, PHS, and Li-ion batteries play only a minor role $(236 \mathrm{GWh}, 168 \mathrm{GWh}$, $151 \mathrm{GWh}$, together less than $3 \%$ of the total energy capacity), since these technologies mainly provide short and mid-term flexibility in the model in order to compensate diurnal $(1 \mathrm{~h}-1 \mathrm{~d})$ and synoptic $(2 \mathrm{~d}-10 \mathrm{~d})$ fluctuations from VRE. $\mathrm{H}_{2}$, in contrast, serves as long-term storage $(>10 \mathrm{~d})$ for electricity from offshore wind turbines. Note that both storage power (GW) and storage energy capacity (GWh) are endogenously derived by REMix for each storage technology. A more detailed analysis of storage dispatch and its spatial distribution is provided by the following section.

\subsection{Spatial distribution of storage capacity}

For each model-region the technology-specific storage expansion depends on the hourly power generation from VRE sources and their regional capacity mix (limited by the technical storage potentials). Moreover, storage requirements are implicitly affected by the spatial balancing ability of the transmission grid between the regions.

Previous research showed that storage portfolios depend on the level of wind and PV penetration within the system [47], [48], where a predominance of one generation technology can influence the overall storage design. Our results indicate that high shares of wind generation tend to require more long-term storage, while, in contrast, larger amounts of short-term storage (e.g. Li-ion batteries) seem to be characteristic for regions which are mainly supplied by electricity from PV systems.

Therefore, we compare the hourly time-series of the residual load (electrical load minus VRE feed-in) with the hourly cumulative charging power of all storage technologies for the model-regions France, $\mathrm{PL}+\mathrm{CZ}+\mathrm{SK}$, and Iberia (Fig. 6). More specifically, the hourly values depicted in this figure are normalized with regard to the total VRE and storage power capacity. A negative residual load indicates a VRE surplus, while positive values indicate a VRE deficit which requires further generation from dispatchable technologies (e.g. fossil-fired power-plants or biomass), storage discharging, or electricity import.

We chose these specific regions due to their different generation and storage mixes (see Fig. 2, Tab. 3). Moreover, each region is characterized by one predominant VRE source: France is mainly supplied by electricity from offshore wind power (74\%), PL $+\mathrm{CZ}+\mathrm{SK}$ largely by onshore wind $(50 \%)$, and Iberia shows high shares of PV generation $(34 \%)$.

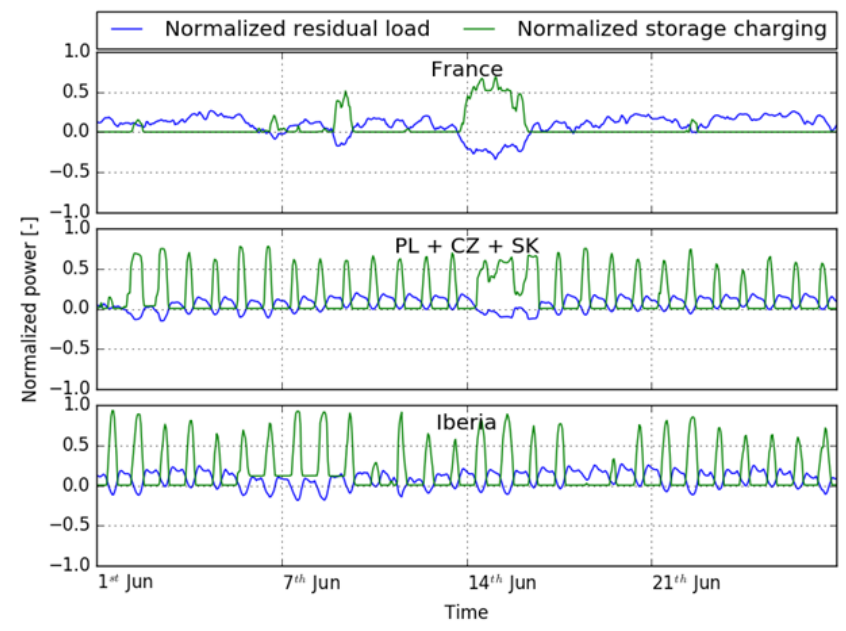

Fig. 6: Model endogenously determined hourly residual load and hourly cumulated charging capacity of all storage technologies for the modelregions France, $\mathrm{PL}+\mathrm{CZ}+\mathrm{SK}$, and Iberia. Storage charging is normalized to the total storage power capacity; the residual load to the region-specific, total VRE capacity.

The plots show a distinct correlation between VRE surpluses and storage charging. Within the regions $\mathrm{PL}+\mathrm{CZ}+\mathrm{SK}$ and Iberia, daily VRE peaks caused by PV generation occur, which, in consequence, foster daily charging of storage. The PV-dominated pattern in $\mathrm{PL}+\mathrm{CZ}+\mathrm{SK}$ is superimposed by a short onshore wind event of a few days $\left(14^{\text {th }}-17^{\text {th }}\right.$ Jun). In the offshore wind region France, in contrast, we do not observe daily storage charging but patterns that correlate on a more synoptic and seasonal basis.

To support these findings, we analyze the linear correlation coefficient $\rho$ between VRE surpluses (i.e. negative residual loads) and the hourly storage charging capacity (cumulated over all storage technologies) for each model-region (Pearson product-moment coefficient, Fig. 7). Additionally, Fig. 7 depicts the VRE share of each modelregion on the color axis.

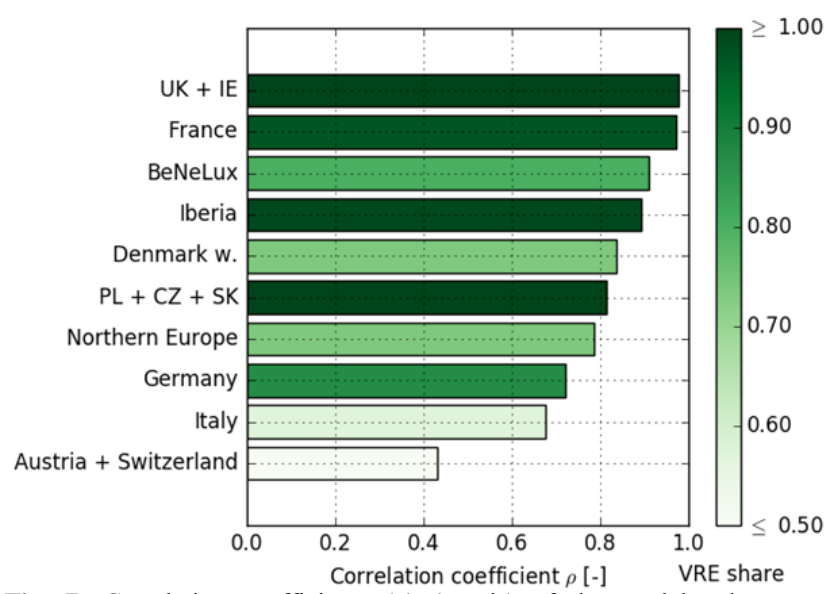

Fig. 7: Correlation coefficients $(\rho)$ (x-axis) of the model-endogenous, hourly times-series of VRE surplus with the model-endogenous, hourly storage charging times-series for all regions. Moreover, the figure depicts the VRE shares (color axis).

A significant correlation $\rho$ between VRE excess and storage charging can be observed in all regions, indicating 
that regional VRE generation that exceeds the electrical load mostly is used for storage charging. In this sense, storage is dispatched to integrate power generation from VRE technologies, and does not, as for example shown for scenarios with lower shares of VRE penetration (see e.g. [49], [50]), ensure the continuous dispatch of thermal power plants and subsequently leads to higher $\mathrm{CO}_{2}$ emissions. Alternatively to storage charging, generation surplus can be curtailed or exported to other regions where an additional demand exists. The results also show that the correlation $\rho$ tends to increase with higher VRE share.

Yet, Fig. 6 and Fig. 7 do not explain why we obtain distinct EES mixes for different model-regions. The reasons are twofold and elaborated subsequently.

(1) As shown previously, storage charging strongly correlates with negative residual loads. In this sense, the shape of the residual load of each model-region directly influences which EES technologies are built to which extent. Residual loads that are characterized by high powers with short time periods require short-term EES (low E2P). In contrast, longer time periods of negative residual loads foster the expansion of EES with high E2P ratios.

Whether an EES is used for short or long-term balancing is primarily defined by the investment costs assumptions; the crucial parameter is the ratio between power-specific and energy-specific investment costs (energy-to-powerinvestment-ratio). On the one hand, EES with low energy investment costs favor large amounts of stored energy and hence long-term applications. On the other hand, low power investment cost foster EES expansion which is preferred for the balancing of high power and short-term usage. In this sense, the charging times-series of $\mathrm{H}_{2}$ correlate significantly with the electricity generation from offshore wind. In general, also Li-ion storage charging is correlated with PV power production and aCAES charging with onshore wind.

(2) Second, limited regional technical potentials for EES expansion will directly affect the storage portfolio. The optimization approach favors the storage expansion of costeffective technologies, such as PHS. Provided that further storage is required to meet $80 \%_{\text {constr }}$, the model will pursue the expansion of such technologies as long as the technical potential is not reached. Tab. 4 underlines that effect, showing that nearly all model-regions exploit their technical potential of $\mathrm{PHS}^{5}$. In contrast, large amounts of unused technical potential still remain for aCAES and $\mathrm{H}_{2}$.

\footnotetext{
5 An exception is the model-region Austria + Switzerland, which, additionally to the existing PHS capacities, provides flexibility mainly through dispatchable reservoir hydroelectricity ( $49 \mathrm{GWh}$, resp. $40 \%$ of the annual demand).
}

Tab. 4: Model-region and technology-specific used and unused technical potential of the storage energy capacity. Note that we assumed unlimited storage energy capacity potentials for $\mathrm{Li}$-ion and redox-flow batteries.

\begin{tabular}{lrrr|rrr}
\hline & \multicolumn{3}{c|}{ Used technical potential } & \multicolumn{3}{c}{ Unused technical potential } \\
& PHS & aCAES & \multicolumn{1}{c|}{$\mathrm{H}_{2}$} & PHS & aCAES & \multicolumn{1}{c}{$\mathrm{H}_{2}$} \\
\hline AT + CH & 40 & 1 & 36 & 22 & 137 & 13,155 \\
BeNeLux & 22 & 44 & 3,117 & - & 269 & 26,838 \\
Denmark w. & - & 4 & 2,264 & - & 183 & 15,709 \\
PL+CZ+SK & 25 & 48 & 86 & - & 1,577 & 155,691 \\
France & 37 & 5 & 6,927 & - & 620 & 52,982 \\
Iberia & 137 & 3 & 901 & - & 1,397 & 133,304 \\
Italy & 77 & 2 & 38 & - & 123 & 11,944 \\
Northern & 27 & - & - & - & - & - \\
Europe & 54 & 58 & 3,671 & - & 1,192 & 116,161 \\
Germany & 22 & 72 & 12,578 & - & 403 & 32,959 \\
UK + IE & & & & & &
\end{tabular}

The technical potentials for storage expansion are discussed in some more detail in Sec. 8 of the supplementary material.

\subsection{Storage dispatch}

The following section takes a closer look at storage utilization in terms of hourly charge and discharge; it addresses two main questions:

(1) Is the temporal storage dispatch pattern technologyspecific?

(2) If so, are those patterns region-specific or do similar patterns occur in all regions?

(1) For the analysis of the hourly dispatch patterns the subsequent metrics are introduced: total number of cycles (NC), number of full cycles (NFC), number of typical cycles $\left(\mathrm{NC}_{\text {typ }}\right)$, representative length $(\Phi)$ of one typical cycle.

i. NC describes each change from charging to discharging and is a measurement of the annual utilization of the storage.

ii. The NFC is defined as the ratio of the sum of annual storage energy (electrical output) and load (electrical input) to the storage energy capacity divided by two. The difference between NC and NFC helps to assess the intensity of the storage utilization.

iii. $\quad \mathrm{NC}_{\text {typ }}$ is defined as the number of charge and discharge processes going through the following states of charge (SOC): $\mathrm{SOC} \leq 0.2 \rightarrow \mathrm{SOC} \geq 0.8 \rightarrow$ SOC $\leq 0.2$. It is the precondition for defining $\Phi$.

iv. $\Phi$ denotes an average length (e.g. in hours or days) of a typical cycle $\mathrm{NC}_{\text {typ }}$.

For the regions Iberia, $\mathrm{PL}+\mathrm{CZ}+\mathrm{SK}$, and France, Fig. 8 displays the relative storage charge, discharge, and the fill level for $\mathrm{Li}$-ion, aCAES, and $\mathrm{H}_{2}$ respectively. 


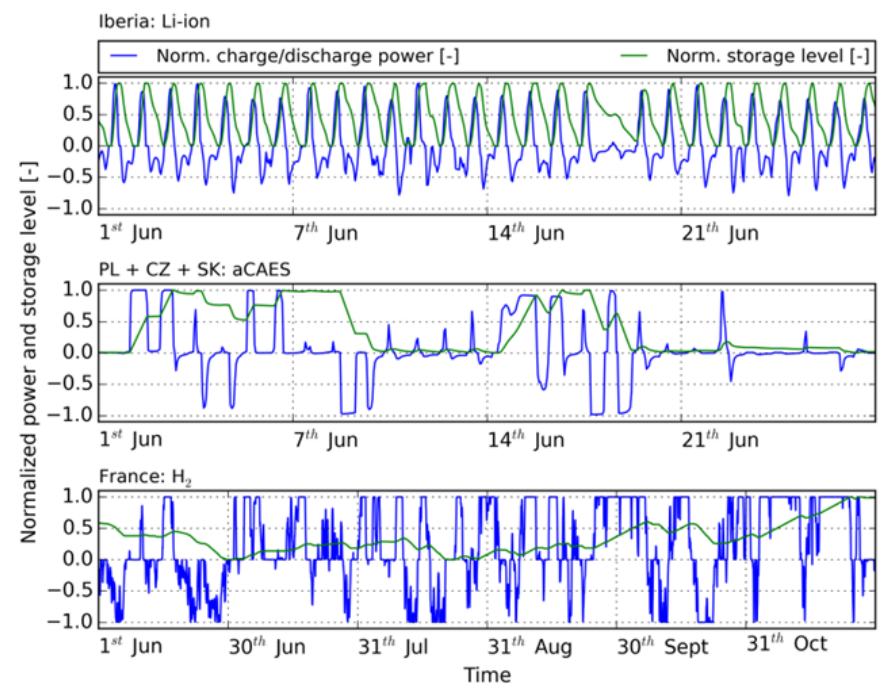

Fig. 8: Storage level as well as charge and discharge power for the storage technologies Li-ion battery (Iberia), aCAES ( $\mathrm{PL}+\mathrm{CZ}+\mathrm{SK})$, and $\mathrm{H}_{2}$ (France). Storage level is normalized to the total storage energy capacity; charge and discharge power are normalized to the total installed storage power. Note that the plots show different temporal intervals on the abscissa in order to illustrate the typical dispatch for each storage technology.

The expansion of short-term storage technologies, such as Li-ion batteries, is typical for regions with high shares of PV generation. The dispatch of these batteries in the modelregion Iberia (upper panel in Fig. 8) shows the most distinct cyclicality of all EES technologies. Daily cycles can be observed, where charging mainly occurs in times of high PV feed-in, as a single peak around noon. Furthermore, the high charging power is striking which usually reaches almost $100 \%$ (in absolute terms $\approx 10 \mathrm{GW}$, see Fig. 4). Discharging of Li-ion batteries in Iberia usually occurs during morning and evening hours. In contrast to the charging process, discharging of Li-ion batteries also occurs with partial power. This implies that the power capacity is mainly optimized in order to balance surplus PV production and less in order to balance nocturnal deficits. A complete discharge $(\mathrm{SOC}=0)$ is usually reached at night times; the typical cycle duration $\Phi$ is around one day.

The middle panel of Fig. 8 represents the dispatch pattern of aCAES in the model-region $\mathrm{PL}+\mathrm{CZ}+\mathrm{SK}$. $\Phi$ is around three to five days. Opposed to Li-ion batteries in Iberia, aCAES charging and discharging also occurs with partial storage power. Moreover, the cyclicality of the storage dispatch is not as distinctive as for stationary Li-ion batteries, mainly since aCAES charging correlates on a more synoptic basis with the feed-in of onshore wind.

Regions with high shares of offshore wind penetrationnamely the model-regions Denmark west, Northern Europe, $\mathrm{UK}+\mathrm{IE}$, and France-require large amounts of $\mathrm{H}_{2}$ longterm storage, provided that the technical potential of the storage energy capacity, i.e. salt caverns, is sufficient (see Tab. 4). The lower panel of Fig. 8 shows the dispatch behavior of $\mathrm{H}_{2}$ storage in France. Since charging strongly correlates with offshore wind generation, rather seasonal changes of the storage fill level are characteristic. This is also indicated by a high E2P ratio (mean over all regions $=316$ ). A typical cycle lasts $\approx 45$ days and charging as well as discharging usually occurs with high power.

(2) In the following section, we investigate to what extent storage dispatch patterns (characterized by NC and NFC) for individual EES technologies are either model-region-specific or similar in all model-regions. For this purpose, we compare the number of storage cycles (NC) to the storage full cycles (NFC) for all storage technologies (except for redox-flow batteries) for four regions (see Fig. 9).
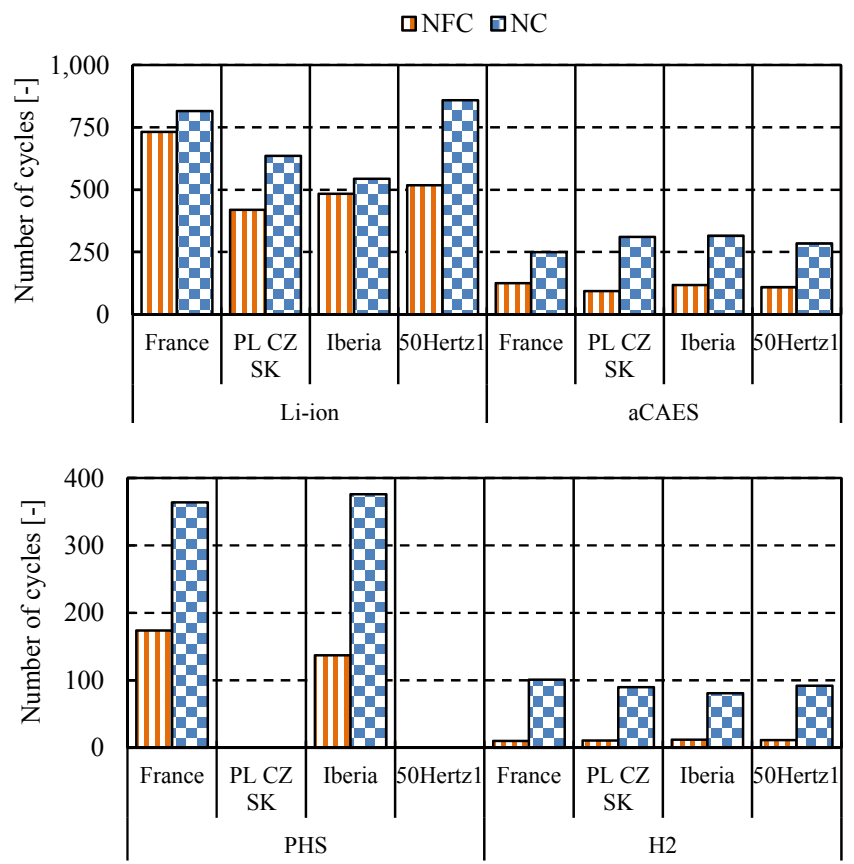

Fig. 9: Number of cycles (NC) and full cycles (NFC) for each storage technology for the model-regions France, $\mathrm{PL}+\mathrm{CZ}+\mathrm{SK}$, Iberia, and 50 Hertz1.

The $\mathrm{NC}$ of $\mathrm{H}_{2}$ storage is between 80 and 100, for aCAES between 250-320, for PHS between 360-380 and for Li-ion batteries between 540 and 860 . With regard to the NFC, model results range from 10 to 12 for $\mathrm{H}_{2}, 90-130$ for aCAES, 140-170 for PHS and 420-730 for Li-ion storage. For each storage technology, similar values for NC and NFC are observed in all model-regions, however, with one exception: Li-ion storage shows notable differences between the regions with regard to the NC and the NFC. The modelregions Iberia and $\mathrm{PL}+\mathrm{CZ}+\mathrm{SK}$, for example, exhibit rather low NC $(\approx 500)$, whereas France and 50Hertzl show relatively high $\mathrm{NC}(\approx 750)$. This also can be supported by the coefficient of variation (cv), which is shown in Tab. 5 for the NFC of each storage technology of all model-regions with non-marginal installed storage capacities. Here, Li-ion batteries show the highest $\mathrm{cv}(0.67)$, indicating the regional differences in the utilization of this technology. 
Tab. 5: Mean values, standard deviation, and coefficient of variation (cv) of the number of full cycles (NFC) over all model-regions. Note that these values were only derived for model-regions with a considerable amount of storage capacity.

\begin{tabular}{lrrr}
\hline \multicolumn{4}{c}{ Number of full cycles (NFC) } \\
\hline & Mean [-] & Std. deviation [-] & cv [-] \\
\hline $\mathrm{H}_{2}$ & 9 & 1.5 & 0.17 \\
Li-Ion & 817 & 550 & 0.67 \\
aCAES & 119 & 19 & 0.16 \\
PHS & 117 & 56 & 0.18 \\
\hline
\end{tabular}

This behavior could be explained by the fact that Li-ion batteries with low NC primarily balance electricity from PV. High NC in contrast, indicate that Li-ion does not exclusively store PV feed-in (daily cycling), but additionally balances electricity from wind power. In order to validate this hypothesis, we analyze the region- and technologyspecific storage dispatch of Li-ion batteries in detail using heat maps.

Fig. 10 shows the normalized charge (left panels) and discharge power (right panels) of Li-ion storage over the hours of a day on the abscissa and over the days of the year on the ordinate for the same model-regions as in Fig. 9.
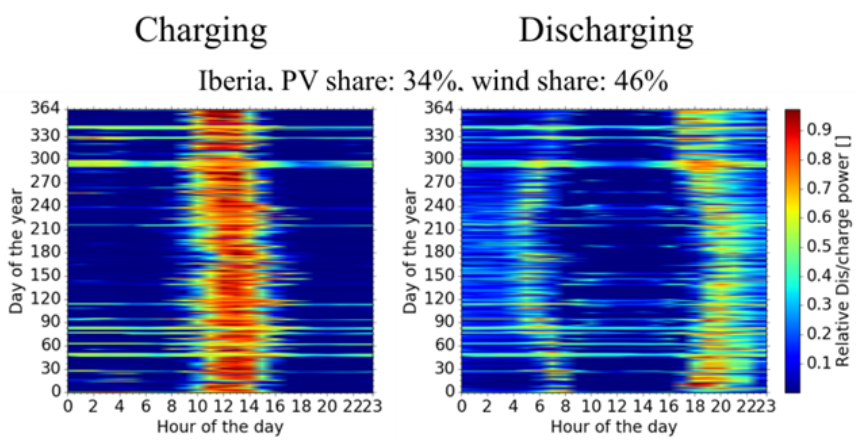

$\mathrm{PL}+\mathrm{CZ}+\mathrm{SK}$. PV share: $23 \%$, wind share: $50 \%$
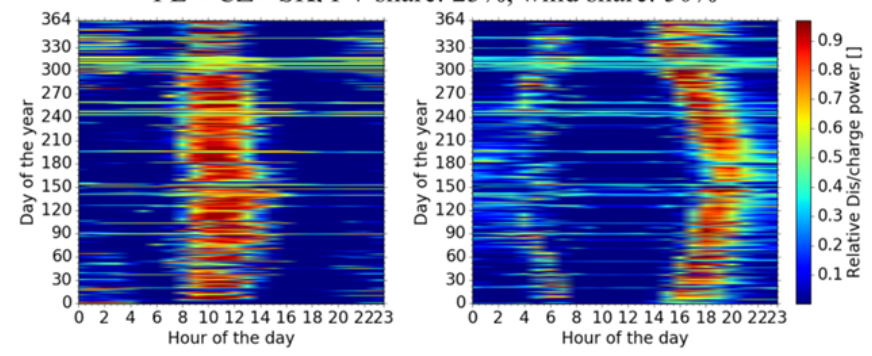
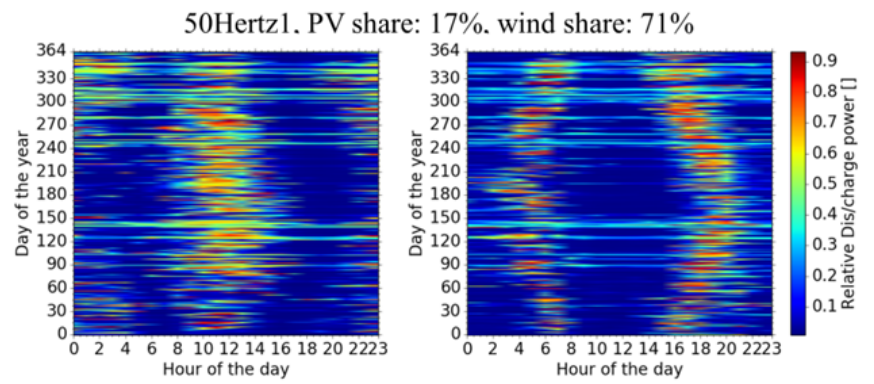

France. PV share: $10 \%$. wind share: $87 \%$

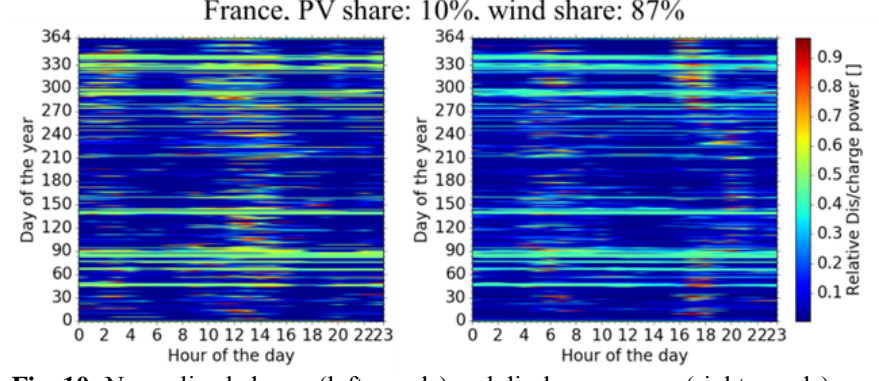

Fig. 10: Normalized charge (left panels) and discharge power (right panels) over the hours of the day and over the days of the year of Li-ion batteries in the model-regions Iberia, PL $+\mathrm{CZ}+\mathrm{SK}, 50 \mathrm{Hertz} 1$, and France.

In all regions shown in Fig. 10, storage loading processes generally occur daily and primarily in the hours of the highest PV power generation, while discharging mainly takes place during hours of high electricity demand and low PV power production. However, some differences exist. For the regions shown in Fig. 10, low PV shares - as in France or 50Hertz1 - are associated with high amounts of electricity generation from wind power due to the required high share of VRE. In consequence, France and 50Hertzl are characterized by a higher number of charging processes during the night times when compared with Iberia or $\mathrm{PL}+\mathrm{CZ}+\mathrm{SK}$. This, in turn, again leads to a higher $\mathrm{NC}$ of Li-ion batteries in France and 50Hertz1 (see Fig. 9).

Furthermore, we observe that higher wind shares and hence increasing $\mathrm{NC}$ lead to lower relative charge powers. Consequently, for PV regions which are characterized with higher Li-ion battery capacities and lower NC, the relative charge power is significantly higher than in wind-dominated regions.

In conclusion, Fig. 10 underlines the assumption that Liion batteries do not exclusively balance short-term diurnal fluctuations from PV generation, but also are charged in times of high wind penetration. Naturally, this effect is more distinctive with increasing wind shares. In these cases, Liion batteries complement mid- and long-term storage with the balancing of synoptic and seasonal fluctuations from wind energy (dual use of Li-ion batteries).

In contrast to $\mathrm{Li}$-ion batteries, the dispatch of PHS, aCAES, and $\mathrm{H}_{2}$ storage is largely region-independent (see Fig. 9).

\section{Discussion}

\subsection{Sensitivity analysis}

In order to validate the model results with respect to EES requirements, an extensive sensitivity analysis has been carried out. Here, we summarize results for a selection of 
sensitivity tests; the detailed sensitivity analysis, as well as all underlying assumptions, can be found in Sec. 10 of the supplementary materials. The sensitivity tests discussed here include:

i. StorInv_low, StorInv_high: 50\% higher (lower) specific investment costs for storage than in the reference case.

ii. VREInv high, VREInv low: 50\% higher (lower) specific investment costs for PV, onshore wind, and offshore wind than in the reference case.

iii. Cur.003: technology- and model-region-specific curtailment limited to $3 \%$ of technology-specific gross power production.

iv. $\mathrm{G}+$ : endogenously optimized power grid expansion.

Fig. 11 shows the differences in installed storage power capacity in the selected sensitivity tests compared to the reference scenario (Ref) (sum over all model-regions).

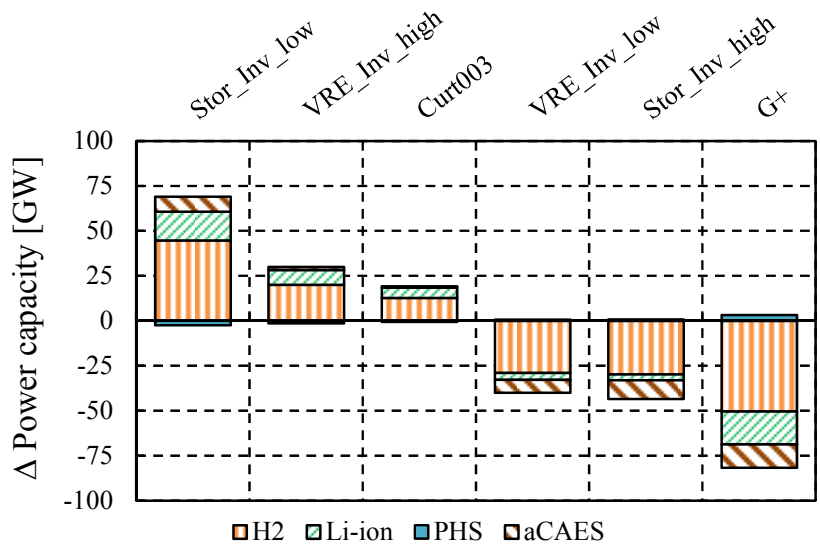

Fig. 11: Selected sensitivity tests: differences in the installed capacity of storage power capacity compared to the reference scenario aggregated over all model-regions.

First reduced storage investment costs (StorInv low) lead to an increased EES expansion; in contrast, higher storage costs reduce EES expansion compared to the reference run (StorInv_high). Second, higher costs for VRE (VREInv_high) lead to reduced installed capacities of VRE and in consequence will foster higher EES capacities through reduced curtailments of VRE (in order to meet $80 \%_{\text {constr }}$ ). Third, more restrictive curtailment requirements (Cur.003) mainly lead to reduced curtailments of offshore wind generation. The wind power otherwise curtailed has to be stored in Cur.003. This results in increased $\mathrm{H}_{2}$ storage capacities (as charging of these capacities mainly correlates with offshore wind, see Sec. 3.3) in this scenario. Finally, we see that endogenously determined grid expansion $(\mathrm{G}+)$ is able to substitute large amounts of EES capacity, in particularly $\mathrm{H}_{2}$. These storage capacities are replaced since in the reference case EES primarily integrates offshore wind power production which otherwise would have to be curtailed due to grid limitations. However, as also shown in other studies (see e.g. [51]), storage capacities are not completely interchangeable by transmission grid. In scenarios with high shares of VRE generation, grid expansion and storage are complementary flexibility options.

The outcome of the sensitivity analysis supports the coherence of the optimization results and the underlying model assumptions. In comparison to the overall installed EES capacity in the reference scenario (166 GW, see Sec. 3.2) the variations shown in Fig. 11 are notable (for StorInv low $+32 \%$ and for $\mathrm{G}+-39 \%$ ). Nevertheless, Fig. 11 only depicts the most influential scenarios (with regard to storage capacity); other sensitivity cases - such as fuels or $\mathrm{CO}_{2}$ emission certificate variations-only show minor effects (see Sec.10 of the supplementary material). Moreover, the findings from Sec. 3 (spatial storage distribution and dispatch) remain robust over all scenarios.

\subsection{Limitations and outlook}

Ranges for EES capacity in the literature vary widely, driven by different methodologies, as well as model and data assumptions. The endogenously derived EES capacities aggregated over all model-regions (166 GW, $30 \mathrm{TWh}$, excluding existing capacities) are in line with some studies (I), while others result in significantly lower (II), or higher (III, IV) storage capacities.

(I) Scholz et al. [66] use the same model as this study, assume similar model-regions, and quantify EES capacities for various theoretical (before curtailment) VRE shares and solar-(PV and CSP)-to-wind ratios, including endogenously derived transmission grid capacities. We, therefore, compare their results to scenario $\mathrm{G}+$. The latter is characterized by a theoretical VRE share of $87 \%$ and a storage power (endogenously expansion, no stock capacities) of $87 \mathrm{GW}$. The authors derive similar results for storage power; $93 \mathrm{GW}$ in a $100 \%$ VRE share scenario and $58 \mathrm{GW}$ in a $80 \% \mathrm{VRE}$ share scenario, both assuming solar-to-wind ratios of 0.25 .

(II) Though analyzing a larger observation area (EU27), the cost minimizing model of Bertsch et al. [52] results in lower EES power $\left(68 \mathrm{GW}\right.$, scenario B: high $\mathrm{CO}_{2}$ prices), which mainly can be explained by the lower VRE share of $75 \%$.

(III) The analysis of Bussar et al. [53] results in 1,060 GW of EES power, including PHS, battery systems, and the capacity of CCGT for the reconversion of $\mathrm{H}_{2}$ (excluding the electrolyzer capacity). Again, we stress that comparability is limited, as Ref. [53] assumes a 100\% VRE share and analyzes a larger observation area, which, compared to this study, additionally includes East and South-East Europe, Turkey, North Africa, and the Middle East. Furthermore, the model assumes that at least $80 \%$ of each country's electricity demand is supplied by national resources. This assumption limits long-range load and generation balancing and thus increases the demand for EES.

(IV) The analysis of Hartman [54] derives storage requirements for Germany, assuming no transmission grid restrictions within the model-region (copper plate). While storage energy capacity is similar (5.4 TWh, in the scenarios with unrestricted curtailments), storage power is more than double $(66 \mathrm{GW})$, even though the renewable share (with regard to the annual gross electricity demand) is lower $(80 \%)$ than in our calculations. However, Hartman [54] does not include power exchange via the transmission grid to 
neighboring countries. The latter has - as we showed in our analysis - a major impact on storage requirements.

Subsequently, we discuss whether some aspects of the chosen methodology and the assumptions might influence the derived EES capacity.

First, the results of the sensitivity analysis already indicate that grid expansion reduces the demand for EES (see Fig. 11, scenario $\mathrm{G}+$ ). Including more flexibility options (e.g. demand side management) and incorporating the coupling to other energy-related sectors (e.g. heating, cooling, and transportation) is likely to decrease the demand for EES (see e.g. [55]).

Second, the proposed method solely includes the high voltage transmission grid and, in consequence, neglects distribution grid restrictions within the defined modelregions (copper plates). Thus, additional EES requirements on the distribution grid level are not taken into account. We tackle this issue by using a high number of model-regions which reduces the size of each copper plate. However, the uneven disaggregation of countries into model-regions (e.g. 20 German model-regions compared to one model-region for France) might lead to over- or underestimation of grid restrictions and thereby affects EES requirements. In the light of existing research, the influence of distribution grids and spatial resolution has not yet been analyzed for European long-term energy scenarios.

To answer the question of optimal spatial distribution of storage capacity, the simultaneous endogenous capacity expansion and dispatch optimization for generation technologies and flexibility options using a high level of temporal, spatial, and technological resolution is a novelty. Despite the aforementioned limitations, the analysis, therefore, is an adequate remedy to answer the research question.

\section{Summary and conclusions}

We applied the linear, cost minimizing optimization model REMix which endogenously determines the installed capacities and dispatch of all power generation and electrical energy storage in a system with at least $80 \%$ power production from variable renewable energies. The analysis region comprises northern, western, south, southwest, and central Europe. Furthermore, we investigated the spatial distribution of those storage capacities and their dispatch in detail.

The model results in storage power capacity that is mainly provided by hydrogen storage and lithium-ion batteries. Adiabatic compressed air and pumped hydro storage can play a role for regions with higher shares of mid-term fluctuations through onshore wind, provided that sufficient energy capacity expansion potentials are available (e.g. salt caverns or water reservoirs). In this analysis, redox-flow batteries only play an insignificant role for power balancing, mainly due to the more favorable techno-economic parameters of lithium-ion batteries and compressed air storage.

From this analysis we also conclude that the spatial distribution of storage capacity expansion is mainly influenced by two factors (see next paragraphs); model- based quantifications, therefore, should carefully consider these aspects in their assumptions.

First, the temporal characteristics of the electricity generation from variable renewable energy sources heavily influence the expansion of storage. In general, surpluses from variable renewable power, i.e. negative residual loads, highly correlate with storage charging in all model-regions. In this sense, the shape of the negative residual loadtypically defined by the predominance of a certain variable renewable energy technology - triggers the need for either short, mid, or long-term storage (or a combination of all three if the residual load is characterized by multiple VRE technologies). More precisely, we observed high correlations between the generation of offshore wind and hydrogen storage charging, onshore wind with hydrogen and compressed air, and, finally, between PV generation and lithium-ion battery charging. These correlation coefficients can be explained by the energy-to-power-investment-ratio of each storage technology.

Second, the results further show that limited technical potentials with respect to storage energy capacity of one technology have an influence on the local, region-specific allocation of other storage technologies. In particular, limited technical potentials for pumped hydro can be substituted by compressed air and stationary lithium-ion storage, if necessary.

For storage utilization, the results show typical dispatch patterns of different storage technologies: while lithium-ion batteries in PV dominated regions (e.g. Iberia) generally cycle daily, onshore wind regions (e.g. $\mathrm{PL}+\mathrm{CZ}+\mathrm{SK}$ ) are characterized by mid-term balancing of compressed air storage with typical cycle lengths of 3-5 days. In contrast, hydrogen storage shows a more seasonal behavior with typical cycle lengths around 45 days. Our results highlight that all three storage technologies have similar characteristic dispatch patterns in all model-regions. The utilization of lithium-ion batteries, however, depends on the generation share of wind and PV generation. In regions with high shares of wind we observed a dual use of lithium-ion storage, where this technology not only balances the daily fluctuation of PV feed-in but additionally is used to level the more diurnal and seasonal volatile generation from wind power.

\section{Acknowledgments}

The authors would like to thank Yvonne Scholz, Thomas Pregger, Hans-Christian Gils, Karl-Kiên Cao, Denis Hess, and Jannik Haas for their valuable input for this work. Felix Cebulla gratefully acknowledges the funding from the Helmholtz Research School on Energy Scenarios (ESS).

\begin{tabular}{ll}
\multicolumn{2}{c}{ Abbreviations } \\
AC & Alternating current \\
aCAES & Adiabatic compressed air storage \\
CCGT & Combined cycle gas turbine \\
CSP & Concentrating solar thermal \\
DC & Direct current \\
E2P & Energy-to-power-ratio \\
EES & Electrical energy storage \\
EEX & European Energy Exchange
\end{tabular}




$\begin{array}{ll}\text { EnDAT } & \begin{array}{l}\text { Energy Data Analysis Tool } \\ \text { ENTSO-E }\end{array} \\ \text { European Network of Transmission System } \\ \text { Operators for Electricity } \\ \text { GAMS } & \text { General algebraic modeling system } \\ \text { GT } & \text { Gas turbine } \\ \mathrm{H}_{2} & \text { Hydrogen storage } \\ \text { Li-Ion } & \text { Stationary lithium-ion battery } \\ \text { NC } & \text { Number of cycles } \\ \text { NFC } & \text { Number of full cycles } \\ \text { PHS } & \text { Pumped hydro storage } \\ \text { PV } & \text { Photovoltaic } \\ \text { RE } & \text { Renewable Energy } \\ \text { REMix } & \text { Renewable Energy Mix model } \\ \text { SOC } & \text { State of charge } \\ \text { VRE } & \text { Variable renewable energy }\end{array}$

\section{References}

[1] IPCC, Climate change 2014: Synthesis Report. Contribution of Working Groups I, II and III to the Fifth Assessment Report of the Intergovernmental Panel on Climate Change. 2014.

[2] North American Electric Reliability Corporation, "Flexibility requirements and metrics for variable generation," 2010.

[3] E. Lannoye, D. Flynn, and M. O'Malley, "Power system flexibility assessment - State of the art," in Power and Energy Society General Meeting, 2012 IEEE, 2012, pp. 1-6.

[4] P. D. Lund, J. Lindgren, J. Mikkola, and J. Salpakari, "Review of energy system flexibility measures to enable high levels of variable renewable electricity," Renewable and Sustainable Energy Reviews, vol. 45, no. 0 , pp. 785-807, 2015.

[5] H. Kondziella and T. Bruckner, "Flexibility requirements of renewable energy based electricity systems - a review of research results and methodologies," Renewable and Sustainable Energy Reviews, vol. 53, pp. 10-22, 2016.

[6] B. Droste-Franke, M. Carrier, M. Kaiser, M. Schreurs, C. Weber, and T. Ziesemer, Improving Energy Decisions Towards Better Scientific Policy Advice for a Safe and Secure Future Energy System. European Academy of Technology and Innovation Assessment, 2014.

[7] B. Steffen and C. Weber, "Efficient storage capacity in power systems with thermal and renewable generation," Energy Economics, vol. 36, pp. 556567, 2013

[8] M. D. Bartos and M. V. Chester, "Impacts of climate change on electric power supply in the Western United States," Nature Climate Change, vol. 5, no. 8, pp. 748-752, 2015.

[9] K. Schaber, F. Steinke, and T. Hamacher, "Transmission grid extensions for the integration of variable renewable energies in Europe: Who benefits where?," Energy Policy, vol. 43, no. 0, pp. 123-135, 2012.
[10] F. Steinke, P. Wolfrum, and C. Hoffmann, "Grid vs. storage in a $100 \%$ renewable Europe," Renewable Energy, vol. 50, no. 0, pp. 826-832, 2013.

[11] J. Haas, F. Cebulla, K. Cao, W. Nowak, R. PalmaBehnke, C. Rahmann, and P. Mancarella, "Challenges and trends of energy storage expansion planning for flexibility provision in low-carbon power systems - a review," Renewable and Sustainable Energy Reviews, vol. 80, pp. 603-619, 2017.

[12] A. Zerrahn and W. P. Schill, "A Greenfield Model to Evaluate Long-Run Power Storage Requirements for High Shares of Renewables," DIW Discussion Paper, no. $34,2015$.

[13] C. Krüger, M. Buddeke, F. Merten, and A. Nebel, "Modelling the interdependencies of storage, DSM and grid-extension for Europe," in 12th International Conference on the European Energy Market (EEM), 2015, 2015, pp. 1-5.

[14] D. Heide, M. Greiner, L. von Bremen, and C. Hoffmann, "Reduced storage and balancing needs in a fully renewable European power system with excess wind and solar power generation," Renewable Energy, vol. 36, no. 9, pp. 2515-2523, 2011.

[15] S. Weitemeyer, D. Kleinhans, L. Wienholt, T. Vogt, and C. Agert, "A European Perspective: Potential of Grid and Storage for Balancing Renewable Power Systems," Energy Technology, vol. 4, no. 1, pp. 114 $122,2015$.

[16] S. Weitemeyer, D. Kleinhans, T. Vogt, and C. Agert, "Integration of Renewable Energy Sources in future power systems: The role of storage," Renewable Energy, vol. 75, pp. 14-20, 2015.

[17] P. Wrobel and D. Beyer, "Local Energy Balancing Demand for Germany," in International Renewable Energy Storage Conference and Exhibition, 2012.

[18] S.-I. Inage, "Prospects for large-scale energy storage in decarbonised power grids," International Energy Agency (IEA), 2009.

[19] J. P. Deane, G. Drayton, and B. P. Ó. Gallachóír, "The impact of sub-hourly modelling in power systems with significant levels of renewable generation," Applied Energy, vol. 113, pp. 152-158, 2014.

[20] H. Pandzzic, Y. Dvorkin, Y. Wang, T. Qiu, and D. S. Kirschen, "Effect of time resolution on unit commitment decisions in systems with high wind penetration," in PES General Meeting, Conference Exposition, 2014 IEEE, 2014, pp. 1-5.

[21] C. O'Dwyer and D. Flynn, "Using Energy Storage to Manage High Net Load Variability at Sub-Hourly Time-Scales," IEEE Transactions on Power Systems, vol. 30, no. 4, pp. 2139-2148, Jul. 2015.

[22] K. Poncelet, E. Delarue, D. Six, J. Duerinck, and W. D'haeseleer, "Impact of the level of temporal and operational detail in energy-system planning models," Applied Energy, vol. 162, pp. 631-643, 2016.

[23] P. Nahmmacher, E. Schmid, L. Hirth, and B. Knopf, "Carpe diem: A novel approach to select representative days for long-term power system modeling," Energy, vol. 112, pp. 430-442, 2016. 
[24] H. Oh, "Optimal Planning to Include Storage Devices in Power Systems," Power Systems, IEEE Transactions on, vol. 26, no. 3, pp. 1118-1128, Aug. 2011.

[25] B. A. Frew, S. Becker, M. J. Dvorak, G. B. Andresen, and M. Z. Jacobson, "Flexibility mechanisms and pathways to a highly renewable US electricity future," Energy, vol. 101, pp. 65-78, 2016.

[26] A. S. Brouwer, M. van den Broek, W. Zappa, W. C. Turkenburg, and A. Faaij, "Least-cost options for integrating intermittent renewables in low-carbon power systems," Applied Energy, vol. 161, pp. 48-74, 2016.

[27] M. Z. Jacobson, M. A. Delucchi, G. Bazouin, Z. A. F. Bauer, C. C. Heavey, E. Fisher, S. B. Morris, D. J. Y. Piekutowski, T. A. Vencill, and T. W. Yeskoo, " $100 \%$ clean and renewable wind, water, and sunlight (WWS) all-sector energy roadmaps for the 50 United States," Energy Environ. Sci., vol. 8, no. 7, pp. 20932117, 2015.

[28] M. Z. Jacobson, M. A. Delucchi, Z. A. F. Bauer, S. C. Goodman, W. E. Chapman, and M. A. Cameron, " $100 \%$ Clean and Renewable Wind, Water, and Sunlight (WWS) All-Sector Energy Roadmaps for 139 Countries of the World," Working paper, 2016.

[29] R. Loulou, "ETSAP-TIAM: the TIMES integrated assessment model. part II: mathematical formulation," Computational Management Science, vol. 5, no. 1, pp. 41-66, 2007.

[30] R. Loulou and M. Labriet, "ETSAP-TIAM: the TIMES integrated assessment model Part I: Model structure," Computational Management Science, vol. 5, no. 1, pp. 7-40, 2007.

[31] P. D. Brown, J. A. Peas Lopes, and M. A. Matos, "Optimization of Pumped Storage Capacity in an Isolated Power System with Large Renewable Penetration," IEEE Transactions on Power Systems, vol. 23, no. 2, pp. 523-531, 2008.

[32] P. Denholm and M. Hand, "Grid flexibility and storage required to achieve very high penetration of variable renewable electricity," Energy Policy, vol. 39, no. 3, pp. 1817-1830, 2011.

[33] A. A. Solomon, D. M. Kammen, and D. Callaway, "The role of large-scale energy storage design and dispatch in the power grid: A study of very high grid penetration of variable renewable resources," Applied Energy, vol. 134, pp. 75-89, 2014.

[34] S. Babrowski, P. Jochem, and W. Fichtner, "Electricity storage systems in the future German energy sector: An optimization of the German electricity generation system until 2040 considering grid restrictions," Computers \& Operations Research, vol. 66, pp. 228-240, 2016.

[35] A. Mileva, J. Johnston, J. H. Nelson, and D. M. Kammen, "Power system balancing for deep decarbonization of the electricity sector," Applied Energy, vol. 162, pp. 1001-1009, 2016.

[36] M. Huber, D. Dimkova, and T. Hamacher, "Integration of wind and solar power in Europe:
Assessment of flexibility requirements," Energy, vol. 69, no. 0, pp. 236-246, 2014.

[37] M. G. Rasmussen, G. B. Andresen, and M. Greiner, "Storage and balancing synergies in a fully or highly renewable pan-European power system," Energy Policy, vol. 51, no. 0, pp. 642-651, 2012.

[38] C. Bussar, P. Stöcker, Z. Cai, L. Moraes, R. Alvarez, H. Chen, C. Breuer, A. Moser, M. Leuthold, and D. U. Sauer, "Large-scale Integration of Renewable Energies and Impact on Storage Demand in a European Renewable Power System of 2050," Energy Procedia, vol. 73, pp. 145-153, 2015.

[39] G. Pleßmann, M. Erdmann, M. Hlusiak, and C. Breyer, "Global Energy Storage Demand for a 100\% Renewable Electricity Supply," Energy Procedia, vol. 46, no. 0, pp. 22-31, 2014.

[40] D. Stetter, "Enhancement of the REMix energy system model: Global renewable energy potentials, optimized power plant siting and scenario validation," University of Stuttgart, 2014.

[41] GAMS Development Corporation, "General Algebraic Modeling System (GAMS) Release 24.2.2." 2014 .

[42] "IBM ILOG CPLEX Optimizer Release 12.4.0.1." 2014.

[43] H. C. Gils, "Economic potential for future demand response in Germany - Modeling approach and case study," Applied Energy, vol. 162, pp. 401-415, 2016.

[44] F. Cebulla, J. Haas, J. Eichman, W. Nowak, and P. Mancarella, "How much energy storage do we need? A review and synthesis for the U.S., Europe, and Germany," Renewable Energy, 2017, under review.

[45] ENTSO-E load and consumption data, https://www.entsoe.eu/fileadmin/user_upload/_library /publications/ce/Load_and_Consumption_Data.pdf (Accessed 09/12/2015).

[46] ENTSO-E hourly load values of all countries for a specific month, https://www.entsoe.eu/dbquery/consumption/mhlv-all-countries-for-a-specificmonth (Accessed 03/20/2015).

[47] A. A. Solomon, D. Faiman, and G. Meron, "Properties and uses of storage for enhancing the grid penetration of very large photovoltaic systems," Energy Policy, vol. 38, no. 9, pp. 5208-5222, 2010.

[48] A. A. Solomon, D. M. Kammen, and D. Callaway, "Investigating the impact of wind-solar complementarities on energy storage requirement and the corresponding supply reliability criteria," Applied Energy, vol. 168, pp. 130-145, 2016.

[49] B. C. Ummels, E. Pelgrum, and W. L. Kling, "Integration of large-scale wind power and use of energy storage in the netherlands' electricity supply," IET Renewable Power Generation, vol. 2, no. 1, pp. 34-46, Mar. 2008.

[50] B. Nyamdash, E. Denny, and M. O'Malley, "The viability of balancing wind generation with large scale energy storage," Energy Policy, vol. 38, no. 11, pp. 7200-7208, 2010.

[51] C. B. Martínez-Anido, M.Vandenbergh, L.deVries, C.Alecu, A.Purvins, G. Fulli, and T.Huld, "Medium- 
term demand for European cross-border electricity transmission capacity," Energy Policy, vol. 61, pp. 207-222, 2013.

[52] J. Bertsch, C. Growitsch, S. Lorenczik, and S. Nagl, "Flexibility in Europe's power sector - An additional requirement or an automatic complement?," Energy Economics, vol. 53, pp. 118-131, 2016.

[53] C. Bussar, P. Stöcker, Z. Cai, L. Moraes, D. Magnor, P. Wiernes, N. van Bracht, A. Moser, and D. U. Sauer, "Large-scale integration of renewable energies and impact on storage demand in a European renewable power system of 2050 - Sensitivity study," Journal of Energy Storage, vol. 6, pp. 1-10, 2016.

[54] N. Hartmann, "Rolle und Bedeutung der Stromspeicher bei hohen Anteilen erneuerbarer Energien in Deutschland: Speichersimulation und Betriebsoptimierung," University of Stuttgart, 2013.

[55] H. C. Gils, "Balancing of Intermittent Renewable Power Generation by Demand Response and Thermal Energy Storage," University of Stuttgart, 2015.

[56] B. Stott, J. Jardim, and O. Alsac, "DC Power Flow Revisited," IEEE Transactions on Power Systems, vol. 24, no. 3, pp. 1290-1300, Aug. 2009.

[57] F. Trieb, C. Schillings, T. Pregger, and M. O'Sullivan, "Solar electricity imports from the Middle East and North Africa to Europe," Energy Policy, vol. 42, pp. 341-353, 2012.

[58] C. Noack, F. Burggraf, S. S. Hosseiny, P. Lettenmeier, S. Kolb, S. Belz, J. Kallo, K. A. Friedrich, T. Pregger, K. K. Cao, D. Heide, T. Naegler, F. Borggrefe, U. Bünger, J. Michalski, T. Raksha, C. Voglstätter, T. Smolinka, F. Crotogino, S. Donadei, P.-L. Horvath, and G.-S. Schneider, "Studie über die Planung einer Demonstrationsanlage zur Wasserstoff-Kraftstoffgewinnung durch Elektrolyse mit Zwischenspeicherung in Salzkavernen unter Druck," 2014.

[59] ENTSO-E, "10-Year Network Development Plan 2014," European Network of Transmission System Operators for Electricity (ENSTO-E), 2014.

[60] H. C. Gils, Y. Scholz, T. Pregger, D. L. de Tena, and D. Heide, "Integrated modelling of variable renewable energy-based power supply in Europe," Energy, vol. 123, pp. 173-188, 2017.

[61] T. Fichter, F. Trieb, and M. Moser, "Optimized Integration of Renewable Energy Technologies Into Jordan's Power Plant Portfolio," Heat Transfer Engineering, vol. 35, no. 3, pp. 281-301, 2013.

[62] F. Cebulla and T. Fichter, "Merit order or unitcommitment: How does thermal power plant modeling affect storage demand in energy system models?," Renewable Energy, vol. 105, pp. 117-132, 2017.

[63] S. Kühnel, "Investigation of the variability of solar and wind electricity generation potantials in Europe and North Africa," Karl von Ossietzky University Oldenburg, 2013.

[64] D. Treuherz, "The impact of various meteorological years on system reliability in a German energy scenario for 2025," University of Applied Sciences Mannheim, 2015.

[65] G. Haydt, V. Leal, A. Pina, and C. A. Silva, "The relevance of the energy resource dynamics in the $\mathrm{mid} /$ long-term energy planning models," Renewable Energy, vol. 36, no. 11, pp. 3068-3074, 2011.

[66] Y. Scholz, H. C. Gils, and R. Pietzcker, "Application of a high-detail energy system model to derive power sector characteristics at high wind and solar shares," Energy Economics, 2016.

[67] D. Luca de Tena, "Large Scale Renewable Power Integration with Electric Vehicles," University of Stuttgart, 2014.

[68] Y. Scholz, H. C. Gils, T. Pregger, D. Heide, F Cebulla, K.-K. Cao, D. Hess, and F. Borggrefe, "Möglichkeiten und Grenzen des Lastausgleichs durch Energiespeicher, verschiebbare Lasten und stromgeführte KWK bei hohem Anteil fluktuierender erneuerbarer Stromerzeugung," DLR, 2014.

[69] F. Trieb, C. Schillings, S. Kronshage, P. Viebahn, M. Kabariti, D. K.M., A. Bennouna, H. El Nokraschy, S. Hassan, L. G. Yussef, T. Hasni, N. El Bassam, and H. Satoguina, "Concentrating Solar Power for the Mediterranian Region: MED-CSP.” DLR, 2005.

[70] F. Trieb, C. Schillings, S. Kronshage, U. Klann, P. Viebahn, N. May, R. Wilde, C. Paul, M. Kabariti, A. Bennouna, H. El Nokraschy, S. Hassan, L. G. Yussef, T. Hasni, N. El Bassam, and H. Satoguina, "TransMediterranean Interconnection for Concentrating Solar Power: TRANS-CSP.” DLR, 2006.

[71] European Energy Agency (EEA), "CORINE Land Cover 2000," 2005.

[72] European Commission, Joint Research Center (JRC), "Global Land Cover 2000," 2003.

[73] H. Chen, T. N. Cong, W. Yang, C. Tan, Y. Li, and Y. Ding, "Progress in electrical energy storage system: A critical review," Progress in Natural Science, vol. 19, no. 3, pp. 291-312, Mar. 2009.

[74] F. Adamek, T. Aundrup, W. Glausinger, M. Kleinmaier, H. Landinger, M. Leuthold, B. Lunz, A. Moser, C. P. amd Helge Pluntke, N. Rotering, D. U. Sauer, M. Sterner, and W. Wellßow, "Energiespeicher für die Energiewende: Speicherungsbedarf und Auswirkungen auf das Übertragungsnetz für Szenarien bis 2050," VDEETG, Frankfurt a.M., 2012.

[75] G. Fuchs, B. Lunz, M. Leuthold, and D. U. Sauer, "Technology Overview on Electricity Storage," RWTH Aachen- Institut für Stromrichtertechnik und elektrische Antriebe (ISEA), 2012.

[76] H. L. Ferreira, R. Garde, G. Fulli, W. Kling, and J. P. Lopes, "Characterisation of electrical energy storage technologies," Energy, vol. 53, no. 0, pp. 288-298, 2013.

[77] X. Luo, J. Wang, M. Dooner, and J. Clarke, "Overview of current development in electrical energy storage technologies and the application potential in power system operation," Applied Energy, vol. 137, pp. 511-536, 2015. 
[78] F. Ausfelder, C. Beilmann, M. Bertau, S. Bräuninger, A. Heinzel, R. Hoer, W. Koch, F. Mahlendorf, A. Metzelthin, M. Peuckert, and others, "Energiespeicherung als Element einer sicheren Energieversorgung," Chemie Ingenieur Technik, vol. 87, no. 1-2, pp. 17-89, 2015.

[79] M. Budt, D. Wolf, R. Span, and J. Yan, “A review on compressed air energy storage: Basic principles, past milestones and recent developments," Applied Energy, vol. 170, pp. 250-268, 2016.

[80] P. Vennemann, L. Thiel, and H.-C. Funke, "Pumped storage plants in the future power supply system," VGB powertech, vol. 90, no. 1, p. 44, 2010.

[81] P. Vennemann, K. Heinz Gruber, J. Ulrik Haaheim, A. Kunsch, H.-P. Sistenich, and H.-R. Thöni, "Pumped storage plants-status and perspectives," VGB powertech, vol. 91, no. 4, p. 32, 2011.

[82] J. P. Deane, B. P. Ó. Gallachóir, and E. J. McKeogh, "Techno-economic review of existing and new pumped hydro energy storage plant," Renewable and Sustainable Energy Reviews, vol. 14, no. 4, pp. 1293$1302,2010$.

[83] N. Hartmann, L. Eltrop, N. Bauer, J. Salzer, S. Schwarz, and M. Schmidt, "Stromspeicherpotenziale für Deutschland," Zentrum für Energieforschung Stuttgart (zfes), 2012.

[84] S\&P Global Platts, "World Electric Power Plants Database." 2010.

[85] A. Gillhaus, "Natural Gas Storage in Salt Caverns: Present Status, Developments and Future Trends in Europe," 2007.

[86] U. I. Ehlers, "Windenergie und DruckluftspeicherNetzentlastung und Reservestellung mit Druckluftspeicher im Rahmen einer deutschen Elektrizitätsversorgung mit hohem Windenergieanteil," University of Flensburg, 2005.

[87] Y. Scholz, "Renewable energy based electricity supply at low costs: development of the REMix model and application for Europe," University of Stuttgart, 2012.

[88] M. Gimeno-Gutiérrez and R. Lacal-Arántegui, "Assessment of the European potential for pumped hydropower energy storage based on two existing reservoirs," Renewable Energy, vol. 75, pp. 856-868, 2015.

[89] J. Nitsch, T. Pregger, T. Naegler, D. Heide, F. Trieb, Y. Scholz, K. Niehaus, N. Gerhardt, M. Sterner, T. Trost, A. von Oehsen, R. Schwinn, C. Pape, H. Hahn, M. Wickert, and B. Wenzel, "Langfristszenarien und Strategien für den Ausbau der erneuerbaren Energien in Deutschland bei Berücksichtigung der Entwicklung in Europa und global," 2012.

[90] M. Schlesinger, D. Lindenberger, and C. Lutz, "Energieszenarien für ein Energiekonzept der Bundesregierung," Prognos, 2010.

[91] J. Nitsch and T. Pregger, "Kostenbilanz des Ausbaus erneuerbarer Energien in der Stromerzeugung bei unterschiedlichen Preisbildungen am Strommarkt," Vierteljahrshefte zur Wirtschaftsforschung, vol. 3, pp. 45-59, 2013.
[92] J. Nitsch, T. Pregger, Y. Scholz, T. Naegler, M. Sterner, N. Gerhardt, A. von Oehsen, C. Pape, Y.-M. Saint-Drenan, and B. Wenzel, "Leitstudie 2010 Langfristszenarien und Strategien für den Ausbau der erneuerbaren Energien in Deutschland bei Berücksichtigung der Entwicklung in Europa und global,” DLR, FhG IWES, IFNE, 2010.

[93] International Energy Agency (IEA), “World Energy Outlook 2014," OECD Publishing, 2014.

[94] T. Pregger, J. Nitsch, and T. Naegler, "Long-term scenarios and strategies for the deployment of renewable energies in Germany," Energy Policy, vol. 59, no. 0, pp. 350-360, 2013. 


\section{Supplementary material}

\section{Spatial examination area and resolution}

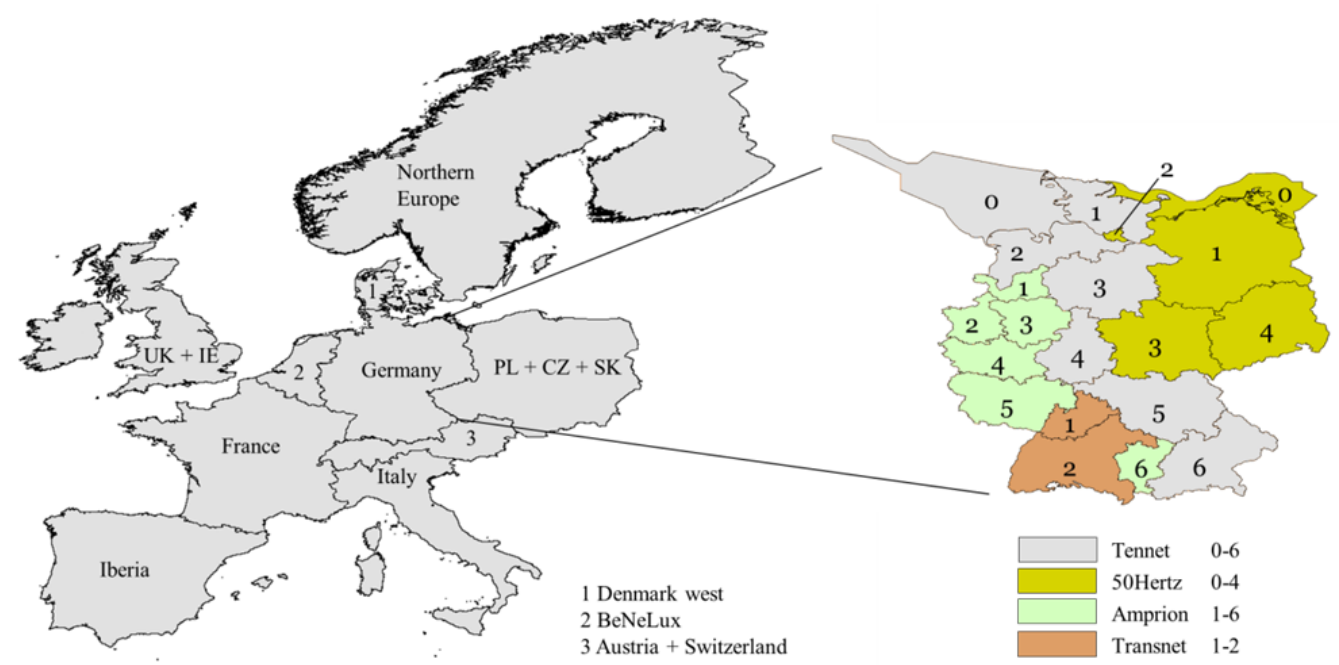

Fig. A 1: European and German observation area

\section{Electricity transmission grid}

Storage systems allow a temporal decoupling of electricity demand and supply. The transmission and distribution grid, in contrast, is able to shift energy on a spatial level. In this analysis both-the three-phase transmission system (AC) as well as the direct current (DC) grid - are considered. Both grid modeling approaches do not include each individual grid line, but aggregate all lines of one model-region to a link between two regions. The AC transmission system is modeled as a DC approximation (see Ref. [56]). It is characterized by its net transfer capacity (NTC) between two neighboring regions, length (approximate airline distance between geographic centers of the regions), the associated losses, and the lifetime. In addition, investment cost assumptions for land- and sea-lines, necessary converter stations as well as fix and variable operations and maintenance costs are part of the optimization problem. The AC transmission line technology is considered to be a $380 \mathrm{kV}$ four bundle $\mathrm{Al} / \mathrm{St}$, whereas DC differentiates between underground cables and overhead high voltage direct current lines as well as between various rated powers from $500 \mathrm{MW}$ up to $3,200 \mathrm{MW}$ for each line. This modeling approach neglects lower voltage levels (distribution grid) and assumes perfect electricity distribution without any losses or limitations within each model-region (copper plate). The technical and economic parameters for the AC and DC transmission grid can be found in Tab. A 1 and Tab. A 2. The values are based on [57], [58].

Tab. A 1: Technical parameter of AC and DC transmission grid.

\begin{tabular}{|c|c|c|c|c|}
\hline & Rated power [MW] & Losses land $[1 / 100 \mathrm{Km}]^{\mathrm{a}}$ & Losses sea $[1 / 100 \mathrm{Km}]$ & Losses converter $[-]^{\mathrm{b}}$ \\
\hline HVDC_2200_UC & 2,200 & 0.0035 & 0.0027 & 0.007 \\
\hline HVDC_3200 & 3,200 & 0.0045 & 0.0027 & 0.007 \\
\hline HVDC_1400 & 1,400 & 0.0045 & 0.0027 & 0.007 \\
\hline HVDC_1000 & 1,000 & 0.0045 & 0.0027 & 0.007 \\
\hline HVDC_0950 & 950 & 0.0045 & 0.0027 & 0.007 \\
\hline HVDC_0750 & 750 & 0.0045 & 0.0027 & 0.007 \\
\hline HVDC_0700 & 700 & 0.0045 & 0.0027 & 0.007 \\
\hline HVDC_0600 & 600 & 0.0045 & 0.0027 & 0.007 \\
\hline HVDC_0500 & 500 & 0.0045 & 0.0027 & 0.007 \\
\hline AC $380 \mathrm{kV}$ & 1,500 & $0.0002^{\mathrm{c}}$ & 0.0002 & - \\
\hline
\end{tabular}

\footnotetext{
${ }^{\mathrm{a}}$ Land losses for AC transmission grid given in $1 / \mathrm{km}$.

${ }^{\mathrm{b}}$ Losses factor for each converter station. Only modeled for DC transmission grid.

${ }^{c}$ The AC modeling approach does not differentiate between land and sea losses. Therefore, the values here are identical and should not be understood additively.
} 
Tab. A 2: Length-specific overnight investment costs for AC and DC transmission grid lines based on [57], [58].

\begin{tabular}{|c|c|c|c|c|c|c|}
\hline Scenario & Technology & Invest land $[\mathrm{k} € / \mathrm{km}]$ & Invest sea $[\mathrm{k} € / \mathrm{km}]^{\mathrm{a}}$ & Interest rate [-] & Amor. time [a] & $O \& M_{\text {fix }}$ \\
\hline $\mathrm{G}^{+}$ & AC $380 \mathrm{kV}$ & 1,000 & 1,000 & 0.06 & 40 & 0.003 \\
\hline $\mathrm{G}^{+}$ & HVDC_2200_UC & 913 & 1,815 & 0.06 & 40 & 0.010 \\
\hline $\mathrm{G}^{+}$ & HVDC_3200 & 384 & 2,640 & 0.06 & 40 & 0.010 \\
\hline
\end{tabular}

The topology of the AC and DC transmission grid is based on the Ten Year Network Development Plan (TYNDP) of the European Network of Transmission System Operators for Electricity (ENTSO-E) [59]. However, the grid infrastructure used in this work was developed for the time horizon 2022 and therefore does not match the high amounts of RE capacities fostered by $80 \%$ constr. In consequence, an initial model run with the grid topology of the TYNDP was performed and the NTCs of overloaded lines were increased subsequently. More specifically, the NTCs of the German offshore grid connection (Tennet0-Tennet1, 50Hertz0-50Hertz2) were increased by $5 \mathrm{GW}$. The resulting AC and DC transmission grids with their associated NTCs are illustrated in Fig. A 2.
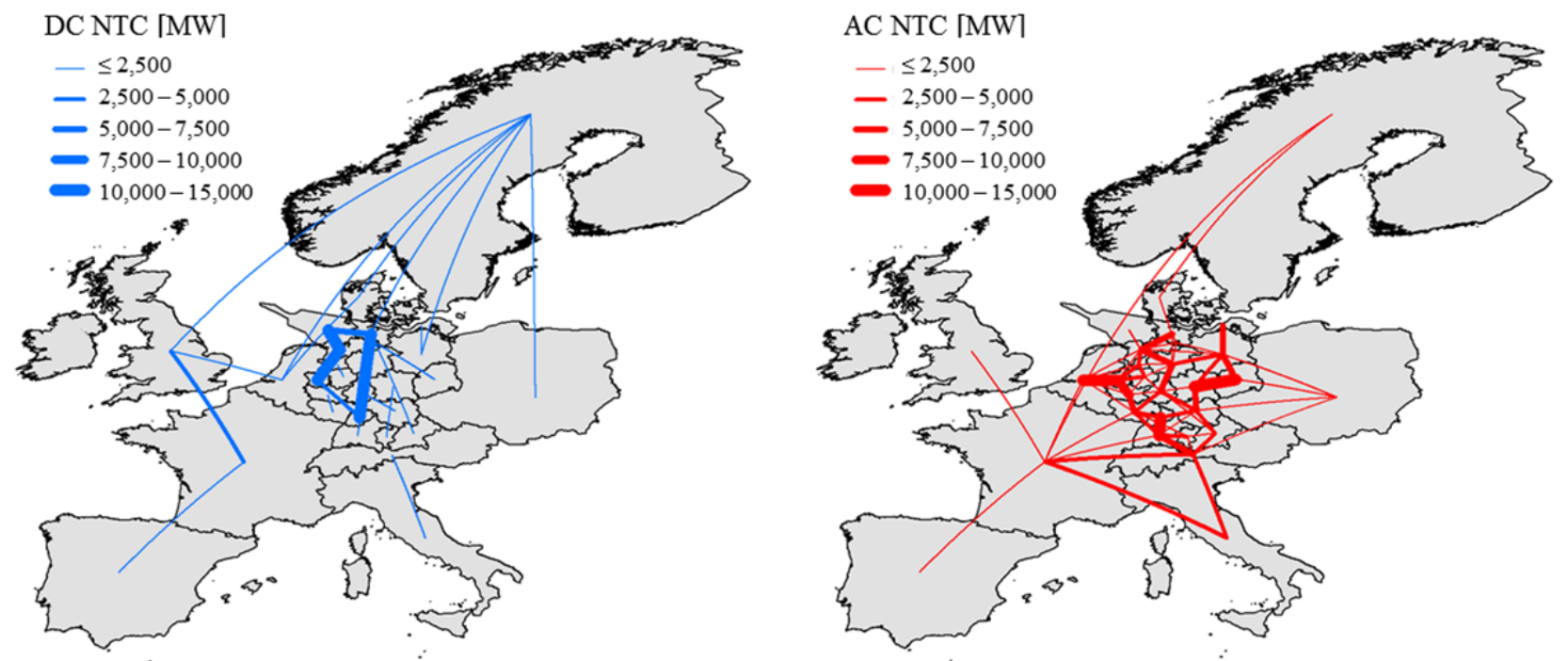

Fig. A 2: Exogenous AC and DC infrastructure for the European examination area based on a modification of the TYNDP.

\section{Stock of generation capacities}

Although the capacity expansion of most of the generation technologies is endogenously optimized (partial greenfield approach), some technologies are exogenously pre-defined and illustrated in Tab. A 3. This either refers to capacities which were built before 2050 and still exist in the observation year (e.g. some fossil-fired technologies) or to technologies which capacities were defined based on an exogenous scenario. 
Tab. A 3: Stock of generation capacities which were exogenously pre-defined for the year 2050 .

\begin{tabular}{|c|c|c|c|c|c|c|c|}
\hline & \multicolumn{7}{|c|}{ Existing generation capacities [GW] } \\
\hline & Nuclear & Lignite & Coal & CSP & Geothermal power & Hydro reservoir & PHS \\
\hline Austria + Switzerland & - & - & - & - & 0.90 & 14.45 & 4.32 \\
\hline BeNeLux & - & - & - & - & 0.30 & - & 2.51 \\
\hline Denmark west & - & - & - & - & 0.10 & - & - \\
\hline $\mathrm{PL}+\mathrm{CZ}+\mathrm{SK}$ & 2.94 & 0.16 & - & - & 1.95 & 0.98 & 3.50 \\
\hline France & 11.71 & - & - & 0.70 & 2.70 & 6.52 & 4.52 \\
\hline Iberia & - & - & - & 7.88 & 3.50 & 15.54 & 6.30 \\
\hline Italy & - & - & 1.00 & 1.00 & 3.74 & 3.35 & 5.94 \\
\hline Northern Europe & - & - & 1.00 & - & 0.90 & 10.11 & 1.45 \\
\hline Germany & - & 1.07 & - & - & 2.95 & 0.35 & 8.23 \\
\hline $\mathrm{UK}+\mathrm{IE}$ & 1.32 & - & - & - & 0.17 & 0.15 & 2.54 \\
\hline Total & 15.97 & 1.23 & 2.00 & 9.58 & 17.21 & 51.44 & 39.31 \\
\hline
\end{tabular}

\section{Electricity generation from fossil-fired and nuclear power-plants}

REMix provides two modeling approaches for the representation of fossil-fired power-plants: a linear programming- (LP, see Ref. [60]) and a mixed integer, clustered unit-commitment approach (MIP, see Ref. [61]). For this analysis the LP methodology was chosen, mainly due to its favorable computational performance. However, this approach neglects certain technological aspects of the power-plant representation, such as part load behavior or ramping constraints. Furthermore, LP modeling does not allow discrete dispatch and expansion decision variables (e.g. on/off decision of a specific power-plant). The approach however seems sufficient, since the importance of the degree of detail in conventional power-plant modeling decreases with increasing share of RE generation. Moreover, as shown by Cebulla and Fichter [62], in highly renewable energy scenario for large observations areas (e.g. Europe) LP modeling for thermal power plants is sufficient when analyzing storage expansion. Conventional power-plant technologies considered here comprise lignite and coal-fired power-plants, gas turbines (GT), combined cycle gas turbines (CCGT), and nuclear power-plants. Within the scenarios, capacity expansion of nuclear power plants is not allowed. The techno-economic parameters can be found in Tab. A 4, whereas the existing capacity stock is shown in Tab. A 3. 
Tab. A 4: Techno-economic parameters for fossil-fired thermal power-plants which are relevant for the observation year 2050 due to their life time. Each technology is further separated into different cohorts with regard to their construction year. These groups differentiate from each other only by their net and gross efficiencies $\eta$ net and $\eta$ gross. Furthermore the table shows the availability, the amortization and life time, interest rate and specific investment costs. The wear and tear costs describe a cost factors that occurs due to power-plant ramping. The variable operations and maintenance costs O\& $\mathrm{M}_{\mathrm{var}}$ are specific to the power output, while the fixed operations and maintenance costs $\mathrm{O} \& \mathrm{M}_{\mathrm{Fix}}$ are related relatively to the total investment.

\begin{tabular}{|c|c|c|c|c|c|c|c|c|c|c|c|}
\hline & $\begin{array}{l}\text { Construc. } \\
\text { year }[-]\end{array}$ & $\eta$ gross [-] & $\eta$ net [-] & $\begin{array}{l}\text { Avail- } \\
\text { ability [-] }\end{array}$ & $\begin{array}{l}\text { Amor. } \\
\text { time [a] }\end{array}$ & $\begin{array}{l}\text { Life } \\
\text { time [a] }\end{array}$ & $\begin{array}{l}\text { Interest } \\
\text { rate [-] }\end{array}$ & $\begin{array}{l}\text { Investment } \\
\text { costs }\left[€ / \mathrm{kW}_{\mathrm{el}}\right]\end{array}$ & $\begin{array}{l}\text { O\&M } \\
{[-]}\end{array}$ & $\begin{array}{l}\text { O\&M } \\
{\left[€ / \mathrm{kWh}_{\mathrm{Var}}\right]}\end{array}$ & $\begin{array}{l}\text { Wear \& tear } \\
\text { costs }\left[€ / \mathrm{kW}_{\mathrm{el}}\right]\end{array}$ \\
\hline CCGT & 2020 & 0.61 & 0.60 & 0.96 & 25 & 30 & 0.06 & 700 & 0.04 & 0.0003 & 0.0005 \\
\hline CCGT & 2030 & 0.63 & 0.62 & 0.96 & 25 & 30 & 0.06 & 700 & 0.04 & 0.0003 & 0.0005 \\
\hline CCGT & 2040 & 0.63 & 0.62 & 0.96 & 25 & 30 & 0.06 & 700 & 0.04 & 0.0003 & 0.0005 \\
\hline CCGT & 2050 & 0.63 & 0.62 & 0.96 & 25 & 30 & 0.06 & 700 & 0.04 & 0.0003 & 0.0005 \\
\hline GT & 2020 & 0.44 & 0.44 & 0.95 & 25 & 30 & 0.06 & 400 & 0.04 & 0.0003 & 0.0005 \\
\hline GT & 2030 & 0.46 & 0.46 & 0.95 & 25 & 30 & 0.06 & 400 & 0.04 & 0.0003 & 0.0005 \\
\hline GT & 2040 & 0.47 & 0.47 & 0.95 & 25 & 30 & 0.06 & 400 & 0.04 & 0.0003 & 0.0005 \\
\hline GT & 2050 & 0.47 & 0.47 & 0.95 & 25 & 30 & 0.06 & 400 & 0.04 & 0.0003 & 0.0005 \\
\hline Lignite & 2010 & 0.46 & 0.43 & 0.90 & 25 & 40 & 0.06 & 1,500 & 0.04 & 0.0001 & 0.0015 \\
\hline Lignite & 2020 & 0.50 & 0.47 & 0.90 & 25 & 40 & 0.06 & 1,500 & 0.04 & 0.0001 & 0.0015 \\
\hline Lignite & 2030 & 0.52 & 0.49 & 0.90 & 25 & 40 & 0.06 & 1,500 & 0.04 & 0.0001 & 0.0015 \\
\hline Lignite & 2040 & 0.52 & 0.49 & 0.90 & 25 & 40 & 0.06 & 1,500 & 0.04 & 0.0001 & 0.0015 \\
\hline Lignite & 2050 & 0.52 & 0.49 & 0.90 & 25 & 40 & 0.06 & 1,500 & 0.04 & 0.0001 & 0.0015 \\
\hline Nuclear & 2000 & 0.32 & 0.31 & 0.90 & 25 & 50 & 0.06 & $5,000^{\mathrm{a}}$ & $0.04^{\mathrm{a}}$ & 0.0001 & 0.0015 \\
\hline Nuclear & 2010 & 0.32 & 0.31 & 0.90 & 25 & 50 & 0.06 & $5,000^{\mathrm{a}}$ & $0.04^{\mathrm{a}}$ & 0.0001 & 0.0015 \\
\hline Nuclear & 2020 & 0.32 & 0.31 & 0.90 & 25 & 50 & 0.06 & $5,000^{\mathrm{a}}$ & $0.04^{\mathrm{a}}$ & 0.0001 & 0.0015 \\
\hline Nuclear & 2030 & 0.32 & 0.31 & 0.90 & 25 & 50 & 0.06 & $5,000^{\mathrm{a}}$ & $0.04^{\mathrm{a}}$ & 0.0001 & 0.0015 \\
\hline Nuclear & 2040 & 0.32 & 0.31 & 0.90 & 25 & 50 & 0.06 & $5,000^{\mathrm{a}}$ & $0.04^{\mathrm{a}}$ & 0.0001 & 0.0015 \\
\hline Nuclear & 2050 & 0.32 & 0.31 & 0.90 & 25 & 50 & 0.06 & $5,000^{\mathrm{a}}$ & $0.04^{\mathrm{a}}$ & 0.0001 & 0.0015 \\
\hline
\end{tabular}

${ }^{\mathrm{a}}$ Not used since capacity expansion of nuclear power-plants is restricted.

\subsection{Fuel price and $\mathrm{CO}_{2}$ emission certificate assumptions}

Tab. A 5: Prices for each fuel type and $\mathrm{CO}_{2}$ emission costs scenarios for the sensitivity analysis (see Sec. 10).

\begin{tabular}{|c|c|c|}
\hline Fuel type & $\begin{array}{l}\text { Fuel price } \\
{\left[€_{2010} / \mathrm{MWh}_{\text {therm }}\right]}\end{array}$ & Source \\
\hline Coal & 20.88 & [92] \\
\hline Lignite & 9.18 & [91] \\
\hline Natural gas & 47.52 & [92] \\
\hline Uranium & 5.24 & [93] \\
\hline
\end{tabular}

\begin{tabular}{lrr}
\hline $\begin{array}{l}\text { Cost } \\
\text { scenario }\end{array}$ & $\begin{array}{l}\mathrm{CO}_{2} \text { costs } \\
{\left[€ / \mathrm{tCO}_{2}\right]}\end{array}$ & Source \\
\hline Reference & 57 & {$[94]^{\mathrm{a}}$} \\
High & 150 & Own assumption \\
\hline
\end{tabular}

${ }^{\text {a }}$ Price path B.

${ }^{\text {a }}$ Scenario B, moderate price path.

\section{Electricity generation from variable renewable energies (VRE)}

The model includes representations of photovoltaic, onshore and offshore wind as well as run-of-the-river hydroelectricity. Conventional hydroelectricity, sometimes referred to as impoundment facilities ('dams'), are accounted as dispatchable renewable energy and therefore covered in Sec 6. In order to derive the cost optimal dispatch of VRE, REMix requires the potential, technology- and region-specific, hourly renewable electricity generation on the one hand (solar irradiation, wind speeds, water runoff) as input. On the other hand, for the capacity expansion, an upper threshold for the maximal installable capacity based on the renewable resource potential of the region is necessary (e.g. maximum installable PV capacity in one region, see Fig. 3). Both, the potential renewable generation time-series as well as the maximal installable capacities are a result of the REMix sub-model EnDAT (Energy Data Analysis Tool) and based on the weather year 2006. In terms of annual electricity generation potential for the VRE technologies, this year shows rather small variations from the mean annual 
electricity generation over the time period of 2006-2012 (see Ref. [63], [64]). It therefore can be considered as a 'typical' weather year and is suitable as a base year. Moreover, in the sensitivity analysis later on, the effect of different weather years is analyzed (see Sec. 10.6). The optimized VRE feed-in derives from the potential generation less the curtailments. The technoeconomic parameters of all VRE technologies are shown in Tab. A 6.

Tab. A 6: Technology and cost parameter for electricity generation from variable renewable energies. Values are based on [92]. The fixed operations and maintenance costs $\mathrm{O} \& \mathrm{M}_{\mathrm{Fix}}$ are related relatively to the total investment.

\begin{tabular}{lrrrr}
\hline Technology & Invest $\left[€ / \mathrm{kW}_{\mathrm{el}}\right]$ & Amor. time [a] & Interest rate [-] & O\&M $_{\text {fix }}[-]$ \\
\hline PV & 903 & 20 & 0.06 & 0.010 \\
Offshore wind & 1,300 & 18 & 0.06 & 0.055 \\
Onshore wind & 900 & 18 & 0.06 & 0.040 \\
Hydro run-of-the-river & 5,030 & 60 & 0.06 & 0.050 \\
\hline
\end{tabular}

\section{Electricity generation from dispatchable renewable energies}

Within the REMix model, dispatchable renewable energies include electricity generation from concentrating solar power (CSP), geothermal and solid biomass systems, and conventional hydroelectricity (reservoir hydroelectricity). Although the electricity generation from conventional hydroelectricity and CSP is dependent on a fluctuating resource, i.e. water inflow and solar irradiation, their ability to store energy over several hours makes these technologies dispatchable to some extent.

\subsection{Concentrating solar power (CSP)}

The modeling of CSP power-plants includes a solar field (SF), a thermal energy storage (TES), a power block (PB), and a natural gas-fired backup system. Additionally to the dispatch optimization, the dimensioning of these components can be endogenously and individually determined by the model. As another option, the model allows to use a pre-defined TES to PB ratio and a solar multiple. The latter describes the ratio of the SF to the PB. For the analysis at hand, we do not use the option to determine the expansion of each individual component model endogenously, but apply a solar multiple of three and a TES to PB ratio of 12 . Based on the hourly solar irradiation, the thermal output of the SF is calculated by the sub-model EnDAT. The TES is characterized by the hourly charging and discharging as well as the associated efficiencies, the storage level, and a selfdischarge rate. The techno-economic parameters are shown in Tab. A 7.

Tab. A 7: Technology and cost parameter for electricity generation from concentrating solar power-plants. Values are based on [92]. The variable operations and maintenance costs $O \& \mathrm{M}_{\mathrm{var}}$ are specific to the power output of the power block, while the fixed operations and maintenance costs O\&M $\mathrm{M}_{\mathrm{Fix}}$ are related relatively to the total investment.

\begin{tabular}{llr}
\hline & \multicolumn{1}{c}{ CSP } & \\
\hline Invest SF & {$\left[€ / \mathrm{kW}_{\text {therm }}\right]$} & 252 \\
Invest TES & {$\left[€ / \mathrm{kWh}_{\text {therm }}\right]$} & 25 \\
Invest PB & {$\left[€ / \mathrm{kW}_{\mathrm{el}}\right]$} & 971 \\
$\eta$ TES & {$[-]$} & 0.95 \\
$\eta$ PB & {$[-]$} & 0.37 \\
TES to PB ratio & {$[-]$} & 12 \\
TES self-discharge rate & {$[-]$} & 0.0005 \\
SM & {$[-]$} & 3 \\
Availability & {$[-]$} & 0.95 \\
Amor. time & {$[\mathrm{a}]$} & 25 \\
Interest rate & {$[-]$} & 0.06 \\
O\&M $_{\text {fix }}$ & {$[-]$} & 0.025 \\
O\&M $_{\text {var }}$ & {$\left[€ / \mathrm{kWh}_{\mathrm{el}}\right]$} & 0.0000001 \\
\hline
\end{tabular}

\subsection{Solid biomass and geothermal systems}

For solid biomass systems, REMix endogenously determines the capacities. In this analysis no upper capacity expansion limits (technical potential) are assumed. The techno-economic parameters of biomass and geothermal systems are shown in Tab. A 8 . 
Tab. A 8: Technology and cost parameter for electricity generation from biomass and geothermal systems. Values are based on [66]. The variable operations and maintenance costs $O \& \mathrm{M}_{\mathrm{var}}$ are specific to the power output, while the fixed operations and maintenance costs O\&M $\mathrm{M}_{\mathrm{Fix}}$ are related relatively to the total investment.

\begin{tabular}{|c|c|c|c|c|c|c|c|}
\hline Technology & $\eta[-]$ & Availability [-] & Invest $\left[€ / \mathrm{kW}_{\mathrm{el}}\right]$ & Amor. time [a] & Interest rate [-] & $\mathrm{O} \& \mathrm{M}_{\mathrm{fix}}[-]$ & $\mathrm{O} \& \mathrm{M}_{\mathrm{var}}\left[€ / \mathrm{kWh}_{\mathrm{el}}\right]$ \\
\hline Solid biomass & 0.28 & 0.95 & 2,500 & 20 & 0.06 & 0.05 & 0.0000001 \\
\hline Geothermal & 0.11 & 0.95 & $7,600^{\mathrm{a}}$ & 20 & 0.06 & 0.045 & 0.0000001 \\
\hline
\end{tabular}

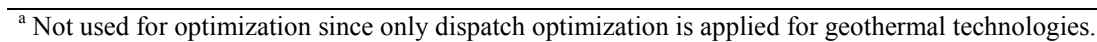

Geothermal electricity generation is modeled via pre-defined scenario capacities. In consequence, only the dispatch is optimized, but no capacity expansion. The values are based on [68] and shown in Tab. A 9 and Tab. A 10.

Tab. A 9: European exogenous scenario capacities for electricity generation from geothermal systems based on [68]. The German regions are aggregated and a model-region specific illustration is depicted in Tab. A 10.

\begin{tabular}{llr}
\hline Country & Model-region & Capacity $[\mathrm{MW}]$ \\
\hline Austria & Austria + Switzerland & 200 \\
Switzerland & Austria + Switzerland & 700 \\
Belgium & BeNeLux & 150 \\
Netherlands & BeNeLux & 135 \\
Luxembourg & BeNeLux & 15 \\
Denmark west & Denmark west & 100 \\
Czech Republic & PL + CZ + SK & 1,300 \\
Poland & PL + CZ + SK & 500 \\
Slovakia & PL + CZ + SK & 150 \\
France & France & 2,700 \\
Portugal & Iberia & 1,300 \\
Spain & Iberia & 2,200 \\
Italy & Italy & 3,738 \\
Finland & Northern Europe & 200 \\
Norway & Northern Europe & 200 \\
Sweden & Northern Europe & 400 \\
Denmark east & Northern Europe & 100 \\
Germany & Germany & 2,950 \\
Ireland & UK + IE & 100 \\
UK & UK + IE & \\
\hline & & \\
\hline
\end{tabular}


Tab. A 10: German exogenous scenario capacities for electricity generation from geothermal systems based on [68]

\begin{tabular}{llr}
\hline Country & Model-region & Capacity [MW] \\
\hline Germany & Amprion1 & 103 \\
Germany & Amprion2 & 98 \\
Germany & Amprion3 & 105 \\
Germany & Amprion4 & 40 \\
Germany & Amprion5 & 184 \\
Germany & Amprion6 & 92 \\
Germany & Transnet1 & 95 \\
Germany & Transnet2 & 325 \\
Germany & Tennet0 & - \\
Germany & Tennet1 & 108 \\
Germany & Tennet2 & 174 \\
Germany & Tennet3 & 264 \\
Germany & Tennet4 & 73 \\
Germany & Tennet5 & 267 \\
Germany & Tennet6 & 186 \\
Germany & $50 H e r t z 0$ & - \\
Germany & $50 H e r t z 1$ & 604 \\
Germany & $50 H e r t z 2$ & 13 \\
Germany & $50 H e r t z 3$ & 98 \\
Germany & $50 H e r t z 4$ & 121 \\
\hline
\end{tabular}




\subsection{Conventional hydroelectricity}

For conventional hydroelectricity the model uses a daily, model-region-specific, normalized (with regard to the turbine power) water inflow to the upper reservoir, based on a GIS analysis in Ref. [87] of the sub-model EnDAT. In order to use the daily resolution in the hourly REMix model, all 24 hours of one day are characterized by the same inflow value. This approximation is valid assumption as the temporal variability of conventional hydroelectricity typically is based on seasonal cycles, influenced by water runoff due to the melting of snow and precipitation. Moreover, in this analysis, conventional hydroelectricity modeling relies on systems with a water reservoir as storage, and, as shown in Haydt et al. [65], hourly variations of the water inflow are negligible in such approaches.

Furthermore, REMix is able to calculate new capacities for the turbine, also including the option to retrofit existing systems with a pump if a suitable lower reservoir is existent. In this analysis however, the dispatch of pre-defined, exogenous pump and turbine capacities is optimized, based on data from [67], [87] (see Tab. A 12, Tab. A 13). The techno-economic parameters of conventional hydroelectricity are shown in Tab. A 11. Purely PHS systems are covered in Sec. 8.2.

Tab. A 11: Technology and cost parameter for electricity generation from conventional, reservoir hydro power-plants. Values are based on [92]. [66]. The variable operations and maintenance costs $O \& \mathrm{M}_{\mathrm{var}}$ are specific to the power output, while the fixed operations and maintenance costs $\mathrm{O} \& \mathrm{M}_{\mathrm{Fix}}$ are related relatively to the total investment.

\begin{tabular}{|c|c|c|c|c|c|c|c|c|c|c|}
\hline Technology & $\begin{array}{l}\eta \text { turbine } \\
{[-]}\end{array}$ & $\begin{array}{l}\eta \text { pump }^{\mathrm{a}} \\
{[-]}\end{array}$ & $\begin{array}{l}\text { Availability } \\
{[-]}\end{array}$ & $\begin{array}{l}\text { Invest system } \\
{\left[€ / \mathrm{kW}_{\mathrm{el}}\right]}\end{array}$ & $\begin{array}{l}\text { Invest retrofit } \\
\text { pump }\left[€ / \mathrm{kW}_{\mathrm{el}}\right]\end{array}$ & $\begin{array}{l}\text { Amor. time } \\
\text { system [a] }\end{array}$ & $\begin{array}{l}\text { Amor. time } \\
\text { pump [a] }\end{array}$ & $\begin{array}{l}\text { Interest } \\
\text { rate [-] }\end{array}$ & $\begin{array}{l}\text { O\&M } M_{\text {fix }} \\
{[-]}\end{array}$ & $\begin{array}{l}\mathrm{O} \& \mathrm{M}_{\mathrm{var}} \\
{\left[€ / \mathrm{kWh}_{\mathrm{el}}\right]}\end{array}$ \\
\hline Reservoir hydro & 0.90 & 0.89 & 0.98 & 1,565 & 640 & 60 & 20 & 0.06 & 0.05 & 0.0000001 \\
\hline
\end{tabular}

${ }^{\text {a }}$ Only used if the reservoir hydro system is retrofitted with a pump.

Tab. A 12: European turbine and pump power (if retrofitted) as well as the reservoir capacity of conventional hydroelectricity based on [67], [87]. The German regions are here shown aggregated and a model-region specific illustration is depicted in Tab. A 13.

\begin{tabular}{llrrr}
\hline Country & Model-region & Turbine power $[\mathrm{MW}]$ & Pump power [MW] & Reservoir capacity [MWh $\left.\mathrm{MW}_{\mathrm{e}}\right]$ \\
\hline Austria & Austria + Switzerland & 5,500 & 3,006 & $3,259,259$ \\
Switzerland & Austria + Switzerland & 10,000 & 3,219 & $8,842,105$ \\
Belgium & BeNeLux & - & - & - \\
Netherlands & BeNeLux & - & - & - \\
Luxembourg & BeNeLux & - & - & - \\
Denmark west & Denmark west & - & - & - \\
Czech Republic & PL + CZ + SK & 660 & - & 737,975 \\
Poland & PL + CZ + SK & 156 & - & 174,430 \\
Slovakia & PL + CZ + SK & 167 & - & 186,730 \\
France & France & 12,317 & - & $10,405,741$ \\
Portugal & Iberia & 2,426 & - & $3,003,619$ \\
Spain & Iberia & 13,113 & - & $31,334,961$ \\
Italy & Italy & 3,350 & - & $3,576,351$ \\
Finland & Northern Europe & 593 & - & 663,059 \\
Norway & Northern Europe & 8,960 & 846 & $102,057,707$ \\
Sweden & Northern Europe & 832 & - & 930,295 \\
Denmark east & Northern Europe & - & - & - \\
Germany & Germany & 350 & - & 391,361 \\
UK & UK + IE & 25 & - & 27,954 \\
Ireland & UK + IE & 122 & - & 136,414 \\
\hline
\end{tabular}


Tab. A 13: German turbine and pump power (if retrofitted) as well as the reservoir capacity of conventional hydroelectricity based on [67], [87].

\begin{tabular}{|c|c|c|c|c|}
\hline Country & Model-region & Turbine power [MW] & Pump power [MW] & Reservoir capacity $\left[\mathrm{MWh}_{\mathrm{el}}\right]$ \\
\hline Germany & Amprion 1 & - & rata & - \\
\hline Germany & Amprion2 & 11 & rata & 11,785 \\
\hline Germany & Amprion3 & 19 & rata & 21,144 \\
\hline Germany & Amprion4 & 8 & & 9,415 \\
\hline Germany & Amprion5 & 30 & . & 32,985 \\
\hline Germany & Amprion6 & 134 & rata & 149,798 \\
\hline Germany & Transnet1 & 17 & & 18,841 \\
\hline Germany & Transnet2 & 116 & & 129,693 \\
\hline Germany & Tennet 1 & - & rata & - \\
\hline Germany & Tennet 2 & - & & - \\
\hline Germany & Tennet3 & 2 & & 2,359 \\
\hline Germany & Tennet4 & - & . & - \\
\hline Germany & Tennet5 & - & . & - \\
\hline Germany & Tennet6 & 14 & rat & 15,341 \\
\hline Germany & 50Hertz1 & - & . & - \\
\hline Germany & 50Hertz2 & - & . & - \\
\hline Germany & 50 Hertz3 & - & . & - \\
\hline Germany & 50 Hertz4 & - & 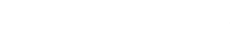 & - \\
\hline
\end{tabular}




\section{Electricity demand}

Tab. A 14: Annual electricity demand for all model-regions of the observation area for the year 2050

\begin{tabular}{|c|c|c|}
\hline Country & Model-region & El. demand [TWh $]^{\mathrm{a}}$ \\
\hline Austria & Austria + Switzerland & 60.43 \\
\hline Switzerland & Austria + Switzerland & 60.38 \\
\hline Belgium & BeNeLux & 82.47 \\
\hline Netherlands & BeNeLux & 109.93 \\
\hline Luxembourg & BeNeLux & 6.63 \\
\hline Denmark west & Denmark west & 22.4 \\
\hline Czech Republic & $\mathrm{PL}+\mathrm{CZ}+\mathrm{SK}$ & 72.03 \\
\hline Poland & $\mathrm{PL}+\mathrm{CZ}+\mathrm{SK}$ & 162.83 \\
\hline Slovakia & $\mathrm{PL}+\mathrm{CZ}+\mathrm{SK}$ & 22.87 \\
\hline France & France & 473.88 \\
\hline Portugal & Iberia & 55.86 \\
\hline Spain & Iberia & 284.95 \\
\hline Italy & Italy & 331.7 \\
\hline Finland & Northern Europe & 77.75 \\
\hline Norway & Northern Europe & 119.71 \\
\hline Sweden & Northern Europe & 132.53 \\
\hline Denmark east & Northern Europe & 13.32 \\
\hline Germany & Germany $^{\mathrm{b}}$ & 514 \\
\hline UK & $\mathrm{UK}+\mathrm{IE}$ & 343.85 \\
\hline Ireland & $\mathrm{UK}+\mathrm{IE}$ & 29.78 \\
\hline \multicolumn{3}{|c|}{$\begin{array}{l}\text { a The annual electricity demand for Germany is based on a modified version } \\
\text { of scenario A of [94]. Opposed to [94], the electricity demand for this } \\
\text { analysis excludes the demand for electric vehicles }(44 \mathrm{TWh} / \mathrm{a}) \text { and heat } \\
\text { pumps (16 TWh/a). These values again are based on [68]. For the European } \\
\text { countries values from [69], [70] were used. In order to disaggregate } \\
\text { Germany's electricity demand to the } 20 \text { sub-regions, artificial surfaces and } \\
\text { associated areas from [87] were applied, which again are based on [71] and } \\
\text { [72]. } \\
\text { b In this table the German model-regions are aggregated to Germany. The } \\
\text { actual model-region resolution within Germany is shown in Fig. A } 1 \text {. }\end{array}$} \\
\hline
\end{tabular}




\section{Storage technologies}

\subsection{Techno-economic parameters}

Tab. A 15: Technology and cost parameter for all considered storage technologies. Values are based on [73-79], [83]. The variable operations and maintenance costs $O \& \mathrm{M}_{\mathrm{var}}$ are specific to storage charging, while the fixed operations and maintenance costs O\&M $\mathrm{M}_{\mathrm{Fix}}$ are related relatively to the total investment.

\begin{tabular}{|c|c|c|c|c|c|}
\hline & aCAES & $\mathrm{H}_{2}$ & Li-ion & PHS & Redox-flow \\
\hline Invest energy $\left[€ / \mathrm{kWh}_{\mathrm{el}}\right]$ & 47 & 1 & 150 & 10 & 100 \\
\hline Invest power $\left[€ / \mathrm{kW}_{\mathrm{el}}\right]$ & 570 & 1,200 & 50 & 450 & 630 \\
\hline Amor. time energy [a] & 40 & 30 & 25 & 60 & 20 \\
\hline Amor. time power [a] & 20 & 15 & 25 & 20 & 20 \\
\hline Interest-rate [-] & 0.06 & 0.06 & 0.06 & 0.06 & 0.06 \\
\hline$O \& \mathrm{M}_{\mathrm{fix}}[-]$ & 0.010 & 0.020 & 0.005 & 0.010 & 0.032 \\
\hline $\mathrm{O} \& \mathrm{M}_{\mathrm{var}}[€ / \mathrm{kWh}]$ & 0.00001 & 0.00001 & 0.00001 & 0.00001 & 0.00001 \\
\hline$\eta$ charge $[-]$ & 0.84 & 0.75 & 0.97 & 0.91 & 0.92 \\
\hline$\eta$ discharge [-] & 0.89 & 0.62 & 0.97 & 0.91 & 0.92 \\
\hline Self-discharge rate $[1 / \mathrm{h}]$ & 0.000833 & 0.000000 & 0.000011 & 0.000005 & 0.000054 \\
\hline Availability [-] & 0.95 & 0.95 & 0.98 & 0.98 & 0.98 \\
\hline
\end{tabular}

\subsection{Potentials for pumped hydro power}

Due to the long lifetime of the storage unit, i.e. the water reservoir, existing PHS also play a role for the observation year 2050. For Germany the existing pump and turbine power is based on a literature review. The data is shown in Tab. A 16.

For storage power capacity in the other European countries, the Platts World Electric Power Plants Database (WEPP) of 2010 is used [84]. This database however does not provide information for the storage energy capacity. To conclude from storage power to the storage energy capacity, an energy-to-power ratio (E2P) of $7 \mathrm{~h}$ for all PHS is assumed.

Within the analysis, PHS expansion is limited by the potential storage energy capacity of the reservoirs (technical potential), whereas the power for the turbine and the pump has no upper limit. For the installable storage energy capacity Gimeno-Guitiérrz and Arantegui [88] provide a GIS based assessment of PHS potentials. Here, a conservative scenario (Topology 1, realisable potential) of this study is used, where for example no further capacity expansion of PHS in Germany is assumed. The calculation of the PHS potentials in this scenario requires two existing reservoirs with an adequate difference in elevation and a sufficient proximity to connect both with a new penstock and electrical equipment. Furthermore, a number of constraints, such as centers of population, protected natural areas or transport infrastructure, reduce the potential for the storage energy capacity. The technical potential for the PHS storage energy capacity for each region can be found in Tab. 4 in the main text. To conclude from the German potential storage energy capacity of Ref. [88] to the German model-regions as used in this analysis (see Fig. A 1), we assume that the storage potentials within Germany are equally distributed as the already existing PHS systems. 
Tab. A 16: Existing German PHS capacities mapped to the model-regions based on [80-83].

\begin{tabular}{|c|c|c|c|}
\hline Location $^{\mathrm{b}}$ & $\begin{array}{l}\text { Model- } \\
\text { region }\end{array}$ & Turbine power [MW] & Energy capacity $\left[\mathrm{MWh}_{\mathrm{el}}\right]$ \\
\hline Atdorf $^{a}$ & Transnet2 & 1,400 & 13,000 \\
\hline Blautal $^{\mathrm{a}}$ & Transnet2 & 46 & 370 \\
\hline Bleiloch & 50 Hertz3 & 80 & 753 \\
\hline Einoden $^{\mathrm{a}}$ & Tennet6 & 200 & 1,600 \\
\hline Einsiedel & Transnet2 & 1 & 23 \\
\hline Erzhausen & Tennet3 & 220 & 940 \\
\hline Geesthacht & Tennet2 & 120 & 600 \\
\hline Glems & Transnet 2 & 90 & 560 \\
\hline Goldisthal & 50 Hertz3 & 1,060 & 8,480 \\
\hline Happburg & Tennet5 & 160 & 900 \\
\hline Häusern & Transnet2 & 144 & 514 \\
\hline Hohenwarte I & 50 Hertz3 & 63 & 795 \\
\hline Hohenwarte II & 50 Hertz3 & 320 & 2,087 \\
\hline Koepchenwerk Herdecke & Amprion3 & 153 & 590 \\
\hline Langenprozelten & Tennet5 & 168 & 950 \\
\hline Leitzachwerk 1 & Tennet6 & 49 & $225^{\mathrm{c}}$ \\
\hline Leitzachwerk 2 & Tennet6 & 49 & $225^{\mathrm{c}}$ \\
\hline Markersbach & 50 Hertz4 & 1,050 & 4,018 \\
\hline Maxhofen-Oberberg & Tennet6 & 10 & 547 \\
\hline Niederwartha & 50 Hertz4 & 120 & 591 \\
\hline Reisach Rabenleite & Tennet5 & 105 & 630 \\
\hline Rönkhausen & Amprion3 & 140 & 690 \\
\hline Säckingen & Transnet2 & 353 & 2,064 \\
\hline Schwarzenbachwerk & Transnet2 & 45 & 198 \\
\hline Sorpetalsperre & Amprion3 & 10 & 44 \\
\hline Tanzmühle Rabenleite & Tennet5 & 35 & 404 \\
\hline Waldeck 1 & Tennet4 & 140 & 478 \\
\hline Waldeck 2 & Tennet4 & 440 & 3,428 \\
\hline Waldshut & Transnet2 & 176 & 476 \\
\hline Wehr & Transnet2 & 980 & 6,073 \\
\hline Wendefurth & 50 Hertz3 & 80 & 523 \\
\hline Witznau & Transnet2 & 220 & 642 \\
\hline Total & & 8,227 & 53,418 \\
\hline
\end{tabular}

${ }^{\text {a }}$ Planned and therefore included (at the time of the model parametrization).

${ }^{\mathrm{b}}$ PHS capacities that are connected to the German transmission grid infrastructure but not located in Germany are not accounted to the German model-regions. This applies for the PHS Vianden (Luxembourg) and the Austrian units Robund I/II, Kopswerk II, Kühtai/Sellrain-Silz, and Lünersee.

${ }^{\mathrm{c}}$ Leitzachwerk 1 and 2 share the same reservoir but have 2 power blocks (each consisting of a pump and a turbine). To account for that in the modeling approach, the storage capacity of $550 \mathrm{MWh}_{\mathrm{el}}$ is divided by 2 . 
Tab. A 17: Existing European PHS capacities based on [84].

\begin{tabular}{lrr}
\hline Model-region & Turbine power $[\mathrm{GW}]$ & Energy capacity $\left[\mathrm{GWh}_{\mathrm{el}}\right]$ \\
\hline Austria + Switzerland & 4.32 & 30.25 \\
BeNeLux & 2.51 & 17.56 \\
Denmark west & 0.00 & 0.00 \\
PL + CZ + SK & 3.50 & 24.50 \\
France & 4.52 & 31.64 \\
Iberia & 6.30 & 44.12 \\
Italy & 5.94 & 41.55 \\
Northern Europe & 1.45 & 10.16 \\
UK + IE & 2.54 & 17.79 \\
\hline Total & 39.31 & 271.08 \\
\hline
\end{tabular}

\subsection{Potentials for adiabatic compressed air and hydrogen storage}

As for PHS, the capacity expansion of aCAES is only constrained by an upper limit of the storage energy capacity (technical potential) and hence the volume of an underground salt cavern. The storage power capacity for aCAES is not limited. As for all storage technologies in this analysis, the charging and discharging units are not modeled individually. In this regard, the storage power of an aCAES consists of the compression unit and the generator. The potentials for the underground salt cavern are based on [87], which, in turn, relies on data from [85]. These volumina are converted into storable electric energy via an energy density of $2.73 \mathrm{kWh} / \mathrm{m}^{3}$. This value again is based on an aCAES pressure difference from 30 to 70 bar [86].

Using the specific energy density of gaseous $\mathrm{H}_{2}$ at a pressure of 120 bar and a temperature of $300 \mathrm{~K}$ in the cavern, the cavern volumina potentials from [87] are converted into storable electricity. For $\mathrm{H}_{2}$ storage the charging unit is an alkaline water electrolyzer; the discharging unit a CCGT. Again, the storage power capacity for the electricity reconversion is not constrained by an upper expansion limit. Since both, aCAES and $\mathrm{H}_{2}$ storage, require an underground salt cavern as storage unit, it is assumed that these technologies both use $50 \%$ of the resource potential. 
9. Detailed results

\subsection{Overall generation capacities}

Tab. A 18: Overall generation capacities in GW, including the model endogenously derived capacities as well as the exogenous stock. Table refers to Fig. 4.

\begin{tabular}{|c|c|c|c|c|c|c|c|c|c|c|}
\hline & $\begin{array}{l}\text { Austria + } \\
\text { Switzerland }\end{array}$ & BeNeLux & $\begin{array}{l}\text { Denmark } \\
\text { west }\end{array}$ & $\begin{array}{l}\mathrm{PL}+\mathrm{CZ} \\
+\mathrm{SK}\end{array}$ & France & Iberia & Italy & $\begin{array}{l}\text { Northern } \\
\text { Europe }\end{array}$ & Germany & $\mathrm{UK}+\mathrm{IE}$ \\
\hline Offshore wind & - & 43.20 & 9.97 & 0.05 & 106.74 & 64.44 & 29.95 & 89.66 & 47.51 & 72.81 \\
\hline PV & 19.91 & 35.51 & 0.06 & 59.78 & 46.74 & 90.45 & 47.73 & 5.03 & 86.90 & 0.06 \\
\hline Run-of-river & 0.02 & 0.01 & - & 0.01 & 0.01 & 0.01 & 0.01 & 0.02 & 4.24 & 0.01 \\
\hline CSP & - & - & - & - & 0.70 & 7.88 & 1.00 & - & - & - \\
\hline Lignite & 0.65 & 0.08 & 0.02 & 8.09 & 0.02 & 0.07 & 15.62 & 0.04 & 21.42 & 0.02 \\
\hline CCGT & 0.04 & 0.24 & 0.02 & 5.13 & 0.12 & 0.10 & 2.05 & 1.23 & 7.20 & 0.04 \\
\hline Coal & 0.03 & 0.03 & 0.02 & 0.05 & 0.02 & 0.03 & 1.05 & 1.03 & 0.63 & 0.02 \\
\hline GT & 0.05 & 2.52 & 0.04 & 5.11 & 13.19 & 0.05 & 4.89 & 21.84 & 10.1 & 0.26 \\
\hline Nuclear & 0.01 & 0.01 & 0.01 & 2.95 & 11.72 & 0.01 & 0.01 & 0.01 & 0.17 & 1.33 \\
\hline
\end{tabular}

\subsection{Storage power capacity}

Tab. A 19: Region-specific installed storage power capacity in GW (including old existing PHS capacities). Table refers to Fig. 4 and the 20 German modelregions are aggregated in this table.

\begin{tabular}{|c|c|c|c|c|c|}
\hline & $\mathrm{H}_{2}$ & Li-ion & aCAES & PHS & Redox-flow \\
\hline Austria + Switzerland & 0.02 & 0.51 & 0.05 & 4.54 & 0.04 \\
\hline BeNeLux & 10.02 & 1.76 & 2.24 & 2.86 & 0.06 \\
\hline Denmark west & 4.99 & 0.87 & 0.21 & - & 0.06 \\
\hline $\mathrm{PL}+\mathrm{CZ}+\mathrm{SK}$ & 0.48 & 6.97 & 2.66 & 3.50 & 0.06 \\
\hline France & 25.99 & 3.42 & 0.25 & 4.89 & 0.06 \\
\hline Iberia & 3.22 & 10.02 & 0.15 & 12.09 & 0.07 \\
\hline Italy & 0.05 & 6.36 & 0.11 & 8.08 & 0.06 \\
\hline Northern Europe & - & 3.21 & - & 2.86 & 0.07 \\
\hline Germany & 10.10 & 15.65 & 3.11 & 8.23 & 0.93 \\
\hline $\mathrm{UK}+\mathrm{IE}$ & 31.14 & 5.28 & 5.36 & 2.92 & 0.07 \\
\hline Total & 86.00 & 54.04 & 14.15 & 49.97 & 1.48 \\
\hline
\end{tabular}


Tab. A 20: Region-specific installed storage power capacity for the German model-regions in GW. Table refers to Fig. 5.

\begin{tabular}{|c|c|c|c|c|c|}
\hline & $\mathrm{H}_{2}$ & Li-ion & aCAES & $\mathrm{PHS}^{\mathrm{a}}$ & Redox-flow \\
\hline Amprion1 & - & 0.71 & - & - & 0.05 \\
\hline Amprion2 & 3.50 & 0.86 & 0.62 & - & 0.06 \\
\hline Amprion3 & - & 0.92 & - & 0.30 & 0.05 \\
\hline Amprion4 & - & 1.14 & - & - & 0.05 \\
\hline Amprion5 & - & 1.72 & - & - & 0.06 \\
\hline Amprion6 & - & 0.60 & - & - & 0.05 \\
\hline Transnet1 & - & 0.79 & - & - & 0.05 \\
\hline Transnet2 & - & 0.62 & - & 3.45 & 0.05 \\
\hline Tennet1 & 0.37 & 0.73 & 0.22 & - & 0.05 \\
\hline Tennet 2 & 5.31 & 0.85 & 0.59 & 0.12 & 0.06 \\
\hline Tennet3 & 0.03 & 0.79 & 0.10 & 0.22 & 0.05 \\
\hline Tennet4 & 0.04 & 0.72 & 0.10 & 0.58 & 0.05 \\
\hline Tennet5 & - & 1.06 & - & 0.47 & 0.05 \\
\hline Tennet6 & - & 0.78 & - & 0.31 & 0.05 \\
\hline 50 Hertz1 & 0.83 & 1.42 & 1.38 & - & 0.05 \\
\hline 50 Hertz2 & - & 0.64 & - & - & 0.05 \\
\hline 50 Hertz3 & 0.03 & 0.64 & 0.10 & 1.60 & 0.05 \\
\hline 50 Hertz4 & - & 0.66 & - & 1.17 & 0.05 \\
\hline Total & 10.10 & 15.65 & 3.11 & 8.23 & 0.93 \\
\hline
\end{tabular}

${ }^{\text {a }}$ Old existing PHS capacities, since it is assumed that no reservoir potentials exist in Germany (based on (Topology 1, realisable potential of [88]). 


\section{Sensitivity analysis}

Following, we test the robustness of the endogenously determined storage capacities through a sensitivity analysis and vary several input parameters as well as methodological approaches. Tab. A 1 gives a summary of the sensitivity tests.

Tab. A 21: Scenario overview and respective main assumptions.

\begin{tabular}{|c|c|c|}
\hline Scenario group & Sub-scenario & Specification \\
\hline Reference scenario & Ref & $\begin{array}{l}\text { Reference scenario (used for the analysis in the main text): unlimited } \\
\text { curtailments, exogenous grid, mean price and cost paths }\end{array}$ \\
\hline \multirow{4}{*}{$\begin{array}{l}\text { (1) Investment cost } \\
\text { scenarios }\end{array}$} & a. Stor_Inv_low & Decreased power and energy investment costs for storage by $50 \%$ \\
\hline & b. Stor_Inv_high & Increased power and energy investment costs for storage by $50 \%$ \\
\hline & c.VRE_Inv_low & Decreased investment costs for VRE by $50 \%$ \\
\hline & d. VRE_Inv_high & Increased investment costs for VRE by $50 \%$ \\
\hline \multirow[t]{4}{*}{ (2) Operating cost scenarios } & a. FP_low & Fuel price path low (see Tab. A 22) \\
\hline & b. FP_high & Fuel price path high (see Tab. A 22) \\
\hline & c. $\mathrm{CO}_{2}$ low & $\mathrm{CO}_{2}$ certificate price path low (see Tab. A 23) \\
\hline & d. $\mathrm{CO}_{2}$ high & $\mathrm{CO}_{2}$ certificate price path high (see Tab. A 23) \\
\hline \multirow[t]{4}{*}{ (3) Grid scenarios } & a. $\mathrm{G}++$ & No transmission grid restrictions (copper plate) \\
\hline & b. $\mathrm{G}+$ & Optimized grid in Europe, reference investment costs (see Tab. A 2) \\
\hline & c. $\mathrm{G}+$ Inv_high & Optimized grid in Europe, increased investment costs by $50 \%$ \\
\hline & d. G+_Inv_veryhigh & Optimized grid in Europe, increased investment costs by $100 \%$ \\
\hline \multirow[t]{2}{*}{ (4) Curtailment scenarios } & a. Cur.003 & Technology- and region-specific VRE curtailments restricted to 3\% \\
\hline & b. Cur.010 & Technology- and region-specific VRE curtailments restricted to $10 \%$ \\
\hline \multirow[t]{3}{*}{ (5) VRE constr. scenarios } & a. VRE_exp_CO $\mathrm{CO}_{2}$ med & No constraint which forces $80 \% \mathrm{VRE}$, medium $\mathrm{CO}_{2}$ certificate price \\
\hline & b. VRE_exp_CO ${ }_{2}$ high & No constraint which forces $80 \% \mathrm{VRE}$, high $\mathrm{CO}_{2}$ certificate price \\
\hline & c. VRE_exp_CO $\mathrm{CO}_{2}$ veryhigh & No constraint which forces $80 \%$ VRE, very high $\mathrm{CO}_{2}$ certificate price \\
\hline \multirow[t]{5}{*}{ (6) Weather scenarios } & a. Weather 2007 & Hourly, potential VRE power generation based on the weather year 2007 \\
\hline & b. Weather 2008 & Hourly, potential VRE power generation based on the weather year 2008 \\
\hline & c. Weather 2009 & Hourly, potential VRE power generation based on the weather year 2009 \\
\hline & d. Weather 2011 & Hourly, potential VRE power generation based on the weather year 2011 \\
\hline & e. Weather 2012 & Hourly, potential VRE power generation based on the weather year 2012 \\
\hline \multirow[t]{2}{*}{ (7) Misc. scenarios } & a. Redox-flow_Inv_low & $\begin{array}{l}\text { Energy related investment costs of redox-flow batteries decreased to the } \\
\text { value of aCAES }\end{array}$ \\
\hline & b. PHS_w/o_old_stock & No old stock capacities of PHS assumed \\
\hline
\end{tabular}

Storage requirements are strongly affected by the model endogenously determined generation portfolio. Fig. A 3 shows the overall installed generation capacities as well as the installed storage power capacities for each scenario over all model-regions. Furthermore, the figure depicts the shares of curtailed energy as measured by the annual electricity generation from VRE for each scenario (percentage values in the middle plot). 

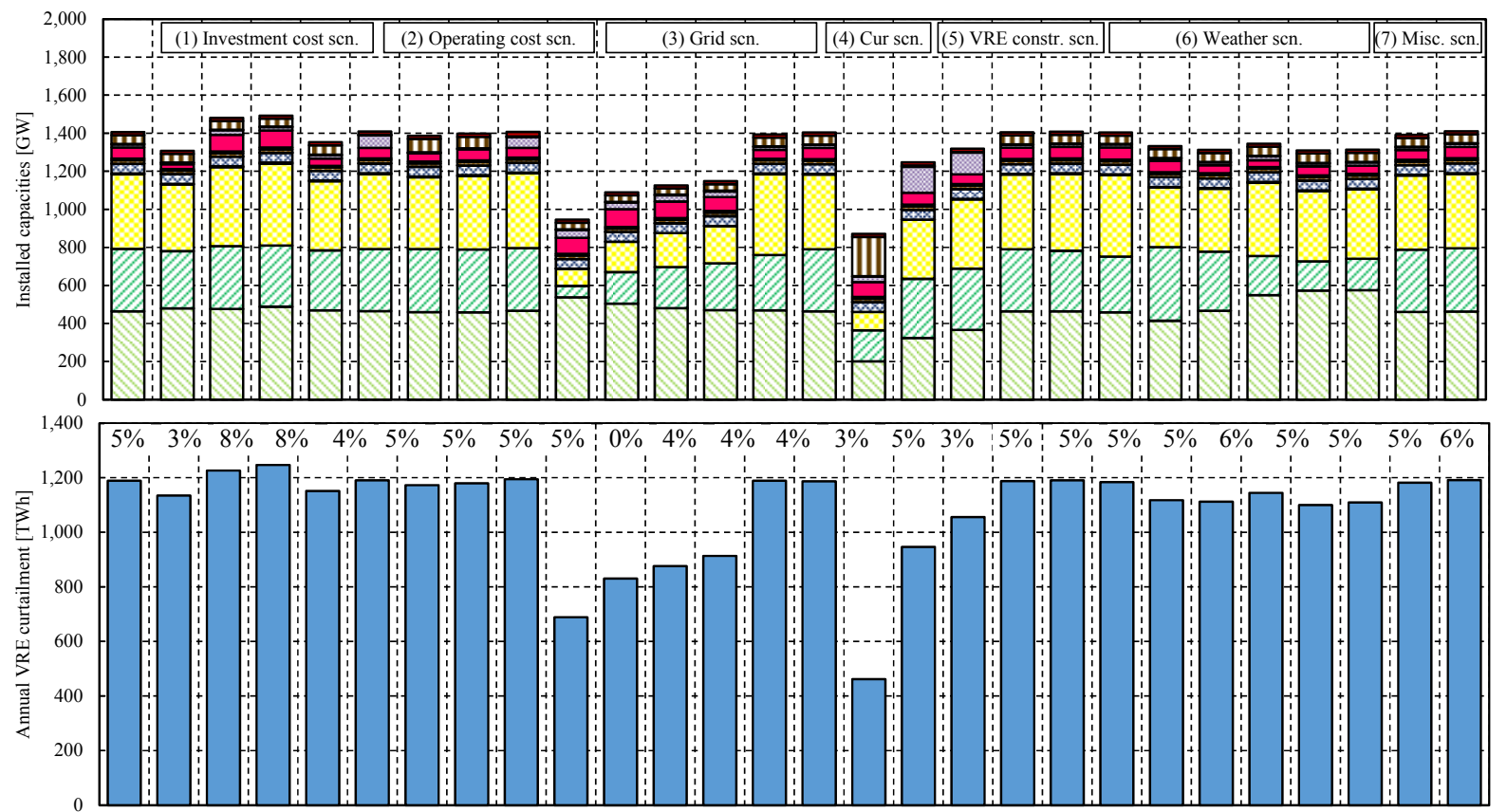
口Wind offshore

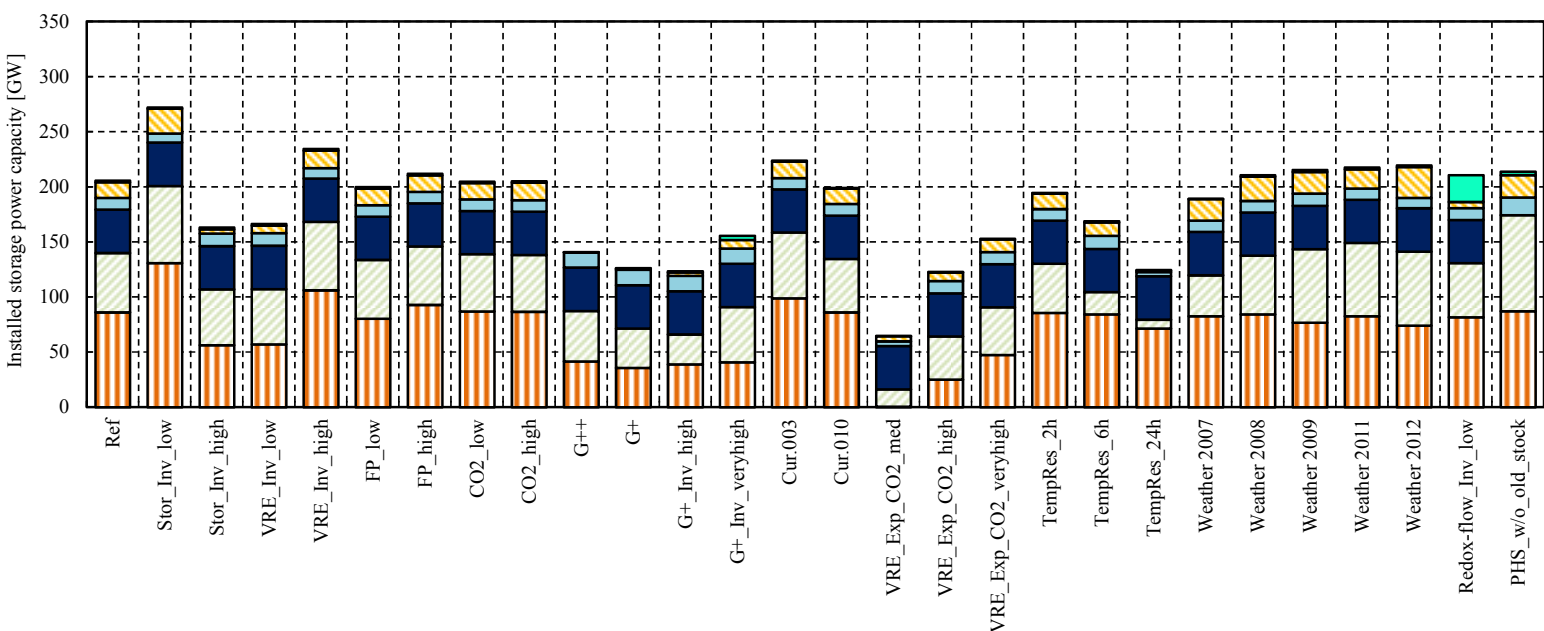

Fig. A 3: Total installed generation capacities (upper plot), annual curtailments of VRE (middle plot), and installed storage power capacities (lower plot) over all scenarios and all model-regions. Note that for PHS in this figure a differentiation between existing (stock) and endogenously determined capacities (new) is illustrated (in contrast to the main text where both capacities are always shown aggregated). Additionally, the percentage values in the middle plot show the share of curtailed VRE electricity generation with regard to the potential annual electricity generation from VRE.

In general, all scenarios are characterized by rather large shares of offshore wind, onshore wind, and PV, mainly fostered by the $80 \%$ VRE generation model constraint $\left(80 \%_{\text {constr }}\right)$. For the investment (1) and operating cost scenarios (2) as well as for the curtailment (4) weather (6), and miscellaneous scenarios $(7)$, the overall VRE capacities only differs in small amounts $(\approx \pm 5 \%$ ) compared to VRE capacities in the reference scenario $(1,185 \mathrm{GW})$. In contrast, the grid and $80 \% \%_{\text {constr }}$ scenarios heavily affect both the generation as well as the storage capacities structure. In the following sections, each scenarios group will be analyzed separately, showing the differences in installed capacity compared to the reference scenario. 


\subsection{Investment cost scenarios}

Fig. A 4 depicts the results of the investment cost scenarios with regard to the installed storage power capacity compared to the reference scenario.

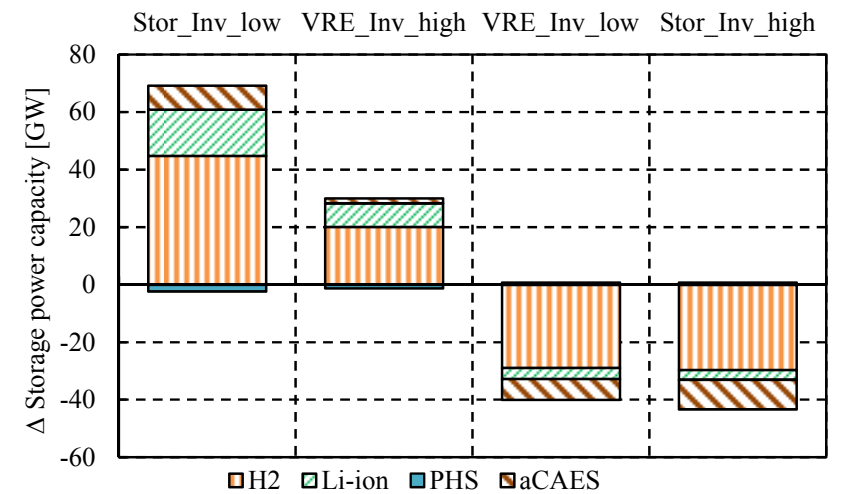

Fig. A 4: Differences in installed capacity of storage power in the investment cost scenarios compared to the reference scenario aggregated over all modelregions.

The scenario Stor_Inv_low (reduced power and energy related investment costs for storage technologies) results in an increase of $\mathrm{H}_{2}$ power of $\overline{45} \mathrm{GW}$. In consequence an increase of offshore wind integration is possible $(+15 \mathrm{GW})$, where onshore wind $(-27 \mathrm{GW})$, PV $(-41 \mathrm{GW})$, and GTs $(-33 \mathrm{GW})$ are substituted (see Fig. A 3). A structurally similar effect (but less pronounced) can be observed for the scenario with increased investment costs for VRE technologies (VRE_Inv_high).

The scenarios Stor_Inv_high and VRE_Inv_low show roughly opposite effects compared with their counterparts Stor_Inv_low and VRE_Inv_high. Again, the analysis supports the findings that certain generation technologies complement certain storage technologies better than other (see Sec. 3.3). Especially offshore wind is often complemented by $\mathrm{H}_{2}$ storage, whereas increased PV capacities most likely go along in a combination of Li-ion batteries and GTs. Due to the relatively low costs of the energy capacity, $\mathrm{H}_{2}$ storages primarily balance seasonal variations in terms of high amounts of energy. The comparatively low power related costs of Li-ion batteries, in contrast, (cheap storage power capacity) favor Li-ion batteries and GTs (low fuel prices compared to other conventional power-plants) for short-term power balancing.

\subsection{Operating cost scenarios}

Uncertainties for the cost projections for fossil-fired power-plants mainly exist with regard to their fuel and emission certificate costs. From a cost minimizing optimization approach, low fuel prices (FP) and low $\mathrm{CO}_{2}$ emission cost will increase the expansion of dispatchable, fossil-fired power-plants (within the limitations set by $80 \%_{\text {constr }}$, i.e. the remaining $20 \%$ of electricity generation from non-VRE capacities). In consequence, smaller capacities of storage might be required. High price paths for fuels and $\mathrm{CO}_{2}$ emissions, in contrast, most likely will favor an increase in storage demand through higher expansion rates of RE technologies. In order to quantify these effects, the analysis uses three different price paths as input parameter. The specific emissions are based on [89]. Tab. A 22 shows the fuel price scenarios for each fuel type, whereas Tab. A 23 illustrates the different cost scenarios for $\mathrm{CO}_{2}$ emissions for the year 2050. Here, the high and medium costs scenarios are based on [94]. The low cost scenario however is assumed to be the arithmetic mean of the European emission allowance prices of the year 2013 from the European Energy Exchange (EEX). 
Tab. A 22: Fuel price scenarios for each fuel type.

\begin{tabular}{llrr}
\hline Fuel type & Cost scenario & Fuel costs $\left[€ / \mathrm{MWh}_{\mathrm{th}}\right]$ & Source \\
\hline Coal & low & 14.04 & {$[90]$} \\
Lignite & low & 8.28 & {$[91]$} \\
Natural gas & low & 33.12 & {$[90]$} \\
Uranium & low & 4.03 & {$[93]$} \\
\hline Coal & medium & 20.88 & {$[92]^{\mathrm{a}}$} \\
Lignite & medium & 9.18 & {$[91]$} \\
Natural gas & medium & 47.52 & {$[92]^{\mathrm{a}}$} \\
Uranium & medium & 5.24 & {$[93]$} \\
\hline Coal & high & 35.28 & {$[92]^{\mathrm{b}}$} \\
Lignite & high & 10.08 & {$[91]$} \\
Natural gas & high & 73.44 & {$[92]^{\mathrm{b}}$} \\
Uranium & high & 6.45 & {$[93]$} \\
\hline${ }^{\mathrm{a}}$ Scenario B, moderate price path. & &
\end{tabular}

${ }^{\mathrm{b}}$ Scenario A, high price path.

Tab. A 23: $\mathrm{CO}_{2}$ emission costs scenarios.

\begin{tabular}{lrr}
\hline Cost scenario & $\mathrm{CO}_{2}$ costs $\left[€ / \mathrm{CO}_{2}\right]$ & Source \\
\hline Very high & 130.0 & Own assumption \\
High & 75.0 & {$[94]^{\mathrm{a}}$} \\
Med & 57.0 & {$[94]^{\mathrm{b}}$} \\
Low & 4.4 & Own assumption ${ }^{\mathrm{c}}$ \\
\hline${ }^{\mathrm{a}}$ Scenario A in [81] (high cost path). & \\
${ }^{\mathrm{b}}$ Scenario B in [81] (moderate cost path). \\
${ }^{\mathrm{c}}$ Arithmetic mean of European emission allowance prices in 2013.
\end{tabular}

Furthermore, one has to take into account that inter-dependencies between the fuel price and emission certificate costs might exist, where high fuel prices, for example, could foster low $\mathrm{CO}_{2}$ emissions certificate costs and vice versa. This is due to the assumption that high fuel prices would decrease the dispatch of fossil-fired power-plants and therefore increase the number of available emission certificates which again would lower their costs. To accommodate such effects, the cost projections are considered in a combined approach for consistent scenarios as shown in Tab. A 24.

Tab. A 24: Combinations of $\mathrm{CO}_{2}$ costs and fuel price paths for the different fuel price and $\mathrm{CO}_{2}$ emission cost scenarios.

\begin{tabular}{lccc|ccc}
\hline & \multicolumn{3}{c|}{$\mathrm{CO}_{2}$} & \multicolumn{3}{c}{ Fuel price } \\
\hline & High & Med & Low & High & Med & Low \\
\hline Ref & & $\mathrm{x}$ & & \multicolumn{3}{c}{$\mathrm{x}$} \\
FP_high & & & $\mathrm{x}$ & $\mathrm{x}$ & & \\
FP_low & $\mathrm{x}$ & & & & & $\mathrm{x}$ \\
$\mathrm{CO}_{2}$ high & $\mathrm{x}$ & & & & $\mathrm{x}$ & \\
$\mathrm{CO}_{2}$ low & & & $\mathrm{x}$ & \multicolumn{3}{|c|}{$\mathrm{x}$} \\
\hline
\end{tabular}

Fig. A 5 shows the differences in installed generation capacities for the operating cost scenarios compared to the reference scenario over all model-regions. 


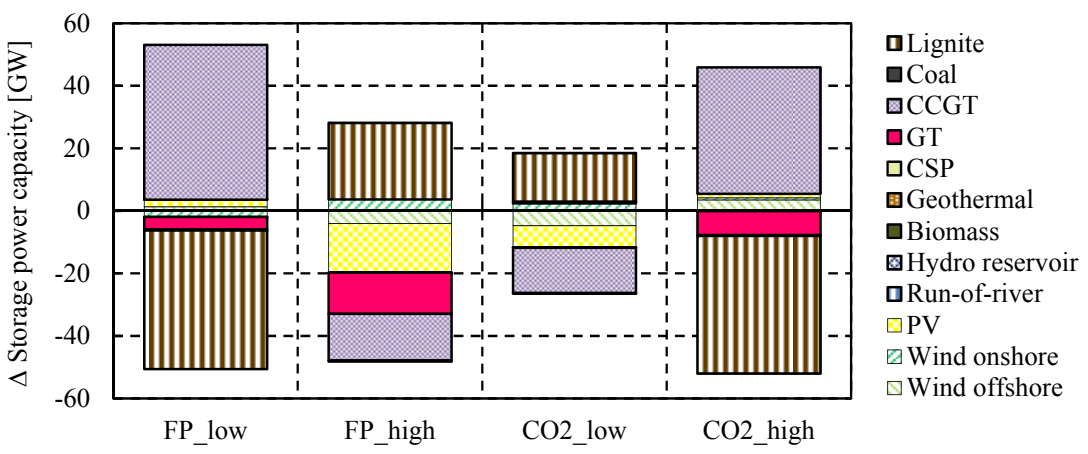

Fig. A 5: Differences in installed capacities of the operating cost scenarios compared to the reference scenario over all model-regions.

Naturally, lower costs for $\mathrm{CO}_{2}$ emission certificates will favor the expansion of $\mathrm{CO}_{2}$ intensive generation technologies, such as lignite-fired power-plants, whereas high $\mathrm{CO}_{2}$ costs will foster the expansion of less $\mathrm{CO}_{2}$ intensive technologies (e.g. CCGT power-plants). The model results reflect this effect in the scenarios $\mathrm{CO}_{2}$ high and $\mathrm{CO}_{2}$ low. The scenario $\mathrm{CO}_{2}$ high substitutes lignite power-plants with CCGT when compared with the reference case, whereas the scenario $\mathrm{CO}_{2}$ low, in contrary, is characterized by larger shares of lignite power-plants. Similar observations can be made for the scenarios which vary the fuel price assumption (FP_low, FP_high). Here, higher fuel prices increase the capacity expansion of lignite power-plants and decrease CCGT and gas turbines. In general, we observe that assumptions regarding the fuel prices and costs $\mathrm{CO}_{2}$ allowance certificates only have a minor influence on the capacity expansion of VRE technologies. This can be explained by the sheer amount of VRE technologies forced by the $80 \%$ VRE generation model constraint $\left(80 \% \%_{\text {constr }}\right)$. In consequence, also the differences in storage capacity expansion are negligible.

\subsection{Grid scenarios}

In order to evaluate the influence of transmission grid expansion as an additional option to allow large-scale spatial balancing of production and demand particularly in highly renewable energy scenarios, we include several scenarios which endogenously determine the expansion of new grid lines additionally to the exogenous AC and DC grid infrastructure based on the TYNDP (see Fig. A 2). This is in contrast to the reference scenario, where the transmission grid was exogenously defined. The different transmission grid scenarios vary in terms of their specific investment costs for grid expansion (see Tab. A 21) and include one scenario with no transmission grid restrictions $(\mathrm{G}++$, copper plate). Fig. A 6 depicts the AC and DC grid expansion for all model-regions in comparison of the different scenarios. As explained in Sec. 2, only the existing grid topology (based on the TYNDP) can be extended; i.e. it is prohibited to establish new grid connections between two model-regions.

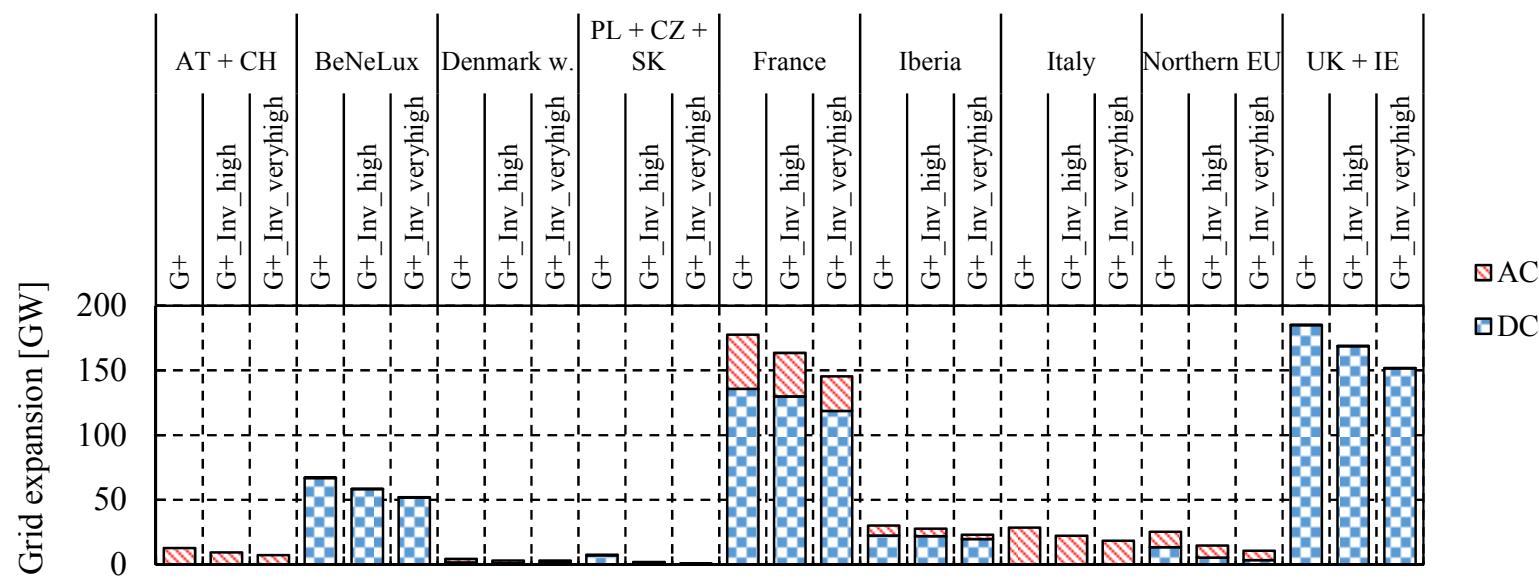

Fig. A 6: Comparison of the capacity expansion of the grid infrastructure for each model-region in the different grid scenarios. Note that the figure depicts the capacity expansion of one model-region to all surrounding regions. It is thereby applicable when observing each model-region individually, but double accounts if aggregated over the whole observation area.

Fig. A 6 highlights the important role of transmission grid expansion in highly renewable energy scenarios. Some regions, such as UK + IE or France, result in additional transmission grid capacities of more than $150 \mathrm{GW}$. For certain grid connections between two model-regions, e.g. UK + IE to France, this translates into capacities of up to $113 \mathrm{GW}$ per model-region link. As expected due to the cost minimizing logic of model, the lowest investment costs lead to the highest grid infrastructure expansion (scenario $\mathrm{G}+$ ). A stepwise increase of these costs (scenario $\mathrm{G}_{+}+$Inv_high, $\mathrm{G}+$ _Inv_veryhigh) subsequently decreases grid expansion. 
In consequence of changes in the transmission capacities, the electricity generation and storage infrastructure is strongly affected. Fig. A 7 illustrates the generation capacity expansion and annual electricity generation for the most relevant technologies over all model-regions for the different grid scenarios in comparison to the reference scenario.

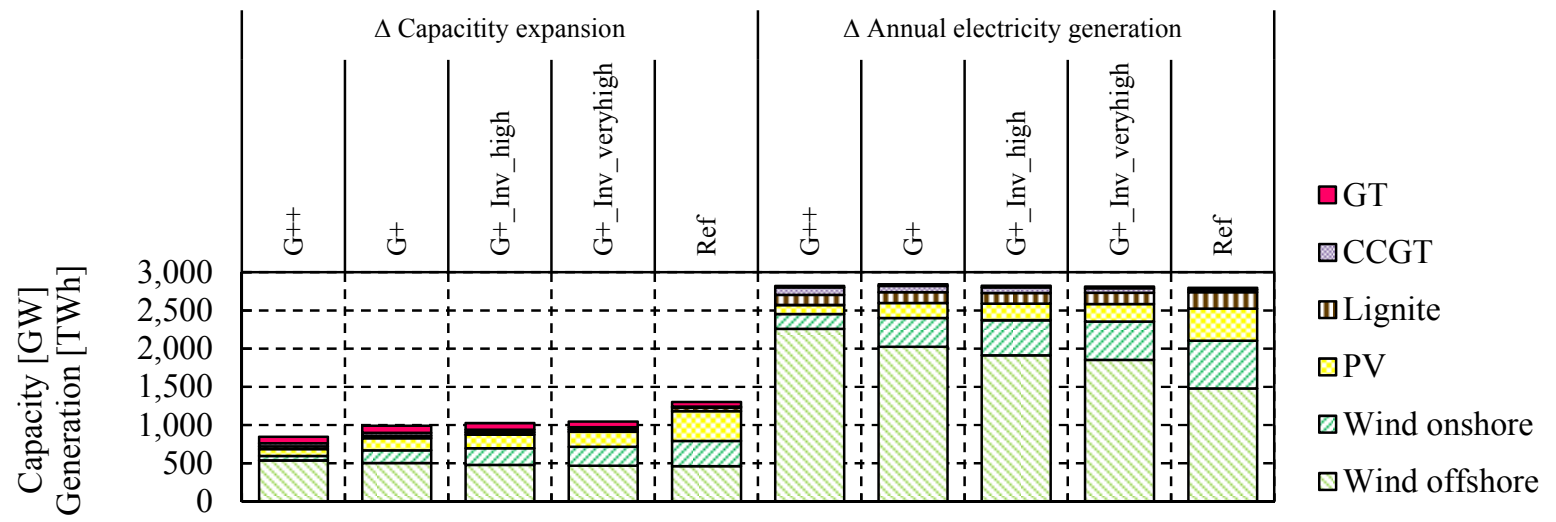

Fig. A 7: Differences in capacity expansion and annual electricity generation compared to the reference scenario aggregated over all model-regions.

In general, endogenous grid expansion allows a noticeable reduction of generation capacity expansion in the observation area. In the scenario with the lowest investment costs for grid expansion $(\mathrm{G}+)$, the net capacity expansion can be reduced by approximately $1 / 4(312 \mathrm{GW})$ compared to total capacity in the reference scenario. Even increased investment costs in the scenarios G+_Inv_high and G+_Inv_veryhigh still result in around 20\% less generation capacity expansion than in the reference scenario. In the hypothetical scenario of a copper plate grid infrastructure for all model-regions, generation technology expansion can be reduced by $35 \%$.

For the annual electricity generation, we see that the overall amount of electricity generation remains similar in all scenarios (in order to meet the demand), whereas the technological distribution changes significantly. Differences in the total electricity production compared with the reference scenario occur due to different amounts of curtailed power. Large shares of onshore wind and PV capacities (and smaller amounts of lignite capacities) are substitutes by comparatively lower amounts of capacity (GW) of offshore wind, gas turbines and CCGT power-plants. This can be explained by the increased transfer capacity of the transmission grid, which now allows a less constrained transport of the electricity from offshore systems at the coast to the demand centers. As expected, improved transmission grid infrastructure generally allows a better utilization of VRE technologies in terms of full load hours (see Tab. A 25).

Tab. A 25: Comparison of full load hours of VRE technologies in the different grid scenarios.

\begin{tabular}{lrrr}
\hline & & Full load hours $[\mathrm{h}]$ \\
\hline & Offshore wind & Onshore wind & PV \\
\hline $\mathrm{G}++$ & 4,198 & 3,253 & 1,305 \\
$\mathrm{G}+$ & 4,015 & 2,265 & 1,237 \\
$\mathrm{G}^{+}$_Inv_high & 3,990 & 2,118 & 1,211 \\
G+_Inv_veryhigh & 3,945 & 2,025 & 1,189 \\
Ref & 3,191 & 1,903 & 1,069 \\
\hline
\end{tabular}

However, considering each model-region individually, capacity expansion is more divers. Fig. A 8 therefore illustrates the differences in capacity expansion of generation technologies compared to the reference scenario for each model-region. 


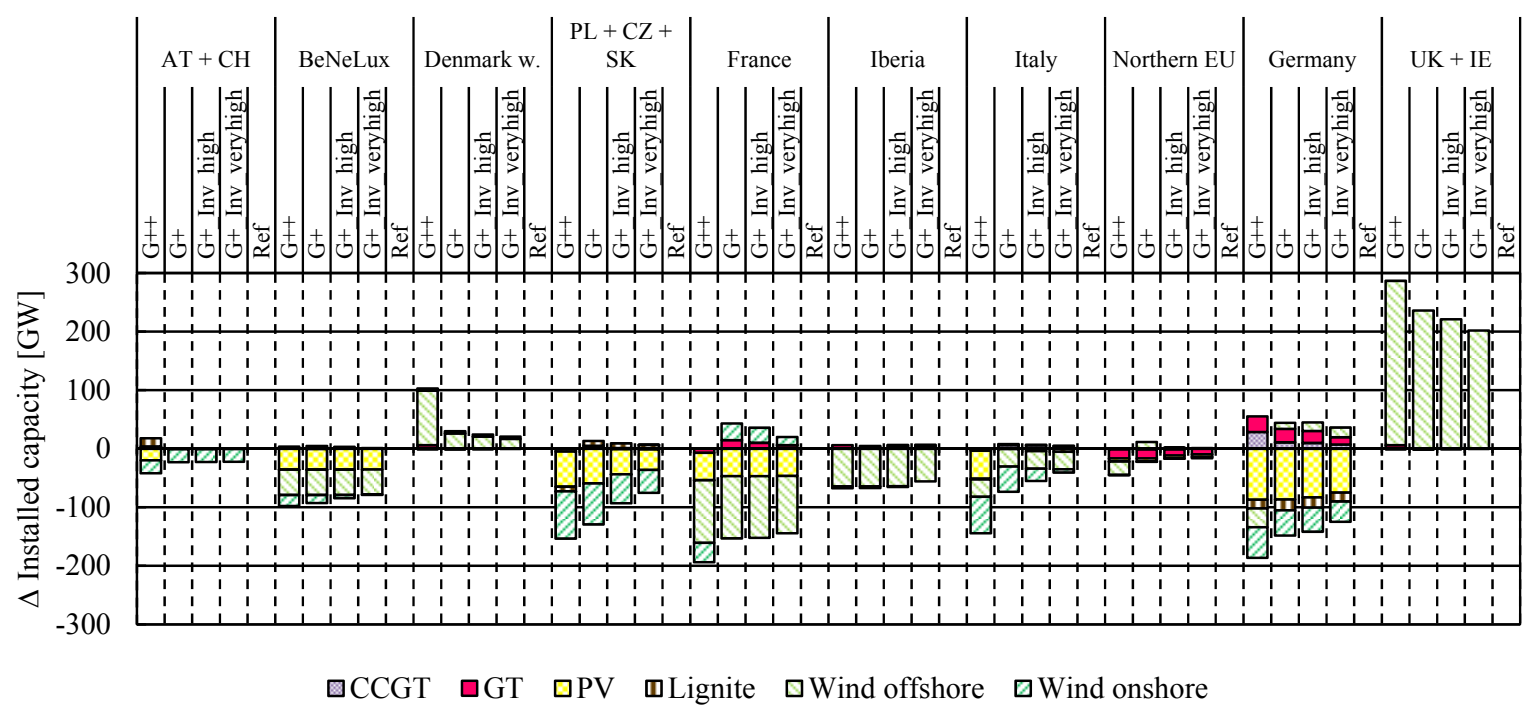

Fig. A 8: Differences in capacity expansion of generation technologies compared to the reference scenario for each model-region. The German model-regions are aggregated.

For most of the model-regions we observe a decrease of VRE capacity compared with the reference scenario if the grid expansion is endogenously calculated by the model. The shift to offshore wind generation which substitutes large amounts of PV and onshore wind observed in Fig. A 7, can mainly be explained by an integration of large offshore wind potentials in the model-region UK + IE (and to some extent Denmark west) through an enhanced grid between UK + IE and the European mainland (including Scandinavia). Since $80 \%$ constr (see Sec. 2.2) still has to be met, reduced capacity expansion translates into improved utilization of the remaining generation assets, i.e. higher average full load hours due to occupation of more favorable sites for wind and PV power production and less curtailment (see Tab. A 26).

We observe that the scenario with the lowest investment costs for the grid infrastructure $(\mathrm{G}+)$ - which leads to the highest amount of AC and DC expansion (see Fig. A 6) - results in the lowest overall curtailed energy, only outreached by scenario $\mathrm{G}++$ where electricity transmission is unlimited. Increasing the investment costs gradually ( $\mathrm{G}+$ Inv_high, $\mathrm{G}+$ Inv_veryhigh) and in consequence reducing the grid extension, naturally will lead to increasing curtailments. Curtailments are the highest in the reference scenarios, since here grid capacity expansion is not allowed. On the other hand, curtailments are the lowest in the hypothetical scenario $\mathrm{G}++$ due to the possibility of unlimited transmission capacities. Furthermore, Tab. A 26 confirms the important role of offshore wind generation in the model-region UK + IE for the whole energy system. Restricting grid expansion in this region will lead high curtailments of VRE. Moreover, when comparing the grid scenarios to the reference scenario, the differences in curtailment are the most distinct in UK + IE. 
Tab. A 26: Model-region-specific curtailments of VRE electricity generation of the different grid scenarios compared to the reference scenario. The German model-regions are aggregated. Furthermore, the table depicts the share of annual curtailed energy of VRE with respect to the potential annual electricity generation of VRE (curtailment share).

\begin{tabular}{|c|c|c|c|c|c|}
\hline \multicolumn{6}{|c|}{ Annual curtailments [TWh] } \\
\hline & $\mathrm{G}^{++}$ & $\mathrm{G}^{+}$ & $\begin{array}{l}\mathrm{G}^{+} \\
\text {Inv_high }\end{array}$ & $\begin{array}{l}\mathrm{G}^{+}+ \\
\text {Inv_veryhigh }\end{array}$ & Ref \\
\hline Austria + Switzerland & - & 0.01 & 0.04 & 0.10 & 0.02 \\
\hline BeNeLux & - & 0.15 & 0.43 & 1.23 & 1.98 \\
\hline Denmark west & - & 13.81 & 12.05 & 9.56 & 3.92 \\
\hline $\mathrm{PL}+\mathrm{CZ}+\mathrm{SK}$ & - & 0.03 & 0.07 & 0.34 & 8.52 \\
\hline France & - & 0.21 & 0.53 & 1.62 & 23.19 \\
\hline Iberia & - & 0.05 & 0.17 & 0.55 & 6.29 \\
\hline Italy & - & 0.03 & 0.07 & 0.19 & 3.57 \\
\hline Northern Europe & - & 15.23 & 17.20 & 17.96 & 34.66 \\
\hline Germany & - & 3.28 & 6.83 & 12.66 & 26.45 \\
\hline $\mathrm{UK}+\mathrm{IE}$ & - & 63.27 & 65.94 & 64.47 & 27.84 \\
\hline Total & - & 96.07 & 103.33 & 108.67 & 136.43 \\
\hline $\begin{array}{l}\text { Total curtailment } \\
\text { share of VRE[-] }\end{array}$ & - & 0.04 & 0.04 & 0.04 & 0.05 \\
\hline
\end{tabular}

\subsection{Curtailment scenarios}

Within the reference scenario, curtailments have no upper limit and theoretically all potential VRE feed-in can be shed. The scenarios cur.010 and cur.003 restrict the curtailment technology- (wind on- and offshore, PV) and model-region-specific to $10 \%$ and $3 \%$ of the annual potential VRE electricity generation. Fig. A 9 shows the annual curtailment share with regard to the theoretically annual VRE electricity generation. It can be observed that already in the reference scenario only a few technologies and model-regions show higher curtailment shares than $10 \%$ (e.g. onshore wind in Northern EU or Denmark west, offshore wind in Germany) and therefore the scenario Cur.010 will not influence generation and storage capacity expansion significantly. The latter however will be affected if the upper limit for curtailments is reduced to $3 \%$ (Cur.003).

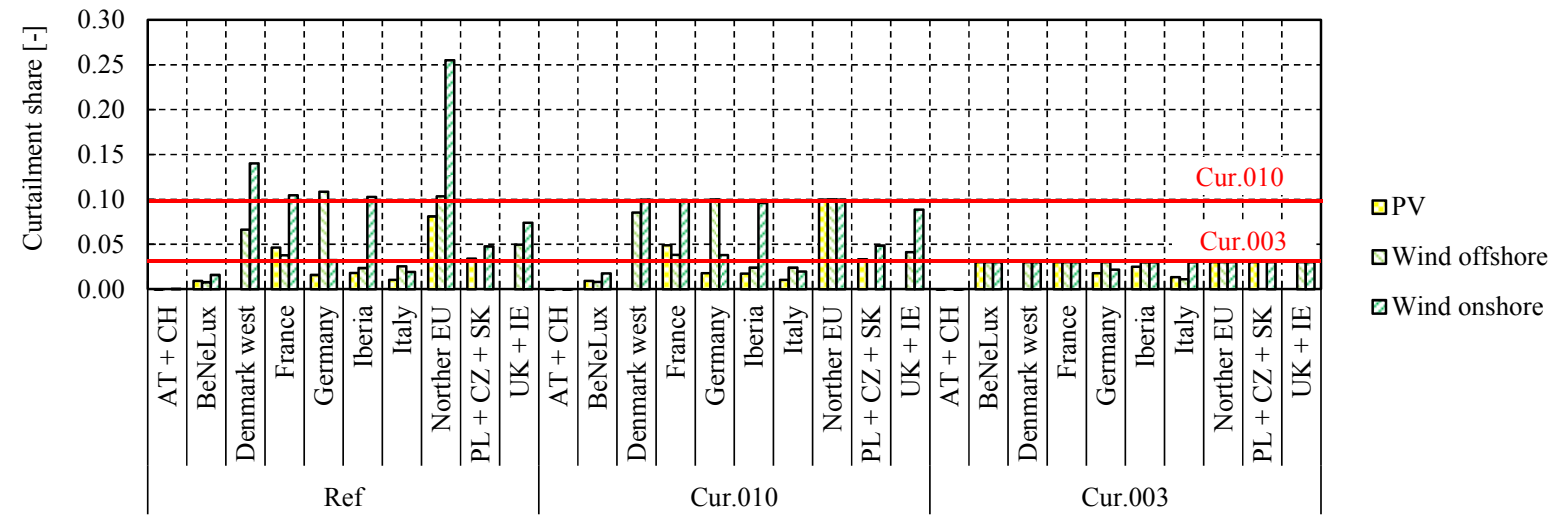

Fig. A 9: Model-region- and technology-specific curtailment shares (with respect to the theoretical annual electricity generation from VRE) of the curtailment scenarios.

More rigid curtailment requirements most likely will lead to an increase in storage expansion, since over-generation from VRE cannot be curtailed unlimitedly. Fig. A 10 shows the differences in storage power in comparison to the reference scenario over all model-regions. 


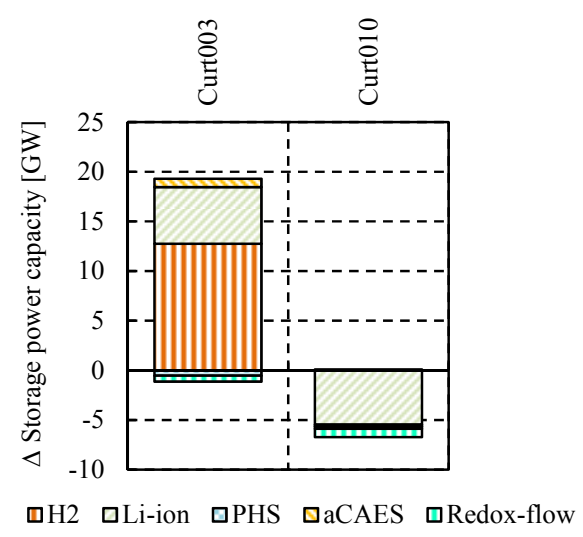

Fig. A 10: Differences in capacity of storage power compared to the reference scenario aggregated over all model-regions.

For the most restrictive curtailment assumptions (scenario cur.003) the results show, as expected, an increase of storage power compared to the reference scenario. In line with the findings in Sec. 3.3 (certain storage utilization correlates with the generation of specific VRE technologies), the increased capacity expansion of PV and onshore wind correlate with more $\mathrm{H}_{2}$ and stationary Li-ion storage. However, for less restrictive curtailment constraints in scenario cur.010 a decrease in storage power capacity compared to the reference scenario can be observed, which contradicts the assumption that restricted curtailments increase storage demand. However, the deviation of storage power capacity expansion in comparison to the reference scenario is only marginal and the affected regions and VRE technologies (e.g. wind onshore in Northern EU or Denmark west, offshore wind in Germany) compensate the restrictions in curtailment through an increased utilization (i.e. higher full load hours) of other VREs.

\subsection{VRE constraint scenarios}

Fig. A 11 depicts the capacity expansion of the most important technologies in the scenarios where $80 \%$ constr is not active compared to the reference scenario. Furthermore, these scenarios differentiate in their costs of the $\mathrm{CO}_{2}$ emission certificates, ranging from $57 € / \mathrm{t} \mathrm{CO}_{2}$ (_med) up to $130 € / \mathrm{t} \mathrm{CO}$ (_veryhigh, see Tab. A 23).

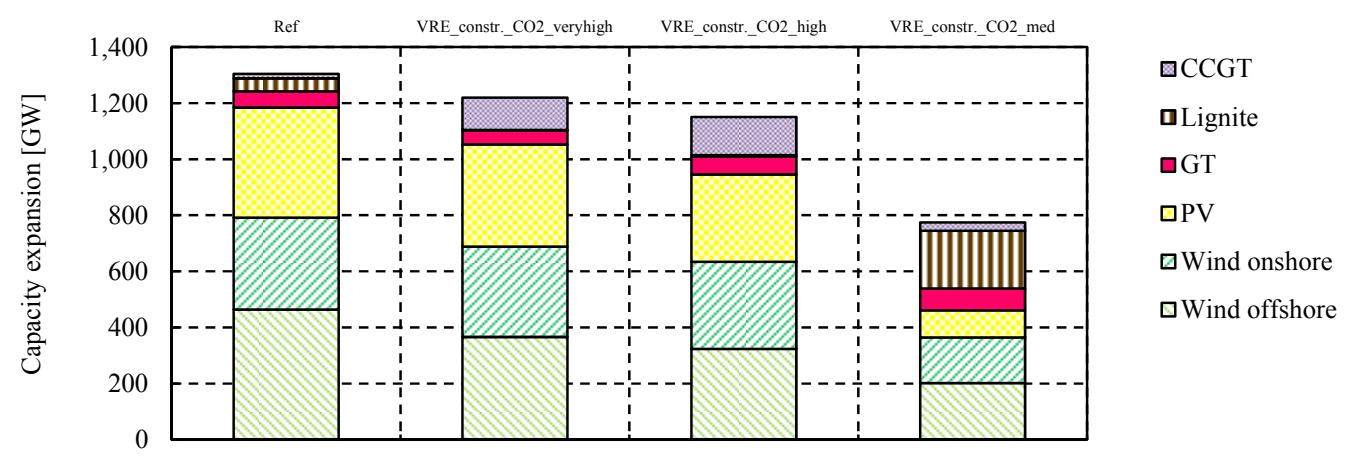

Fig. A 11: Comparison of the capacity expansion over all model-regions of the scenarios without $80 \%_{\text {constr }}$ and different assumptions regarding the $\mathrm{CO}_{2}$ certificate price to the reference scenario.

As expected, the scenarios without $80 \%_{\text {constr }}$ result in lower VRE shares than the reference scenario. While the reference scenario shows a VRE share of $86 \%$, the rest of the scenarios, in order from very high to medium $\mathrm{CO}_{2}$ prices, range from $75 \%$ to $42 \%$. A CO 2 certificate price of $130 € / t \mathrm{CO}_{2}$ (VRE constr. $\mathrm{CO}_{2}$ veryhigh) however, is sufficient to almost reach the VRE share of the reference scenario. Furthermore, this scenario is characterized by noticeable larger amounts of CCGT generation which is less $\mathrm{CO}_{2}$ intensive. Not surprisingly, we observe a correlation where higher $\mathrm{CO}_{2}$ prices foster the replacement of $\mathrm{CO}_{2}$ intensive technologies with less $\mathrm{CO}_{2}$ intensive generation capacities. In the calculations at hand, this is the case for lignite power-plants, which are substitutes by capacities of CCGT. Moreover, higher $\mathrm{CO}_{2}$ prices increase the diffusion of VRE technologies. These effects also can be observed when analyzing each model-region individually (see Fig. A 12). 


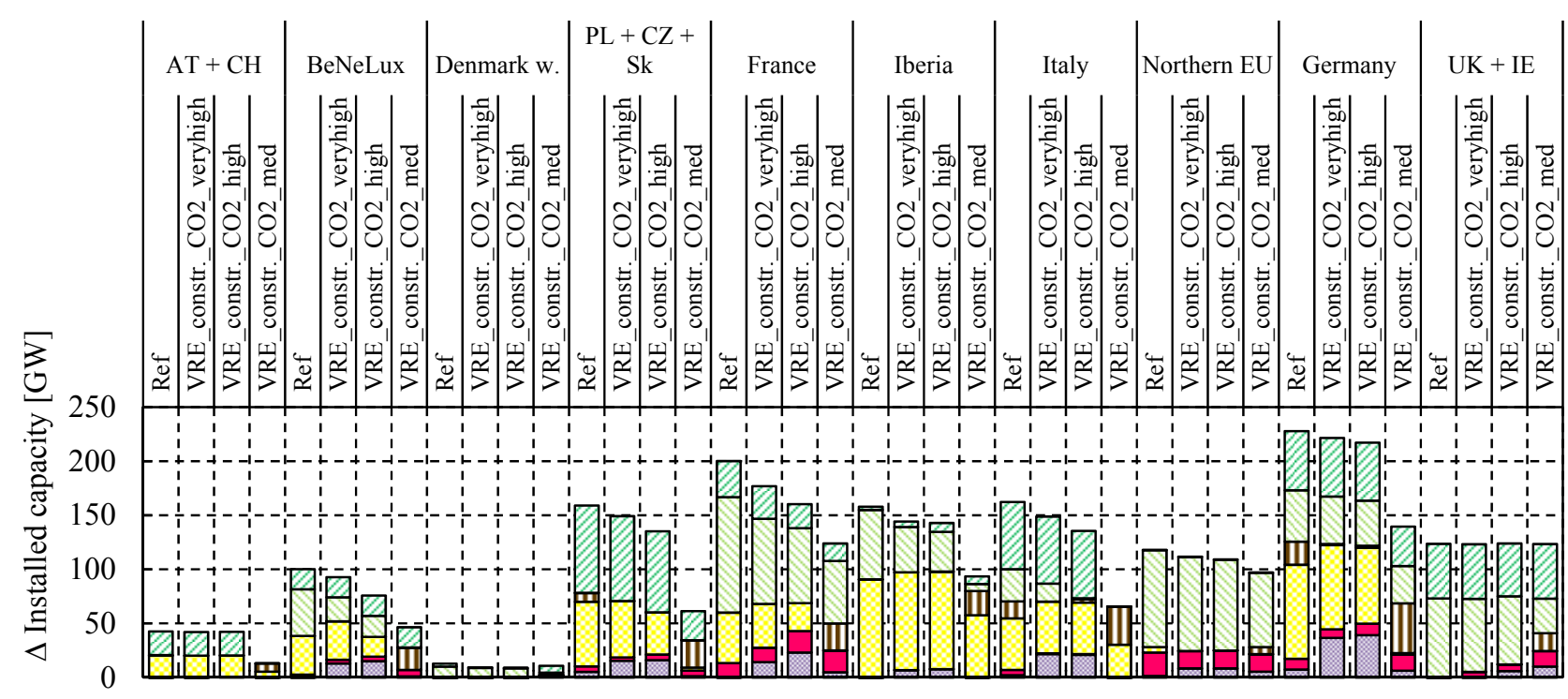

$\square$ CCGT $\quad$ GT $\square \mathrm{PV}$ mLignite $\square$ Wind offshore $\square$ Wind onshore

Fig. A 12: Comparison of the capacity expansion for each model-region of the scenarios without $80 \%_{\text {constr }}$ and different assumptions regarding the $\mathrm{CO}_{2}$ certificate price to the reference scenario.

Fig. A 13 shows the difference in annual electricity generation in the VRE constraint scenarios compared to the reference scenario for all VRE generation and storage technologies. More specifically, the annual electricity generation from storage refers to the discharged electricity over the observation year, and, opposed to the analyses in the main text, not to the storage energy capacity. The sensitivity analysis supports the findings from the main text, where generation from offshore wind correlates with the utilization $\mathrm{H}_{2}$ storage, onshore wind with aCAES and partially Li-ion and PV mostly with Li-Ion. Thereby, the distribution of annual electricity from storage follows the distribution of the annual electricity from VRE technologies.

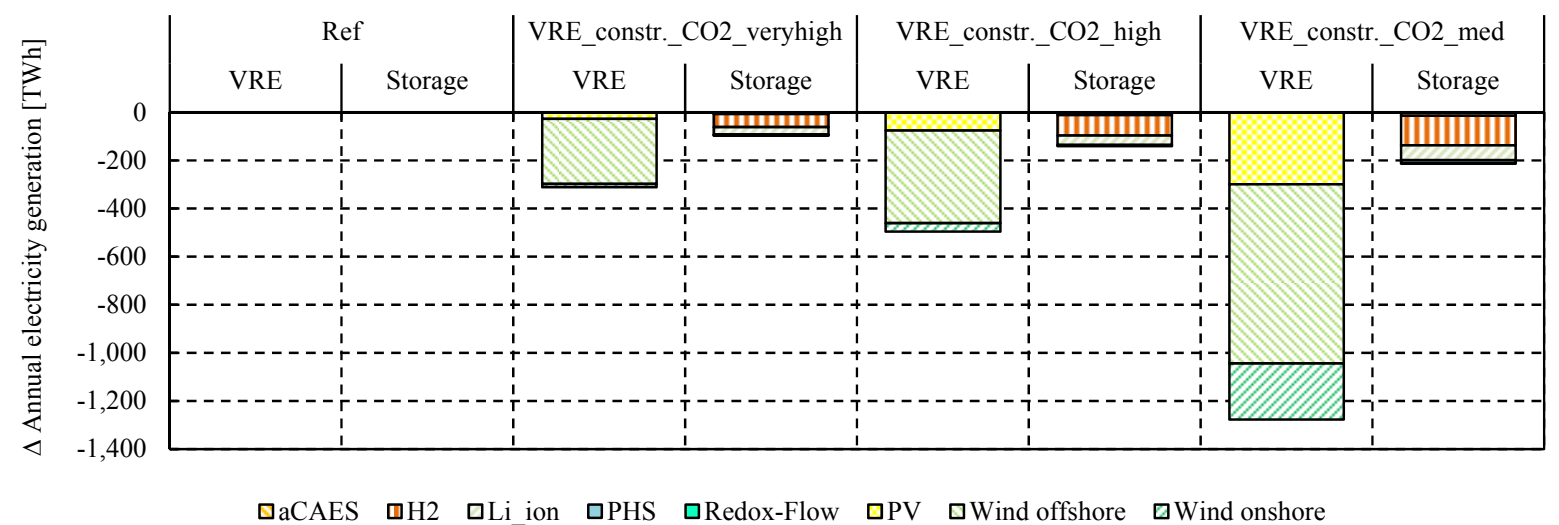

Fig. A 13: Differences in annual electricity generation from VRE and storage technologies compared to the reference scenario. Note that the annual electricity generation from storage refers the discharged electricity over the observation year.

\subsection{Weather year scenarios}

The potential power generation of VRE is based on hourly values of wind speeds and solar irradiation of the year 2006 in the reference scenario. Within the main text of this study, it was shown that storage expansion and utilization is strongly dependent on the generation mix of a region as well as its temporal characteristics of power generation. As the latter again is influenced by the underlying weather year, we test to what extents other weather years influence VRE and storage capacity expansion. Fig. A 14 shows the difference in installed capacity for the most relevant generation as well as storage technologies of the scenarios with different weather years compared to the reference scenario aggregated over all model-regions. We intentionally do not show the results for the weather year 2010. It is characterized by unusual poor solar and wind potentials, resulting in unrealistically high storage expansion in some model-regions in order to meet $80 \%$ constr. 


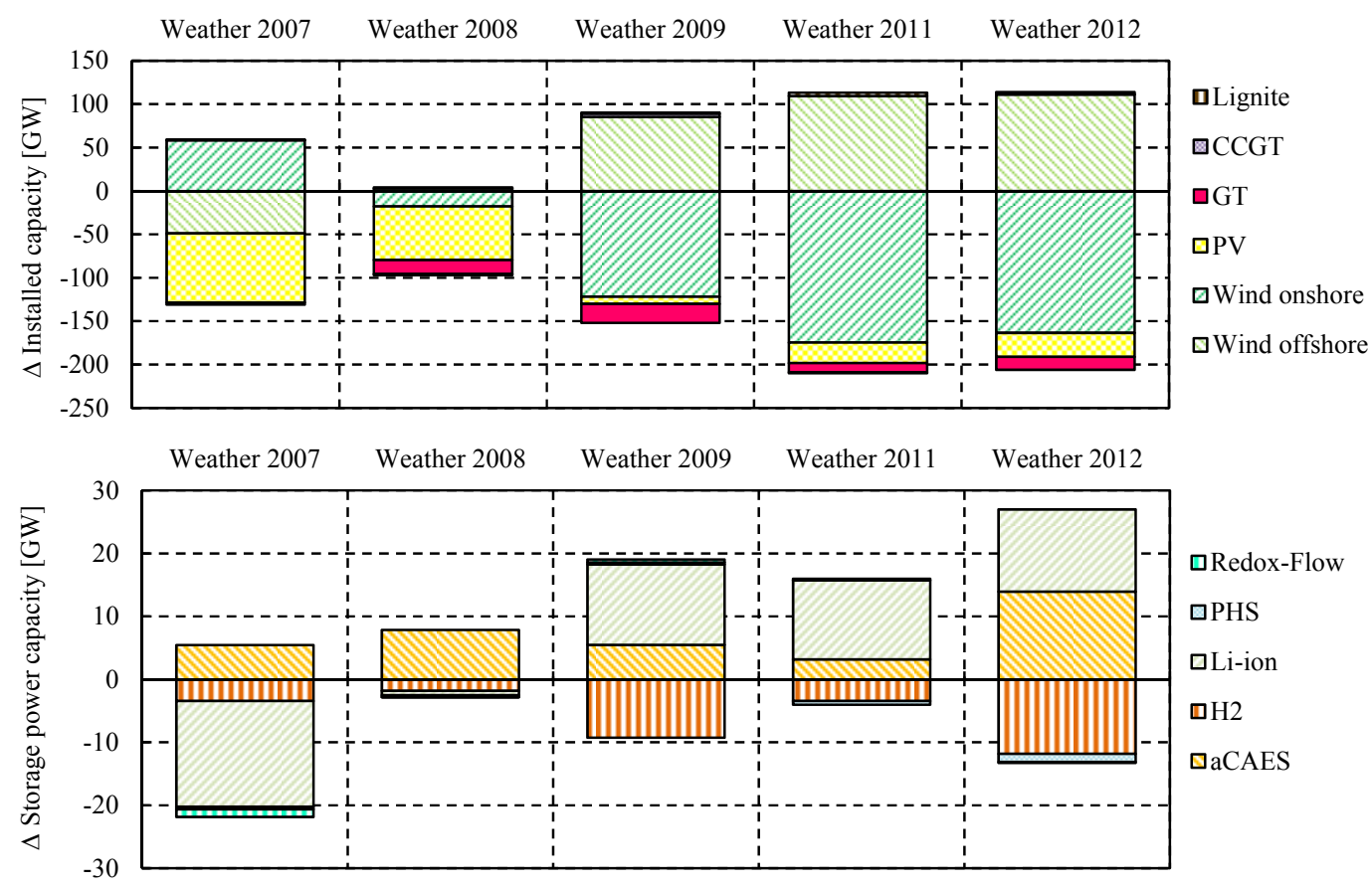

Fig. A 14: Differences in installed capacity for the most relevant generation as well as storage technologies compared to the reference scenario aggregated over all model-regions.

In relation to the overall installed capacities, the deviations of the installed capacities in the model runs with different weather years are rather small. Some of the sensitivity cases (e.g weather year 2007) support the findings of the main text, where, for example, we see that the increase of onshore wind capacities goes along with higher capacities of aCAES storage. On the other hand, in the same year, PV capacities decrease which again fosters a decrease of Li-ion batteries. However, in the years 2009 , 2011, and 2012 we observe that the increase of offshore wind capacities actually is complemented by more storage capacities of aCAES and Li-Ion. As showed in Sec. 3.3 and 3.4 of the main text, dual use of some storage technologies is common, where LiIon not only balances daily fluctuations from PV power, but also stores surplus of wind electricity generation. This effect is particularly pronounced in regions with high shares of wind power generation (e.g. model-region France).

\subsection{Miscellaneous scenarios}

\section{Improved techno-economic input parameters for redox-flow batteries}

Within the reference scenario, we see a lack of capacity expansion of redox-flow batteries. As stated in Sec. 3.2, we assume that this can be explained by the cost optimizing model logic, where redox-flow storage competes with aCAES for mid-term balancing. In comparison, both technologies show rather similar techno-economic parameters, differentiate however significantly in the energy related investment costs (this includes the amortization time for the storage unit as well as the fixed operations and maintenance costs). On the one hand, these costs $\left(€ / \mathrm{kWh}_{\mathrm{el}}\right)$ are around twice as high for redox-flow batteries compared to aCAES, whereas the power related costs $\left(€ / \mathrm{kW}_{\mathrm{el}}\right)$ are almost identical. On the other hand, charging and discharging efficiency slightly favors redox-flow batteries. We assume that large shares of aCAES can be substituted by redox-flow capacities, if the energy related investment costs decrease to the value of aCAES. To verify this hypothesis we performed validation model runs with the aforementioned changes in the relevant parameters. Fig. A 15 shows the comparison of the storage power capacity and generation expansion for each model-region in the reference scenario (Ref) and scenario with changed techno-economic parameters for redox-flow batteries (Ref_VRF). 


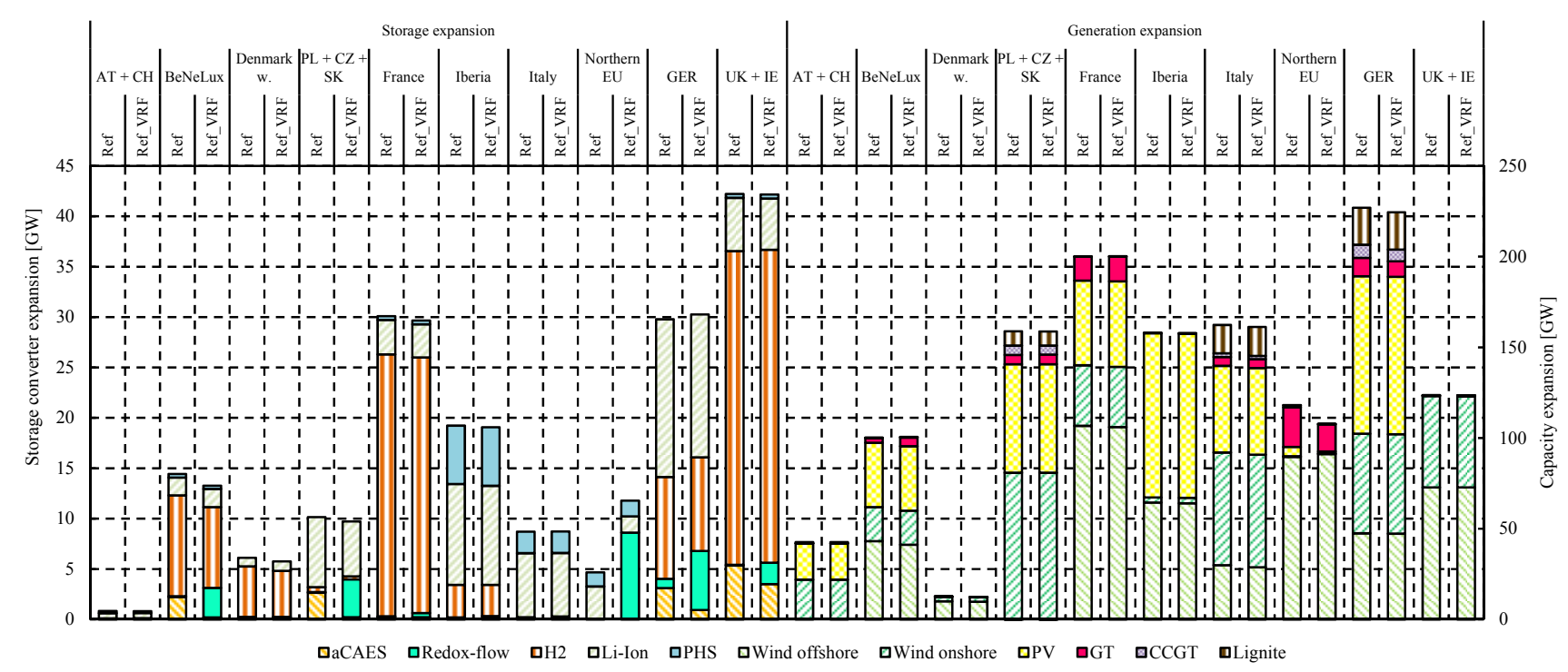

Fig. A 15: Comparison of storage (left) and generation (right) capacity expansion for each model-region. Scenario Ref VRF is characterized by improved techno-economic parameters for the redox-flow batteries. The German model-regions are aggregated to GER.

As expected, we observe a substitution of aCAES capacities in the relevant model-regions (e.g. BeNeLux, Germany, or $\mathrm{UK}+\mathrm{IE}$ ), while the structure of the generation portfolio remains relatively unchanged in both scenarios. One exception can be found in the model-region Northern Europe (Northern EU). As shown in Sec. 3.3, this region does not have any underground cavern storage available. In consequence, the balancing of the large shares of offshore wind electricity generation in the reference scenario is done with Li-ion batteries and GT capacities. In the scenario REF_VRF, the latter are partially substituted by redox-flow batteries. Furthermore, redox-flow storage allows an increase in offshore wind capacities, whereas capacities from PV systems disappear completely.

\section{No existing stock capacities of PHS}

In this scenario no old capacities of PHS were assumed to exist in the observation year 2050. This sensitivity case aims to test whether the technical potentials of the storage energy capacity are still reached. In the main text it was shown that almost every model-region (with an exception of $\mathrm{AT}+\mathrm{CH}$ ) completely uses the technical potential, as PHS is a very cost effective technology. Apart from the model-region Austria + Switzerland, Tab. A 27 shows that the storage energy capacity expansion for both scenarios is identical and the hypothesis is confirmed.

Tab. A 27: Comparison of storage energy capacity expansion $\left(\mathrm{GWh}_{\mathrm{el}}\right)$ for the reference scenario and the scenario without old PHS capacities (PHS_w/o_old_stock).

\begin{tabular}{lrr}
\hline \multicolumn{3}{c}{ Storage energy capacity expansion $\left[\mathrm{GWh}_{\mathrm{e}]}\right]$} \\
\hline & PHS_w/o_old_stock & Ref \\
\hline AT + CH & 32.00 & 9.51 \\
BeNeLux & 4.67 & 4.67 \\
Denmark west & - & - \\
PL CZ SK & - & - \\
France & 5.00 & 5.00 \\
Iberia & 93.00 & 93.00 \\
Italy & 35.00 & 35.00 \\
Northern EU & 17.00 & 17.00 \\
Germany & - & - \\
UK + IE & 4.00 & 4.00 \\
\hline
\end{tabular}

